\title{
Feinstrukturelle Untersuchungen zur Oogenese der Käferschnecke Lepidochitona cinereus (Mollusca, Polyplacophora)
}

\author{
H.-P. RICHTER \\ I. Zoologisches Institut der Justus-Liebig-Universität; \\ Gießen, Bundesrepublik Deutschland
}

\begin{abstract}
Ultrastructural investigations of oogenesis in the chiton, Lepidocbitona cinereus (Mollusca, Polyplacophora). Oocyte development of Lepidochitona cinereus L. has been examined by electron microscope with special regard to ultrastructural changes during vitellogenesis. Oogenesis can be subdivided into five stages based on cytological and histochemical features. Typical oogonia have not been found; only early oocytes of the meiotic prophase with an incomplete nucleolus are situated on the basallamina of the gonadal wall. The single nucleolus is formed in stage I; osmiophilic nucleolar granules pass through the nuclear envelope. Stage II - oocytes are characterized by simple Balbiani-bodies or yolk nuclei, which consist of ribosomes and a hull of mitochondria. The formerly homogenous nucleolus disintegrates into caryoplasmic vacuoles and produces paranucleoli. In the previtellogenetic stage III the yolk nuclei are reduced and large systems of endoplasmic reticula - arranged concentrically or flattened - and voluminous cytoplasmic vacuoles appear. Three types of vacuolar complexes can be observed: Complete membrane bounded vacuoles with a filaceous content built up by Golgi dictyosomes, vacuoles with remains of membranes which seem to originate from endoplasmic cisternae and vacuolar spaces lying free in the cytoplasm. The vacuoles contain either acid mucopolysaccharides or acid lipids. The actual vitellogenesis starts in stage IV after depression of the oocyte membrane to ooplasmic bumbs by the perioocytal follicle epithelium. Extensive piles of annulate lamellae contact the cytoplasmic vacuolar bodies. Striated long rootlets branch off microtubules at their terminal end in the direction of the oocyte membrane below the oocyte hull. Microvilli secrete mucopolysaccharides into the intercellular space between oocyte membrane and inner follicle cell membrane. The resulting eight cup-like hull processes are composed of three layers. Possibly there are three ways of forming vitelline bodies: (a) transforming mitochondria and multivesicular bodies lead to protein yolk; (b) mitochondria connect with cytoplasmic vacuoles and probably participate in genesis of lipid yolk; (c) microvesicles become protein yolk precursors. The lipoprotein yolk spheres consist of a homogenous internum and a paracrystalline structured cortex. Lipid yolk accumulates at the periphery of the cytoplasmic vacuoles, which degenerate later. The mature oocyte secretes another primary oocyte envelope, the vitelline membrane, shortly before spawning. Cortical granules appear below the oocyte membrane.
\end{abstract}

\section{EINLEITUNG}

Während zur Entwicklung der Eizellen anderer Molluskenklassen bereits diverse Beobachtungen vorliegen, ist die Oogenese der Polyplacophora wenig untersucht. Von 
den Arbeiten, die sich mit dem Ablauf der Oogenese beschäftigen, seien hier vor allem die Publikationen von Loven (1856), Garnault (1888), Plate (1901), Schweikart (1904), Lyngnes (1924), von KNoRre (1925) sowie - in neuerer Zeit - Gabe \& Prenant (1949), Cowden (1961), Anderson (1969), Sezwood (1968, 1970) und Richter \& Götring (1974) genannt.

Großes Interesse haben immer wieder die mannigfaltig ausgebildeten Hüllschichten der Ovarialoocyten und im besonderen der reifen, bereits abgelaichten Oocyten der verschiedenen Chitonenarten auf sich gezogen, ohne daß deren Bildungsmodus geklärt worden ist. Über die Funktion der Hüllschichten ist nichts bekannt. An Eiern von Lepidochitona cinereus hat Lyngnes (1924) erstmals die kompliziert gebauten acht becherförmigen Hüllfortsätze beobachtet und beschrieben. Speziell geht es um das Problem, ob diese Oocytenanhänge in ihrer Gesamtheit primäre Eihüllen sind, d. h, allein von der Eizelle abgeschieden werden oder ob sie sekundäre Hüllen darstellen, also als Derivate des Follikelepithels in den interzellularen Raum zwischen Oocytenmembran und der inneren Follikelzellmembran abgelagert werden und als Chorion zu bezeichnen sind. Es liegen außer von Chiton tuberculatum (Cowden, 1961), Mopalia muscosa und Chaetopleura apiculata (ANDERSON, 1969) und Sypharochiton septentriones (SEL wood, 1970) keine Befunde über ihren chemischen Aufbau und ihre Genese vor. Um diese Fragen beantworten zu können, sind vorausgegangene lichtmikroskopische Nachweisreaktionen fortgesetzt und durch elektronenoptische Verfahren ergänzt worden.

Elektronenmikroskopische Untersuchungen über den Feinbau der PolyplacophoraOocyte mit umfassenden Beschreibungen der Stadien und ihren organellären Veränderungen während der Oogenese finden sich lediglich bei ANDERSON (1969) und SELwOOD (1970). Um Vergleiche zu anderen Molluskenklassen anstellen zu können, wird die vorliegende Arbeit intensiv auf die Cytologie der spezifischen Entwicklungsstadien bei den Eizellen von $L$. cinereus eingehen. Besondere Beachtung finden die Genesen des Nuclcolus, des Balbiani-K̈örpers, der verschiedenen Formen des Endoplasmatischen Retikulums und die Vesikulation des Oocytoplasma. Diese Strukturen sind als notwendige Voraussetzungen für die Vitellogenese während der oocytären Wachstumsphase anzusehen. Darüber hinaus bedarf es einer gründlichen Klärung der Verhältnisse während der Vitellogenese selbst. Auf Grund morphologischer und histochemischer Befunde ist anzunehmen, daß verschiedene Dotterkompartimente gleichzeitig in reifen Oocyten anzutreffen sind. Jedoch vermeiden es die meisten Autoren, diese Syntheseräume genauer nach inhaltlichen und funktionellen Gesichtspunkten zu benennen. Hier soll der Versuch unternommen werden, Protein- und Lipiddotter zu diagnostizieren, in den Entwicklungsstadien zu lokalisieren und auf dem Wege ihrer Genese zu verfolgen. Wichtige Aspekte in diesem Zusammenhang sind die pinocytotische Aktivität der Oocytenmembran, Vorkommen von multivesikulären Körpern und Mitochondrien und ihre Umwandlung zu vitellogenetischen Komplexcytosomen. Die vorliegenden feinstrukturellen Untersuchungen zur Dotterbildung stellen die Basis für weitere Arbeiten dar, die Aufschluß über den Modus der Reservestoffeinlagerung in die Eizelle geben sollen. 


\section{MATERIAL UND METHODEN}

Lepidocbitona cinereus L. ist die im Küstenbereich der deutschen Nord- und Ostsee häufigste Käferschnecke. Sie ist getrenntgeschlechtlich und zeigt keinen Geschlechtsdimorphismus. Besonders häufig kommt sie im Wattengebiet der Insel Sylt (z. B. bei List) vor, wo auch die hier untersuchten Exemplare über einen Zeitraum von März bis Oktober 1973-75 gesammelt wurden.

Die Tiere wurden in Pufferlösung oder bereits im Fixans von dorsal durch vorsichtiges Abpräparieren der Schalenplatten eröffnet, das Ovar stückweise entfernt und in Blockglasschalen fixiert.

Für die elektronenmikroskopischen Untersuchungen kamen die folgenden Fixierungsgemische zur Anwendung: 2\%iges $\mathrm{OsO}_{4}$, nach WOHLFARTH-BotTERMANN (1957); $1 \%$ iges $\mathrm{OsO}_{4}$ in Veronal-Acetat-Puffer nach SJöstRand (1963); 5\% iges Glutaraldehyd in Phosphatpuffer nach SABATIN et al. (1963) mit anschließender Nachfixierung mit $2 \%$ gepuffertem $\mathrm{OsO}_{4}$. Alle Ovarteile und Oocyten wurden bei $+4^{\circ} \mathrm{C}$ im Kühlschrank, 2 Stunden lang, bei einem $\mathrm{pH}$ zwischen 7,2 und 7,4 fixiert. Die mit Glutaraldehyd fixierten Objekte wurden über 12 Stunden im Phosphatpuffer belassen, die Osmiumfixantien 1 Stunde lang mehrmals mit Puffer ausgewaschen. Entwässert wurde über eine Aqua bidest-Aceton-Reihe (jeweils $30 \mathrm{Min} .30 \%, 60 \%, 90 \%, 3 \times 100 \%$ ).

Als Einbettungsmedium diente ausschließlich Vestopal (Jäger, Braunschweig), das bereits als Intermedium (Aceton-Vestopal-Stufen $30 \%, 60 \%, 90 \%, 2 \times 100 \%$ ) verwendet, mit 1,5\% Benzoylperoxid-Initiator homogenisiert worden war. Die Objekte polymerisierten nacheinander bei $30^{\circ} \mathrm{C}(2-3 \mathrm{~h}), 60^{\circ} \mathrm{C}(24 \mathrm{~h})$ und $90^{\circ} \mathrm{C}(12 \mathrm{~h})$.

Zur Herstellung von Semi- und Ultradünnschnitten standen die Ultramikrotome Om U2 und Om U3 der Fa. Reichert zur Verfügung. Die Schnitte wurden nach der Methode von Venable \& Coggeshall (1965) kontrastiert. Zum Mikroskopieren diente ein EM 9S-2 $(60 \mathrm{kV})$ der Fa. Zeiss (aus Mitteln der Deutschen Forschungsgemeinschaft).

Zur Darstellung von Triglyceriden an syntheseaktiven Membranen und im Lipiddotter während der Vitellogenese wurde der Nachweis von Adams et al. (1966) durchgeführt. Mit der Rutheniumrot-Kontrastierung nach Monis \& Zambrano (1968) zur Untersuchung neutraler und saurer Polysaccharide konnten keine eindeutig sicheren Ergebnisse erzielt werden.

Zur besseren Lokalisation von Reservestoffen, wie Glykogen und Gerüstsubstanzen der Oocytenanhänge, wie verschiedenen Polysacchariden, sowie zur Klärung der Dottergenese wurden folgende lichtmikroskopisch histochemische Methoden angewendet: Da nur säurehaltige Fixierungsflüssigkeiten zur Entfernung des Kalkes der Schalenplatten Verwendung finden konnten, boten sich die Gemische nach Bourn und BounN-Allen an. Anschließend wurde in Tissuemat eingebettet und 7-10 $\mu \mathrm{m}$ dicke Schnitte angefertigt. Alcian-Blau-PAS und die metachromatische Färbung mit Toluidinblau wurden zur Darstellung neutraler und saurer Polysaccharide herangezogen. Lipide wurden in Dotterschollen durch die Sudanschwarz-B-Färbung nach Lison angezeigt, neutrale bzw. saure Lipide durch Nilblau-Sulfat nachgewiesen.

Die Vorschriften der Fixierungsgemische und Nachweise für die Lichtmikroskopie finden sich bei RomeIs (1968) und ARNOLD (1968) und wurden kaum modifiziert. 


\section{BEFUNDE}

\section{Die Oocyten und ihre Entwicklung}

Die Eizellen von Lepidochitona cinereus entstehen im ventralen Keimepithel der Gonade. Sie werden stets von perioocytären Follikelzellen umschlossen. Im Verlauf der Wachstumsphase schieben sie sich in das Gonocoel, bleiben jedoch die meiste Zeit ïber einen Oocytenstiel an die Basallamina gebunden. Erst laichreife Oocyten unterbrechen diese Verbindung und treiben frei im dorsalen Bereich des Ovarlumens. Sie werden von den Ovidukten aufgenommen und über die Kiemenrinne in das freie Wasser entlassen. Die Eierstöcke älterer Weibchen enthalten während der Laichperiode in den Sommermonaten meist alle Entwicklungsstadien gleichzeitig (Kontinuitätstyp). Die Oogenese läßt sich nach cytomorphologischen und histochemischen Gesichtspunkten in 5 Stadien einteilen (Stadium I bis V).

\section{Oogonien}

Bei Anwendung der lichtmikroskopischen Technik sind im Ovarium von L. cinereus Oogonien von Oocyten nicht zweifelsfrei zu unterscheiden. Der einzige Anhaltspunkt, der einen Übergang von der Oogonie zur Oocyte erkennen läßt und möglicherweise sogar eine Trennung dieser beiden Oogenesestadien erlaubt, ist die Konden-

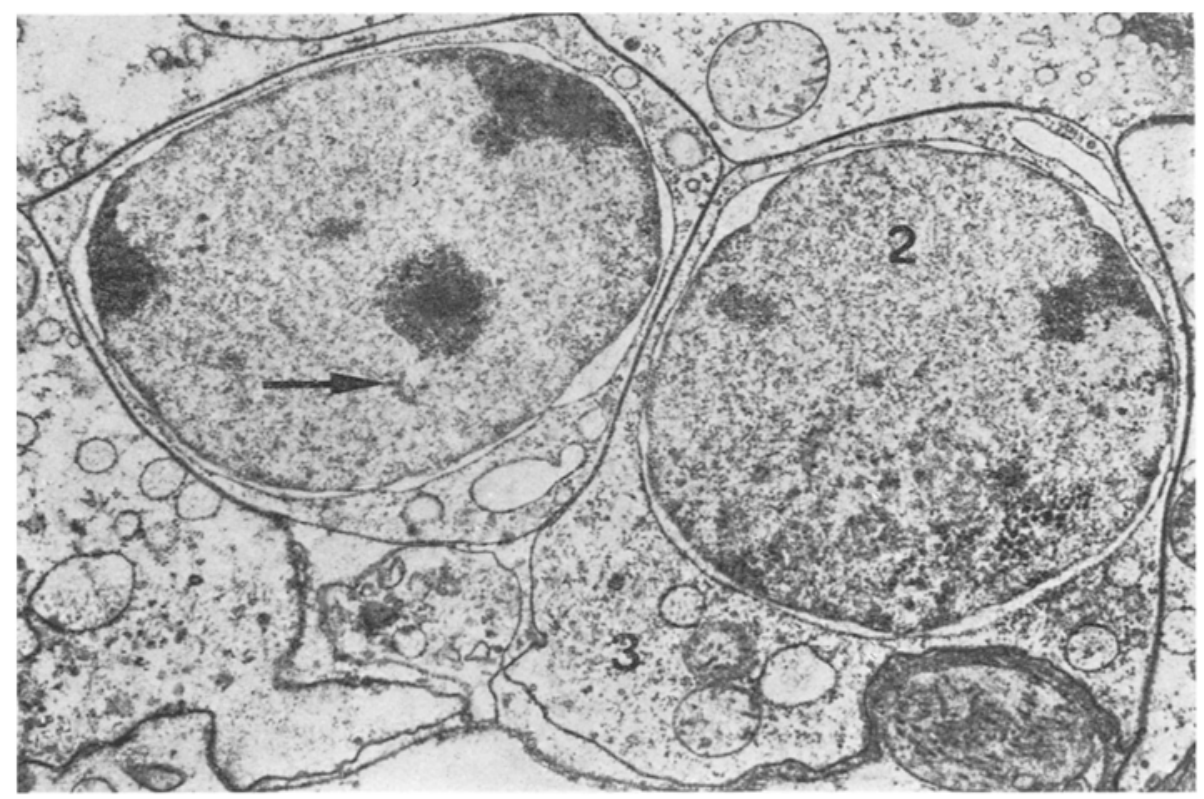

Abb. 1: Zwei späte Oogonien in unmittelbarem Kontakt. Dic Kerne enthalten Chromosomenanschnitte und zeigen den Beginn der Nucleolus-Organisation. 2 Kern; 3 Oocytoplasma: ribosomengroße Partikeln (Pfeil) $(5130: 1)$ 
sation der Nucleolarsubstanz im Kern. Dabei ist in Keimzellen bis zu $10 \mu \mathrm{m}$ Durchmesser vornehmlich an der Peripherie des Kernes unterschiedlich elektronendichtes Kernmaterial nachzuweisen, das unmittelbar der Kernhïlle angelagert und unregelmäßig geformt, auf verschiedene Bereiche der Hülle verteilt ist. Es handelt sich um anfangs runde bis langgestreckte Anschnitte mit einem elektronendichteren Zentrum und einer in Auflösung befindlichen Oberfläche. $\mathrm{Zu}$ einem späteren Zeitpunkt verschwindet dieses Material; im Caryoplasma bleibt nur noch mehr oder weniger homogen verteiltes Chromatin zurück. Dafür erscheinen Wolken isolierter, Ribosomen-ähnlicher Grana, die sich zu kontrastreichen, unregelmäßig geformten Sphären zusammenlagern und schließlich den einzigen kugeligen Nucleolus bilden (Abb. 1).

Es ist in Anbetracht der Nucleolus-Organisation und der Tatsache, daß die Zellen noch nicht durch Follikelzellen separiert worden sind, eine Klassifizierung in späte Oogonien und Oocyten des Stadiums I möglich. Typische Oogonien, in deren Kern eindeutig Chromosomen oder synaptische Komplexe zu finden sind, fehlen in den Schnittserien. Die späten Oogonien liegen meist in Gruppen von nur wenigen Zellen oder vereinzelt der Basallamina auf. Die Zellmembranen liegen sehr eng aneinander; Zellhafte fehlen. In ihrer äußeren Form differieren die Oogonien außer in ihrer geringeren Größe nicht von dem frühen Oocytenstadium I. Ein gravierender Unterschied besteht lediglich auf Grund des äußerst heterogenen Kerninhaltes, der vermuten läßt, $\mathrm{daß}$ die meiotische Prophase noch nicht vollständig durchlaufen ist.

\section{Stadium I}

Das Stadium I ist auf Grund cytomorphologischer Gegebenheiten wie folgt definiert: Eizellen von einer linsen- bis bohnenförmigen Gestalt und einem mittleren Durchmesser von ca. $15 \mu \mathrm{m}$ sind als Primäroocyten anzusprechen. Sie liegen in den Ovarien oft in Gruppen, zu Keimlagern verbunden, dem ventralen Keimepithel auf. Meist sind sie in größeren Mengen von Follikelzellen eingebettet, werden jedoch stets, auch wenn sie an exponierten Stellen der nach dorsal ziehenden Follikelepithelfalten sitzen, von einem einschichtigen Follikelepithel umschlossen.

Der Nucleus nimmt den größten Teil der Oocyte ein; bei einem Durchmesser der Eizelle von $20 \mu \mathrm{m}$ können $15 \mu \mathrm{m}$ auf den Kern entfallen. Das Cytoplasma ist entsprechend auf einen schmalen Saum von 2-5 $\mu \mathrm{m}$ Breite beschränkt. Der zentral gelegene Nucleolus erscheint bei einem Oocyten-Durchmesser von $10 \mu \mathrm{m}$ und hat dann eine Größe von $4 \mu \mathrm{m}$. Die Oocytenmembran ist glatt und grenzt ohne breiten Interzellularspalt und Ausbildung von Zellhaften an die Follikelzellmembran (Abb. 2).

Das Grundcytoplasma des frühen Stadiums I entspricht einer homogenen Matrix, die gleichmäßig den Raum zwischen Kern und Zellmembran ausfüllt. Fs ist gegenüber dem Caryoplasma wesentlich dichter, weniger flockig und fein granuliert, was auf einen hohen Anteil von Ribosomen zurückzuführen ist. Im typischen Stadium I tritt eine Zonierung ein: Während das periphere Cytoplasma homogen verteilt bleibt, kondensieren sich im juxtanucleären Bereich elektronendichte Wolken, die teils auf zusammengelagerte freie Ribosomen, teils auf unregelmäßig geformte größere Partikeln zurückzuführen sind. Der Kern wird in der Regel vollständig von einem geschlossenen Saum dieser beiden osmiophilen Komponenten umgeben. 


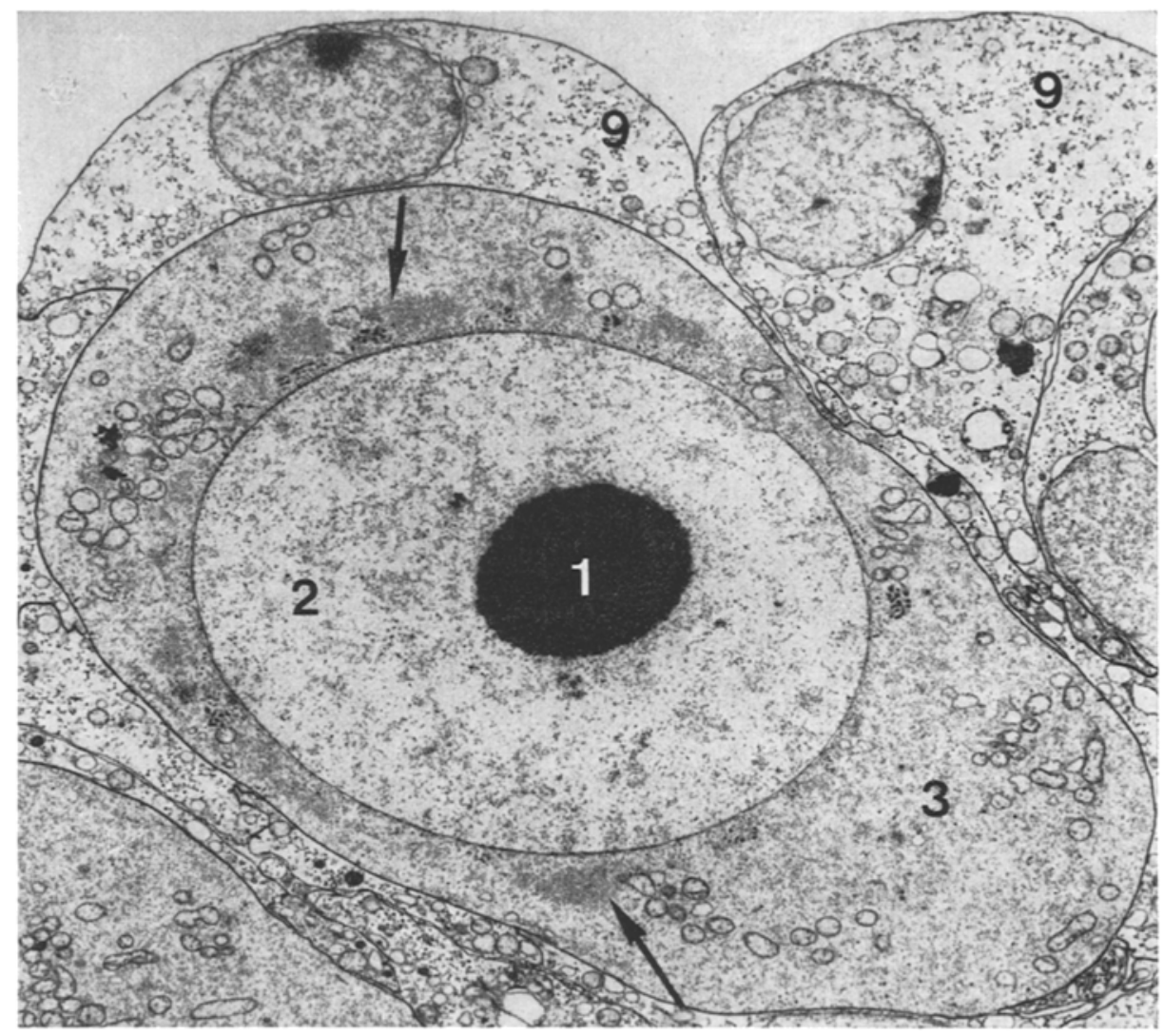

Abb. 2: Oocyte in Stadium I mit perioocytären Follikelzellen (9). 1 Nucleolus; 2 Kern; 3 Oocytoplasma; juxtanucleärer Saum mit extrusiertem nucleolärem Material (Pfeile) (4180:1)

Betrachtet man letztgenannte Partikeln bei höheren Vergrößerungen, erkennt man unter anderem gehäuft Ribosomen, in einer Grundsubstanz eingelagert. In unmittelbarer Kernnähe gefundene Partikelansammlungen haben die gleiche Struktur wie im Caryoplasma liegende Substanzen. Im Laufe der weiteren Entwicklung der Oocyten dieses Stadiums entfernt sich das kontraststarke RNS-haltige Material vom Zellzentrum zur Peripherie, ohne jedoch sein Erscheinungsbild zu ändern. Es ist dann vermehrt in der Umgebung von Mitochondrien zu finden und unterhält auch Verbindungen zu endoplasmatischen Membransystemen.

Der Golgi-Apparat des Stadiums I beschränkt sich auf nur wenige (wahrscheinlich höchstens 1-3) Dictyosomen. Die Dalton-Komplexe setzen sich aus meist 2-3 wellenförmig gebogenen Doppelmembranen zusammen, an deren Endstücken Vesikulation erfolgt. In den hier betrachteten Eizellen können zwei Dictyosomentypen vorhanden sein: (a) Ein polar gebauter Typ, der nur auf einer der beiden Flachseiten Golgi-Vesikeln bildet ("Sekretionsseite"), während die andere keine Zisternen erkennen läßt ("Regenerationsseite"). Diese Vesikeln liegen teils im peripheren Zellbereich, 
teils mit Mitochondrien vergesellschaftet. (b) Daneben ist ein zweiter Typ zu beobachten, der nach beiden Seiten Vesikeln abgibt, die größtenteils bedeutend kleiner sind als die des ersten Typs, in der Nähe des Dictyosoms verbleiben und einen Vesikelkomplex aufbauen. Unmittelbar am Oolemm angetroffene Bläschen können der Oocytenmembran flach anliegen und stehen oft cytoplasmatischen Vesikeln der Follikelzellen direkt gegenüber. Pinocytose ist nicht mit Sicherheit beobachtet worden. Diese Befunde sprechen dafür, daß die im Cytoplasma angetroffenen Vesikeln verschiedenen Ursprungs sind, sich in ihrer Ausbildung jedoch nicht unterscheiden lassen.

So selten wie Dalton-Komplexe, sind Kanäle oder Zisternen des Endoplasmatischen Retikulums. Erst im späten Stadium I treten die ersten Membransysteme auf, die bis auf Ausnahmen aus sehr kurzen Röhren bestehen und stets zusammen mit Vesikeln angetroffen werden. Granuläres und agranuläres ER werden gleichsam ausgebildet. Bereits recht früh im Verlauf der Oogenese entwickeln sich Vorstufen von annulate lamellae. Sie stehen in Verbindung mit den unregelmäßig geformten, stark elektronendichten Partikelansammlungen und kleinen Vesikeln des Grundcytoplasma. Diese Form des ER kann als in sich gewundener, rinnenartig gebogener, abgeflachter Kanal beschrieben werden. Exakte Längsschnitte zeigen das typische Bild von abwechselnd kontrastreichen und kontrastarmen parallellaufenden Membranabschnitten. Ein Tangentialschnitt läßt Poren in gleichbleibenden Abständen erkennen (Abb. 3).

Mitochondrien sind konstant auf jedem Anschnitt einer Oocyte anzutreffen. Bei L. cinereus ist der Crista-Typ ausgebildet. In Oogonien und Eizellen des Stadiums I sind die Mitochondrien kugelig bis ellipsoid. Hantelförmige Stadien treten oft, unregelmäßige Formen (Y-Form) selten auf. Die größtenteils runden Querschnitte zeigen entweder extrem kurze Cristae (Promitochondrien) oder das ganze Organell durchziehende Leisten der inneren Mitochondrienmembran. Bei größeren Mitochondrien liegen im inneren Matrixraum wenige Granula intramitochondrialia. Im späten Entwicklungsstadium I liegen Mitochondrien ab und $\mathrm{zu}$ um aus dem Kern extrusierte Nucleolarsubstanzen gruppiert. Es erscheinen die ersten multivesikulären Körper.

\section{Stadium II}

Die noch im Keimepithel liegenden Oocyten unregelmäßiger Form schieben sich zu Ende des Stadiums II allmählich aus dem Follikelepithelverband in Richtung auf das Gonadenlumen. Der Durchmesser beträgt im Mittel $35 \mu \mathrm{m}$, ihr Nucleolus bleibt im Wachstum relativ zurück ( $\varnothing$ bis $25 \mu \mathrm{m}$ ). Neben dem einzigen großen Kernkörper treten von nun an kleine, ebenfalls stark osmiophile Nucleolus-ähnliche Grana überwiegend im peripheren Caryoplasma auf. Im Cytoplasma differenzieren sich bis zu Beginn des Stadiums III charakteristische Balbiani-Körper (Dotterkerne).

Als Dotterkerne sind von vielen Autoren auf Grund licht- und elektronenmikroskopischer Untersuchungen verschiedene Strukturen und oocytäre Elemente beschrieben worden. Es hat sich gezeigt, daß eine umfassende und allgemeingültige Definition nicht gegeben werden kann (GötTING, 1968). Die "Mitochondrienwolken" der Anuren (BaLINSKy \& Devis, 1963), sogenannte vitelline bodies bei Spinnen, Echinodermaten und Mollusken (z. B. BeDford, 1966; TAYlor \& ANDERson, 1969) und die Dot- 

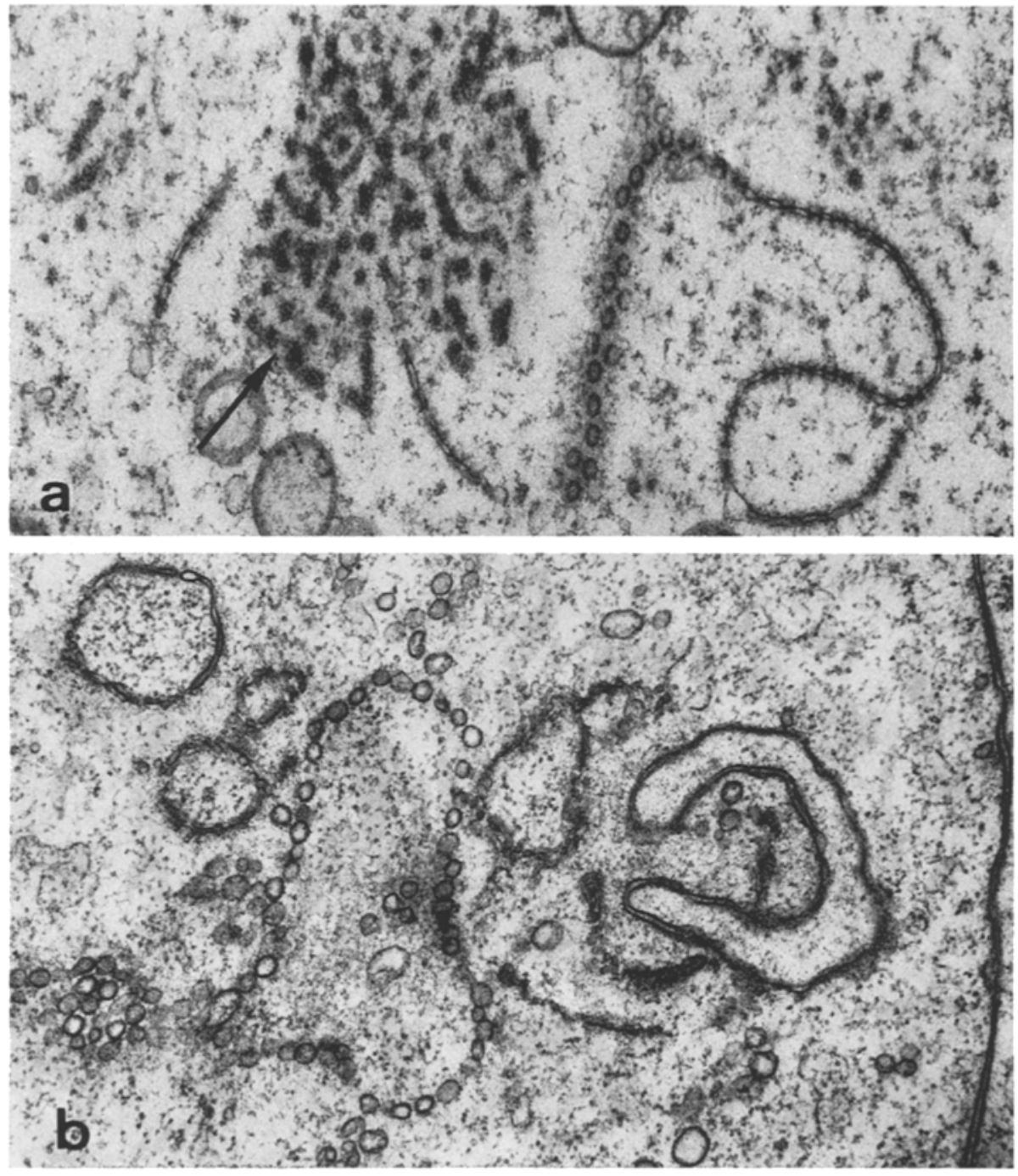

Abb. 3: Genese des Endoplasmatischen Retikulums. a Anschnitt bandförmiger annulate lamellae in der Nähe nucleolärer Substanzcn (Pfeil) (21 410:1). $b$ Formation des glatten ER aus endoplasmatischen Vesikeln $(32940: 1)$

terkerne in Eizellen innerhalb der Klasse der Wirbeltiere (z. B. Götting, 1968; Wartenberg \& Stegner, 1960) machen Aussagen über annähernd gleiche Strukturelemente der heranwachsenden Oocyten.

Im Verlauf der oocytären Differenzierungen zum Stadium II wandern die Mitochondrien zunehmend in 1-2 Zellbereiche ein, die sich dutch erhöhten Kontrast auszeichnen. Die weitaus größte Anzahl von Mitochondrien bildet schließlich eine lockere Schale um einen nahezu runden Cytoplasmakörper, der in seiner Konsistenz 
dichter und osmiophiler erscheint als das umliegende Grundcytoplasma. Nur vereinzelt liegen Mitochondrien im Innern dieses Balbiani-Körpers (Abb. 4). Die erhöhte Osmiophilie ist auf die zunehmende Dichte von Ribosomen zurückzuführen und läßt auf verstärkt einsetzende Proteinsynthese schließen. Sie kann ohne weiteres mit der durch die Lichtmikroskopie nachgewiesenen basophilen Kappe verglichen werden (GABE \& Prenant, 1949; Richter \& Götting, 1974). Die Kombination aus Cytoplasma,

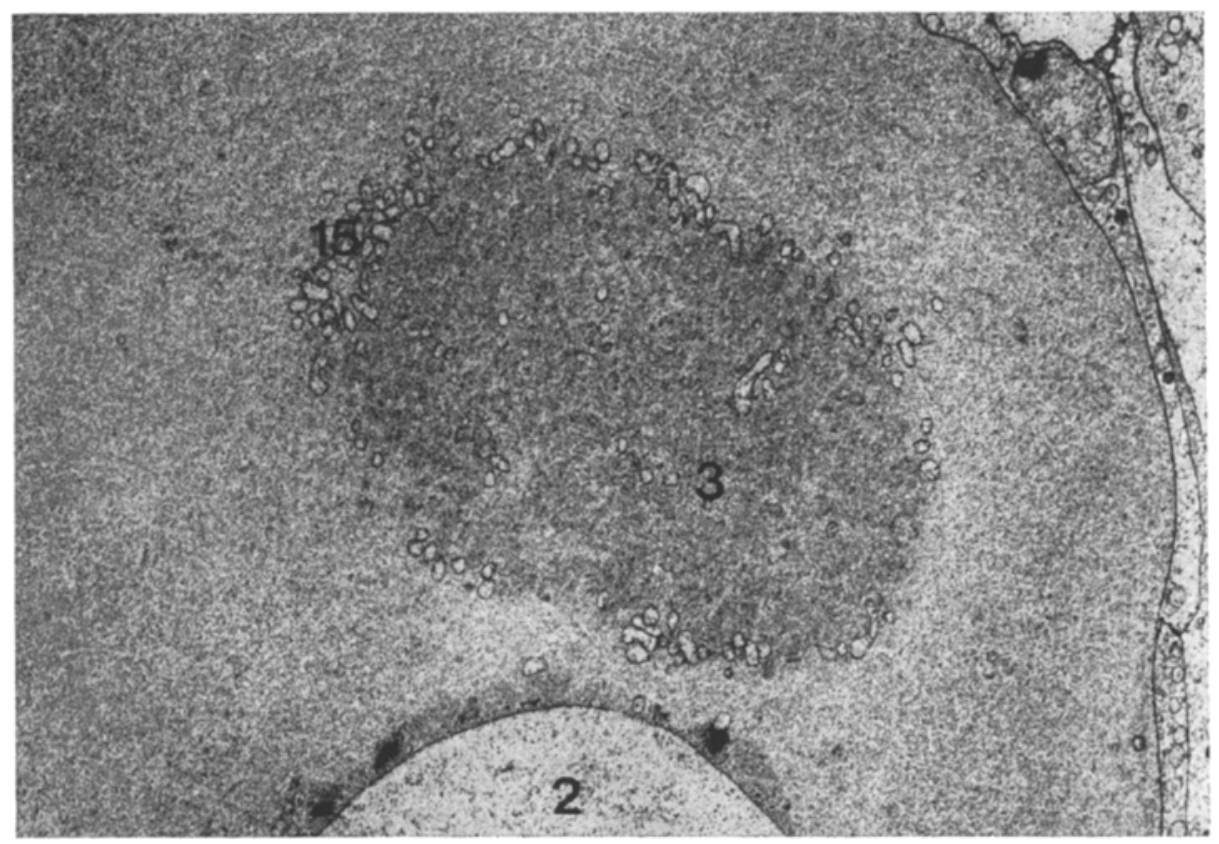

Abb. 4: Dotterkern im Stadium II. 2 Kern; 3 ribosomendichtes Cytoplasma, das peripher von Mitochondrien (15) umgeben ist $(2380: 1)$

Ribosomen und Mitochondrien ist nicht nur auf diesen einen Komplex beschränkt, sondern sie bildet einen markant elektronendichten juxtanucleären Saum, in dem die schon vom Stadium I bekannten extrusierten Nucleolarsubstanzen liegen. An einigen Objekten ist eine innige Verzahnung der normalerweise getrennten Bereiche zu beobachten.

Parallel zur Kondensation der Dotterkerne verläuft eine verstärkte Verdichtung des gesamten Oocytoplasma. In einzelnen Oocyten finden sich darüber hinaus noch dichte Ribosomenwolken, die nicht unbedingt mit Organellen in Verbindung stehen. In ihrer Ribosomendichte unterscheiden sie sich nicht vom Zentrum des Dotterkerns.

Die Mitochondrien des Stadiums II durchlaufen eine extreme Gestaltsänderung. Verschiedene Schnittebenen zeigen, daß die vormals kugelig-ellipsoide Form in eine unregelmäßig wurst- bis schüsselförmige übergeht. In Abschnürung begriffene oder bereits geteilte Organellen sind häufig und lassen auf eine Vermehrungsphase schließen. Bei diesem Prozeß entstehen keine gleichgroßen, sondern ein kleines und ein großes Tochtermitochondrium. Die Cristae nehmen an Länge zu. 

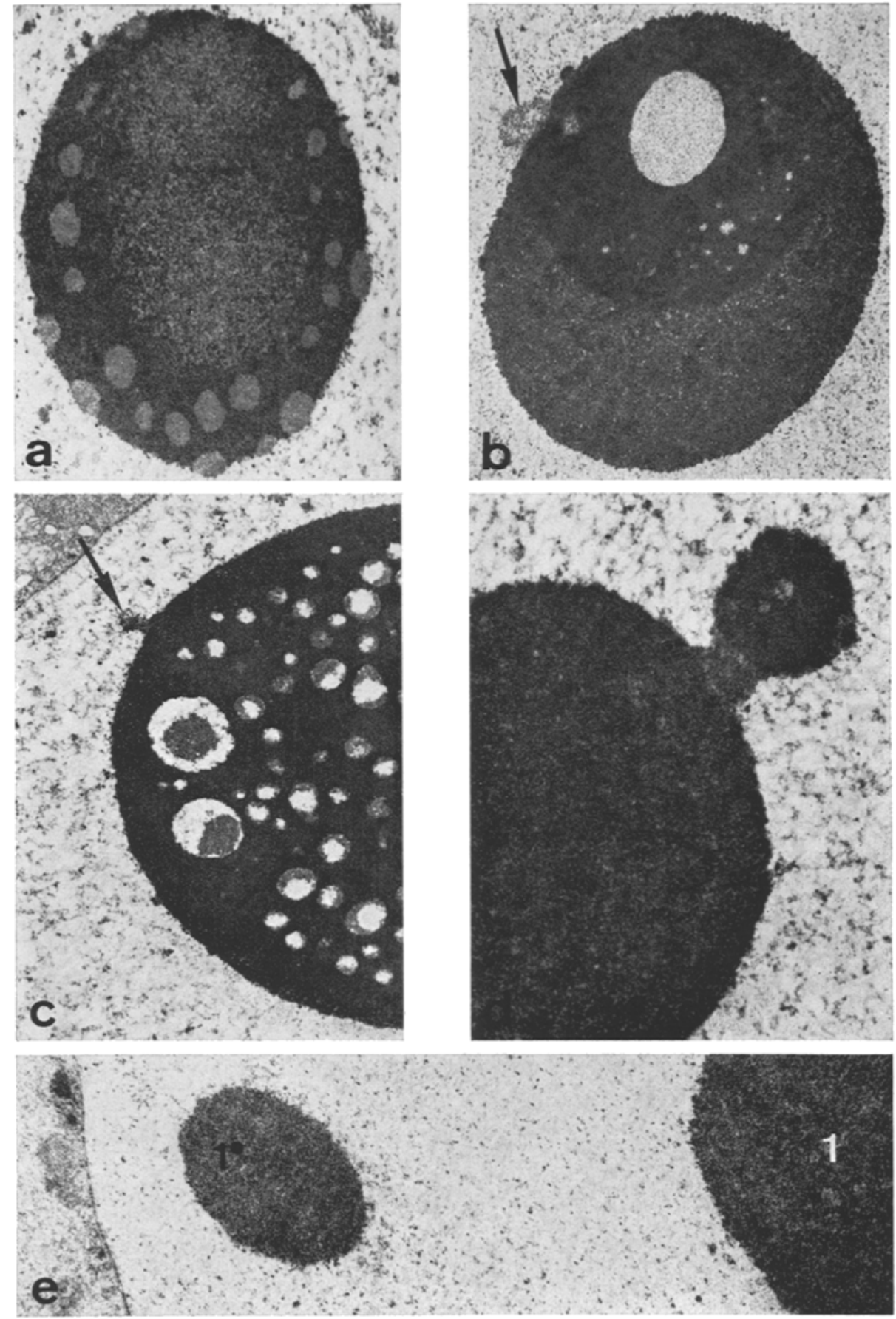

Abb. 5: Aktivitäten des Nucleolus. a Multilokale Auflösungserscheinungen (5700:1). b Zonierung des Nucleolus, Bildung einer Zentralvakuole (6240:1). c Fortgeschrittene Auflösung $(5060: 1) . d$ Nebennucleolus mit Satelliten (27300:1). e Hauptnucleolus (1) und Nebennucleolus (1•) zeigen einen weitgehend identischen Aufbau (4500:1). Die Pfeile markieren extrusicrtes Nucleolarmaterial 
Das Membransystem des Endoplasmatischen Retikulums hat sich gegenüber dem Stadium I weiterentwickelt. Die Zisternen des agranulären ER sind zu ringförmigen Komplexen geschlossen. Der Zusammenschluß erfolgt wahrscheinlich durch Verschmelzen einzelner, kettenartig aneinandergelagerter Vesikeln. Die Zahl der Membranstapel der annulate lamellae kann sich auf drei erhöhen.

Annulate lamellae und geschlossene Membranen sind meist in enger Nachbarschaft von Mitochondrien zu finden. Dabei kommt es vor, daß die Mitochondrien vollständig vom ER eingeschlossen werden.

Die Kernhülle enthält im Vergleich zum Stadium I weniger Poren, die im Durchmesser kleiner sind und von relativ großen Abschnitten parallel verlaufender Hüllmembranen getrennt sind. Das Caryoplasma bleibt grob-flockig; es treten vermehrt dichte Zonen auf, die sich aus Grana von 15-20 nm Durchmesser zusammensetzen. Besonders interessant werden die Kerne dieser Oocyten dadurch, daß neben dem großen Haupt-Nucleolus kleinere Kernkörperchen in Erscheinung treten, die sich in ihrem Feinbau und Kontrast nicht voneinander abheben. Bis zu 35 solcher $1-3 \mu \mathrm{m}$ großen Nucleolar-Grana können gezählt werden.

Der eigentliche Nucleolus durchläuft ab der Mitte des typischen Stadiums II gravierende strukturelle Veränderungen. War er bisher homogen aus Ribosomen-großen Grana zusammengesetzt und gleichbleibend in der Oberflächenbeschaffenheit, zeichnen sich von nun an Auflösungserscheinungen ab, die zu stark divergierenden NucleolusBildern führen (Abb. 5). Aus dieser Serie kann man ersehen, daß alle Übergänge vom einheitlich gebauten bis zum stark vakuolenhaltigen, aktiv Material ausschleusenden Nucleolus innerhalb eines Oocytenstadiums vorkommen können. Die Peripherie des Nucleolus ist unregelmäßig ausgebuchtet; in der Rindenschicht befinden sich of dichtere Körnchen. Im Inneren liegt exzentrisch mindestens ein großer runder Körper unterschiedlicher Dichte. Dieses Material kann entweder homogen elektronendichter oder kontrastärmer sein oder bei gleichen Intensitäten fast leere Vakuolen enthalten.

$\mathrm{Da}$ während der Wachstumsphase die meisten strukturellen und cytochemischen Veränderungen kontinuierlich ineinander übergehen, setzt sich dementsprechend die Wandlung des Nucleolusbildes über die weiteren Stadien fort, ohne daß scharf zwischen den einzelnen Entwicklungsschritten unterschieden werden kann.

\section{Stadium III}

Die Eizellen treten von nun an in eine Phase des intensiven Wachstums. Bedingt durch die Größenzunahme (Oocytendurchmesser von 40-80 $\mu \mathrm{m}$ ), schieben sie sich vollständig aus dem Keimepithel heraus, nehmen eine birnenförmige Gestalt an und bleiben nur durch einen "Oocytenstiel" mit der Basallamina des Keimepithels verbunden. Das gesamte Cytoplasma zerfällt rasch in geräumige Vakuolen, in einem Prozeß, der von außen nach innen bis zum kernnahen Bereich abläuft. Es enthält weiterhin einen bis mehrere Dotterkerne, die sich bereits im typischen Stadium III in Auflösung befinden (praevitellogenetisches Stadium). Die Zahl der Nucleolus-ähnlichen Grana im Kern erhöht sich auf 80. Die Nucleoli erreichen Durchmesser bis zu $15 \mu \mathrm{m}$. In ihnen führt die zu Ende des Stadiums II begonnene Vakuolisierung zur Bildung von zwei 


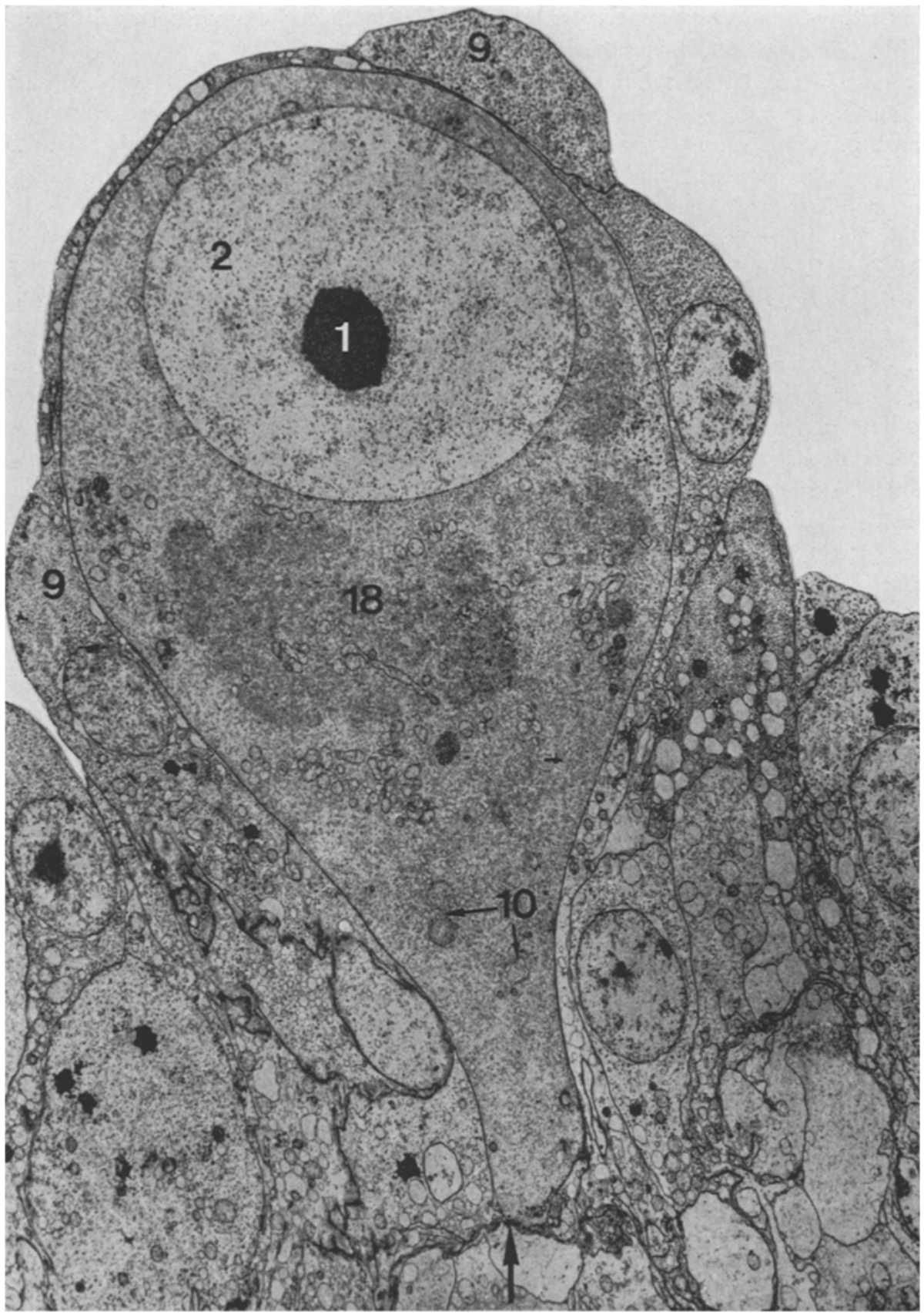

Abb. 6: Die birnenförmige Oocyte im späten Stadium II sitzt direkt mit dem Oocytensticl der Basallamina (Pfeil) auf. 1 Nucleolus; 2 Kern; 9 perioocytäre Follikelzelle; 10 ER; 18 Dotterkern $(5890: 1)$ 
großen, ineinandergelagerten, verschieden anfärbbaren und kontrastierten Körpern, die bald in kleine caryoplasmatische Räume zerfallen (Abb. 6).

Im Caryoplasma liegen nach wie vor vereinzelt Gruppen Ribosomen-ähnlicher Grana. Elektronendichtere Komplexe gleichen den Strukturen, die konstant in unmittelbarer Kernnähe im Cytoplasma anzutreffen sind. In der gleichen Region finden sich von einer feinen Membran ausgekleidete multilamelläre Körper mit stark osmiophilen, meist in sich geschlossenen Lamellen, die in dichten, nahezu parallelen Lagen in der Vakuole aufgewunden sind. Ahnliche lamelläre Körper kommen oft im Plasma der Follikelzellen und vereinzelt im Caryoplasma der Oocytenkerne verschiedener Stadien vor.

Der große Nucleolus ändert seine Zusammensetzung dahingehend, daß im Stadium III zwei konzentrische Bereiche verschiedener Kontraststufen und Struktur zu beobachten sind. Diese Zonierung des Nucleolus ist aus lichtmikroskopischen Untersuchungen bekannt (RIchter \& GöTTING, 1974). Die Untereinheiten der Pars granularis und Pars fibrillaris sind jedoch nicht durch eine deutliche Grenzfläche voneinander abgesetzt, sondern gehen an ihren Außenrändern verschwommen ineinander über. Lediglich die Zentralvakuole grenzt scharf eine Portion Caryoplasma gegenüber der extrem osmiophilen weitgehend granulären Zwischenschicht ab. Die Ribonucleoprotein-Granula sind nicht nur auf diese kompakten Zonen beschränkt. Sie werden über den gesamten Querschnitt des Nucleolus verteilt von der Pars amorpha aufgenommen, verringern ihre Dichte oft an der Peripherie zum Caryoplasma hin und erzeugen teilweise perlschnurartige parallel geordnete Muster (GL ÄTZER, 1971).

Andere Nucleoli zeigen mannigfaltige Übergänge vom Beginn der erhöhten Kondensation nucleolären Materials bis zum Zerfall der Nucleolus-Zonen (Abb. 5). Eindeutige Amphinucleoli fehlen. Abnabelungen nucleolären Materials erfolgen häufig an der Peripherie der Nucleolen in Form von ellipsoiden bis kugeligen Komplexen, die der Größe der Nucleolar-Grana entsprechen. Doch können auch diese Grana selbst Satelliten abgliedern, wenn sie in die Nähe der Kernhülle gelangt sind. Die stets um vieles kleineren Grana rekrutieren sich demnach in der Regel aus dem großen HauptNucleolus und sind nicht als Nucleoli im engeren Sinne zu bezeichnen. Sie zerfallen nicht in caryoplasmatische Räume und sind stets homogen granuliert.

Das elektronenmikroskopische Bild zeigt, daß bereits zu Ende des Stadiums II eine Auflockerung des Cytoplasma stattfindet. An den Stellen, an denen keine Dotterkerne liegen, verringert sich die Konzentration der Ribosomen. Der osmiophile Saum entlang der Kernhülle bleibt vorerst noch bestehen, verschwindet aber beim Übergang $\mathrm{zu}$ Stadium IV. Es bilden sich anfangs an der Oocytenperipherie vakuolenartige Räume, die nur noch mit einem feinfädigen Netzwerk ausgefüllt sind. Im weiteren Verlauf der Oogenese setzt das Cytoplasma die Auflockerung so weit fort, bis es schwammähnlich von flüssigkeitserfüllten, teilweise zusammenhängenden Vakuolen durchsetzt ist.

Die Vakuolen lassen sich ihrem Erscheinungsbild nach in 3 Typen klassifizieren: (a) Vakuolen von maximal $5 \mu \mathrm{m}$ Durchmesser und annähernd runder Gestalt, wenn sie frei im Grundcytoplasma liegen. Sie sind eckig abgeflacht, wenn bereits ein Vakuolenverband zustande gekommen ist. Sie werden nicht von Anfang an von einer Membran umgeben, stehen kaum mit dem Endoplasmatischen Retikulum in Verbindung und werden wahrscheinlich nur aus Substanzen des cytoplasmatischen Raumes 

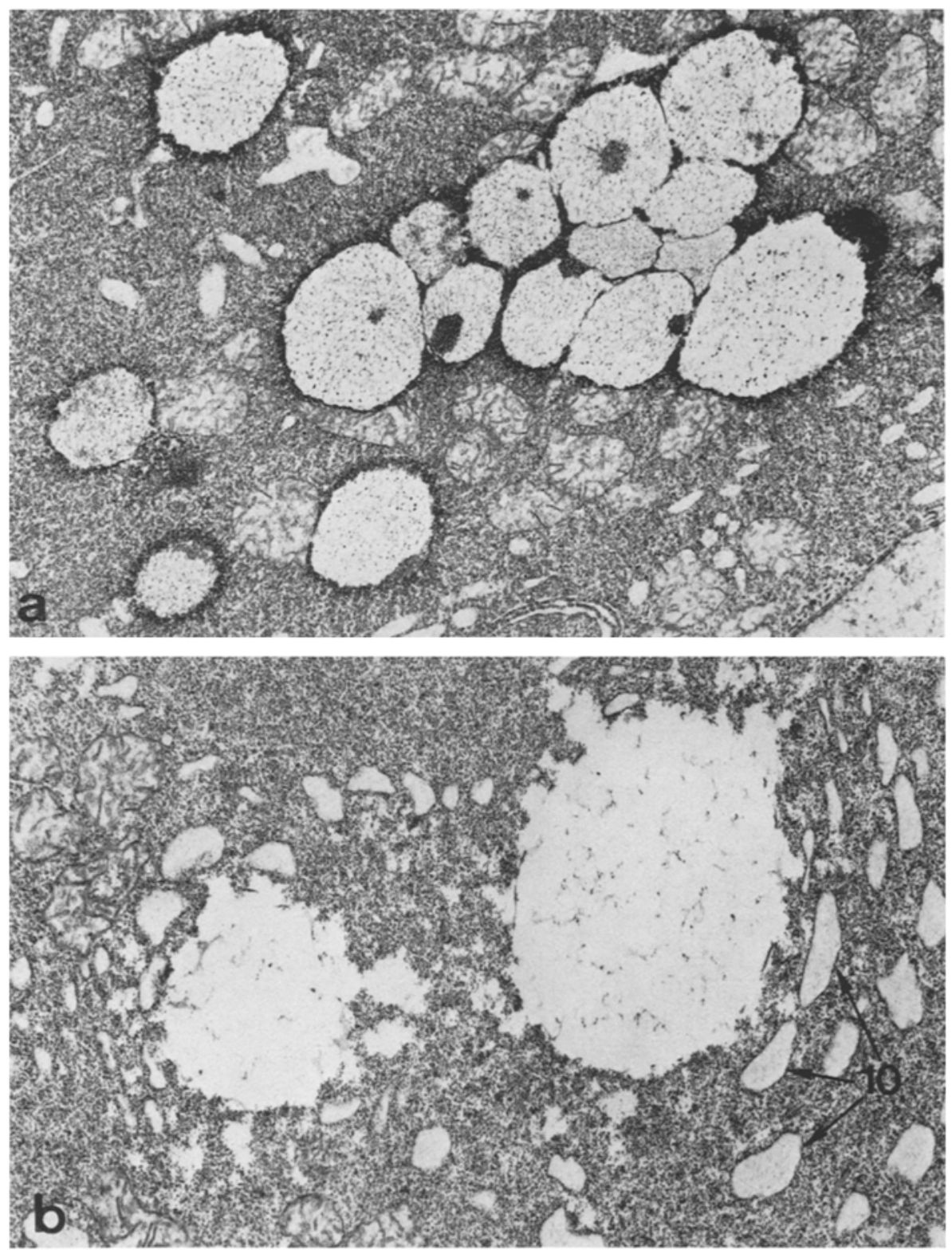

Abb. 7: Offene cytoplasmatische Vakuolen im Stadium III. a Großer Vakuolenverband in Kernnähe $(7600: 1)$. b Einzelvakuolen, an deren Peripherie Vesikeln des Endoplasmatischen Retikulums (10) liegen (14300:1) 
aufgebaut. Thre äußere Kontur erscheint demzufolge nicht scharf begrenzt. Die Peripherie der Vakuole wird strahlenförmig von Spalten unterbrochen, die durch auseinandergewichenes Cytoplasma entstanden sind.

Näher zusammengelegene kleinere Vakuolen verdrängen während des Größerwerdens das verbindende Plasma, bis sie aneinanderstoßen und nur noch durch ein dünnes, elektronendichteres Septum getrennt sind. Im weiteren Verlauf der Vakuolisierung wird diese Grenzschicht an mehreren Stellen durchbrochen, so daß ein einheitlicher Flüssigkeitsraum entsteht. In unmittelbarer Nachbarschaft liegen ER- bzw. Golgi-Vesikeln, Mitochondrien und stark kontrastierte Dotterkörnchen unterschiedlicher Größe. Über den Inhalt der Vakuolen können auf Grund der angewendeten cytochemischen Methoden der Elektronenmikroskopie keine Angaben gemacht werden. Doch lassen lichtmikroskopische Nachweise auf saure Mucopolysaccharide schließen. Die Vakuolen erscheinen nach Fixierung mit gepuffertem $\mathrm{OsO}_{4}$ und Schnittkontrastierung meist leer oder enthalten wenige, diffus verteilte, fädige Strukturen. Mit Glutaraldehyd fixierte Oocyten zeigen dagegen Vakuolen mit elektronendichter, ausstrahlender Peripherie. Die fädigen Elemente sind zum Teil stark vernetzt und bilden ein regelloses Gerüst, zwischen dem Ribosomen-große Partikeln liegen (Abb. 7).

(b) Vakuolen, die bis zu einem Durchmesser von 2-3 $\mu \mathrm{m}$ eine geschlossene Abschlußmembran besitzen, von vielen ER-Vesikeln umgeben sind und sehr oft mit dem feinen Kanalsystem des agranulären ER und speziell mit den Stapeln der annulate lamellae in Kontakt treten. Dieser zweite Vakuolentyp unterscheidet sich, vollständig ausgebildet, in seinem Inhalt nicht von dem oben beschriebenen ersten Typ. Verschieden große Anschnitte erwecken den Eindruck, daß die Membran dem Vakuolenwachstum eine zeitlang folgt, bis sie an einigen Stellen gleichzeitig aufreißt und an der Vakuolenoberfläche oder $z$ wischen den sich vereinigenden Vakuolenkomplexen liegen bleibt (Abb. 7, 8).

(c) Ein dritter Vakuolentyp scheint sich vornehmlich aus den Vesikeln benachbarter Golgi-Felder zu entwickeln. Die typisch polare Form der Dictyosomen ist schüsselförmig, wobei die Sekretionsseite meist dem Zellzentrum zugekehrt ist. Innere, bereits abgeschnürte Vesikeln haben die Größe von Mikrovesikeln, treten in sehr großer Zahl auf und haben teilweise einen homogenen, wenig kontrastierten Inhalt. Am Rande der Dalton-Komplexe liegende Zisternen sind von unterschiedlicher Gestalt, bedeutend größer und elektronenoptisch leer. Der Golgi-Apparat dieses praevitellogenetischen Stadiums beschränkt sich in seiner Lage und Ausdehnung hauptsächlich auf das corticale Cytoplasma. Häufig werden die Dictyosomen direkt an der Oocytenmembran angetroffen. Speziell dieser Bereich weist Vakuolen auf, die von einer stets geschlossenen Plasmamembran umgeben sind. Ihre Oberfläche steht in Kontakt mit kleineren Zisternen, die wahrscheinlich den benachbarten Golgi-Dictyosomen entstammen. Die Vesikelmembranen verschmelzen nicht sofort bei Berührung, sondern werden teilweise oder vollkommen in die große Vakuole aufgenommen (Abb. 8b, c). Vakuolen dieses Typs sind besonders häufig in Eizellen zu beobachten, die ein extrem ausgedehntes Endoplasmatisches Retikulum aufweisen, dessen Zisternen sehr voluminös und verzweigt im Oocytoplasma eingebettet sind. In den aufgeblähten ER-Schläuchen scheinen keine Fette eingelagert zu sein; dagegen finden sie sich an den Membranen und im Lumen der Vakuolen. 

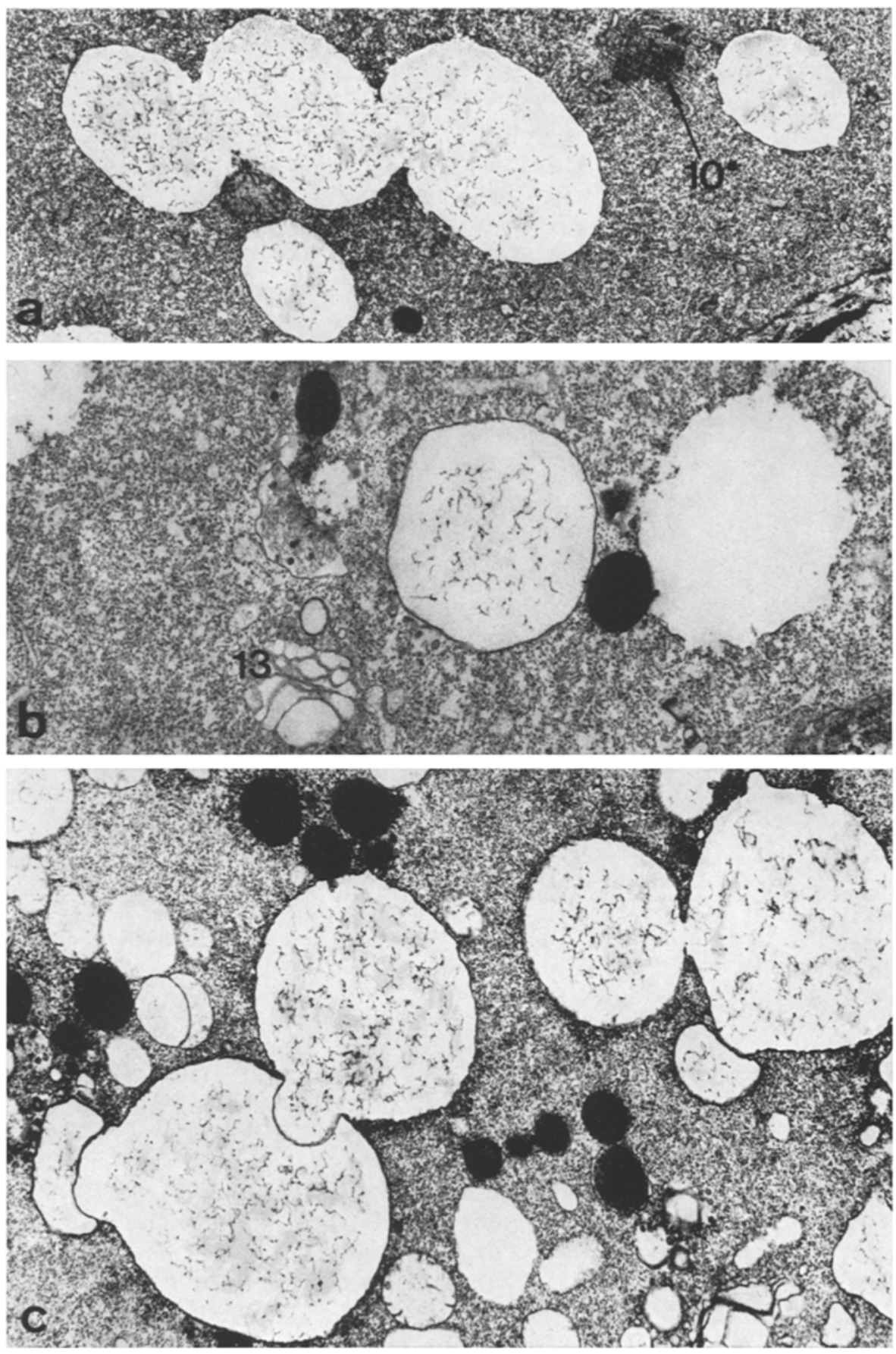

Abb. 8: Cytoplasmatische Vakuolen mit geschlossenen Hüllmembranen. a In der Nähe von annulate lamellae (10) (8360:1). b In der Nähe eines Golgi-Dictyosoms (13) (16 220:1). $c$ Golgi-Vakuolen im Verband $(19500: 1)$ 


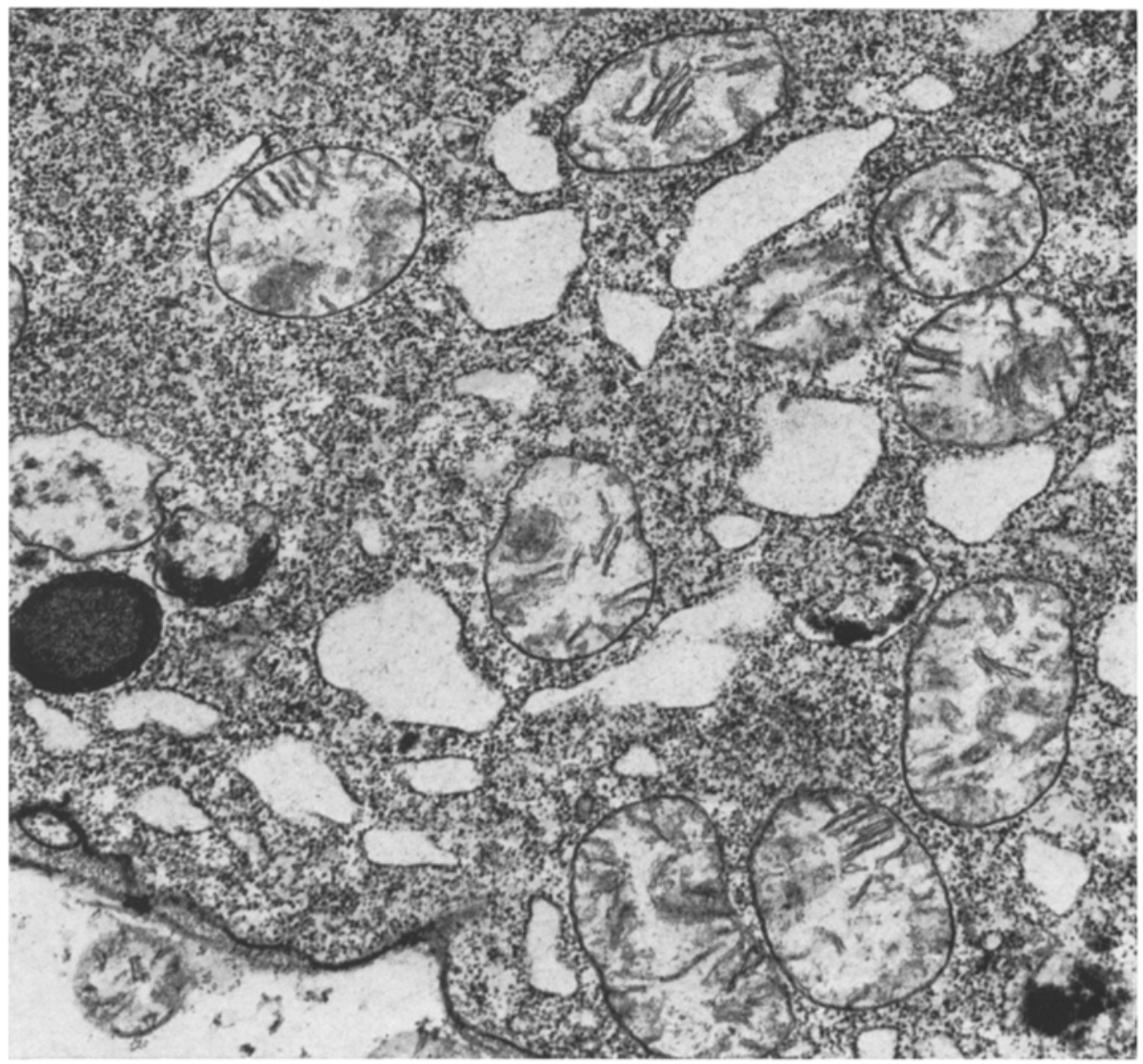

Abb. 9: Transformierende Mitochondrien mit amorphem Material im Chondrioplasma. Die Cristae sind teilweise aufgelöst $(24050: 1)$

Die wohl für die Oocyten der meisten bisher elektronenmikroskopisch untersuchten Tiergruppen charakteristischen, vollkommen geschlossenen, konzentrisch gestapelten Membransysteme des ER treten bei $L$. cinereus erst im späten Stadium III auf. Diese membranumschlossenen Bezirke werden anfangs von einer, später von bis zu 15 Doppelmembranen gebildet, die sich konzentrisch um Portionen des ribosomenreichen Grundcytoplasma legen. Die innere Membran trägt wie die an das ER-System angeschlossene äußere Membran Ribosomen. Beide Membranen trennt eine Zisterne, die im Anfangsstadium dem Abstand der Kernmembranen entspricht und im weiteren Entwicklungsverlauf sich mehr und mehr weitet, in dem Maße, wie weitere Doppelmembranen eingeschoben werden. In der Mehrzahl sind diese Membrankomplexe globulär. Ihr Entstehungsmodus ist wohl so zu verstehen, daß die inzwischen reichlich in das Oocytoplasma vorgetriebenen verzweigten Kanalsysteme Plasmabezirke umschließen, denen im folgenden weitere Kanalsysteme angeschlossen werden.

Neben den konzentrisch gebauten und regellos verzweigten Zisternen sind noch 

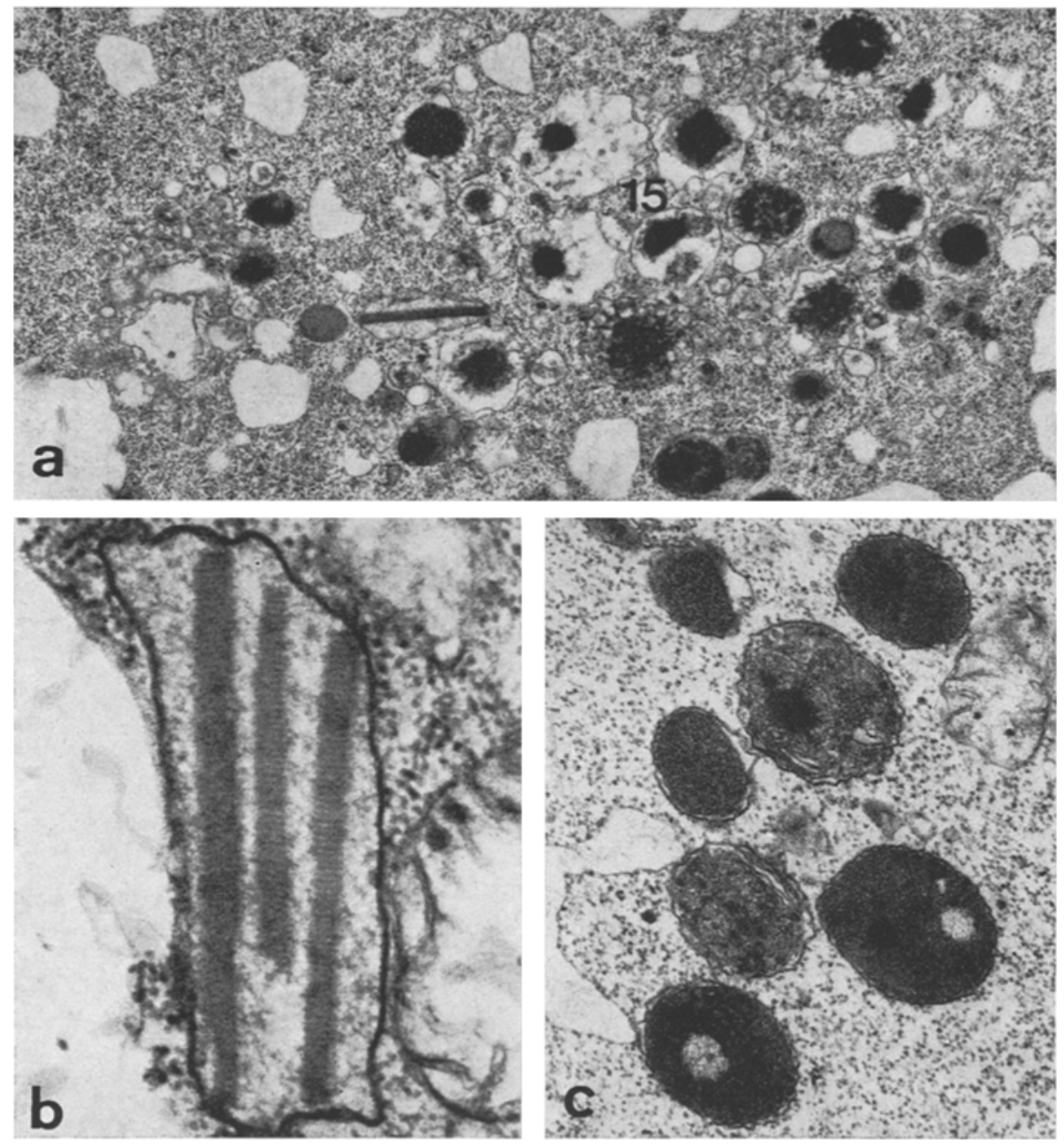

Abb. 10: Cytosomale Dottervorstufen. a Gruppe von transformierten Mitochondricn (15) mit kondensierten Dottersubstanzen in verschiedenen Entwicklungsstadien $(14930: 1)$. b Cytosom mit parakristallinen Strukturen (60390:1). c Dottervorstufen mit Myelinlamellen (27 $300: 1)$

die engen, langgestreckten, flach zusammengepreßten Röhren zu erwähnen, die sich unterhalb der Oocytenmembran entlangziehen. Sie verbinden in Form eines Kanalnetzes die Golgi-Komplexe und Vakuolen des corticalen Plasma miteinander.

Im Stadium der Praevitellogenese jeder Oocyte bildet sich im corticalen Cytoplasma eine Zahl von einfachen Cytosomen (Dottervorstufen). Sie setzen sich zusammen aus bereits vorhandenen multivesikulären Körpern oder transformierenden Mitochondrien. Die Vesikeln enthaltenden Körper liegen zu Beginn ihrer Bildung direkt unter der Oocytenmembran, enthalten gleichgroße Mikrovesikeln und können von zwei Membranen begrenzt sein. Auf ihrem Weg zum Zellzentrum vergrößern sie sich 
und nehmen unregelmäßige Formen an. In ihrer Nähe befinden sich einige Mitochondrien mit Ansammlungen amorphen Materials im inneren Matrixraum (Abb. 9).

Darüber hinaus ist in den Oocyten eine weitere Spezialisation membranumschlossener Körper zu beobachten. Es handelt sich hierbei um irregulär geformte Vesikeln oder in Transformation begriffene Mitochondrien, die im Inneren stabförmige, meist parallel angeordnete, kristalline Elemente aufweisen. Diese Strukturen setzen sich aus bis zu 80 scheibenförmigen Untereinheiten zusammen, die durch gleichgroße Zwischenräume getrennt werden (Abb. 10).

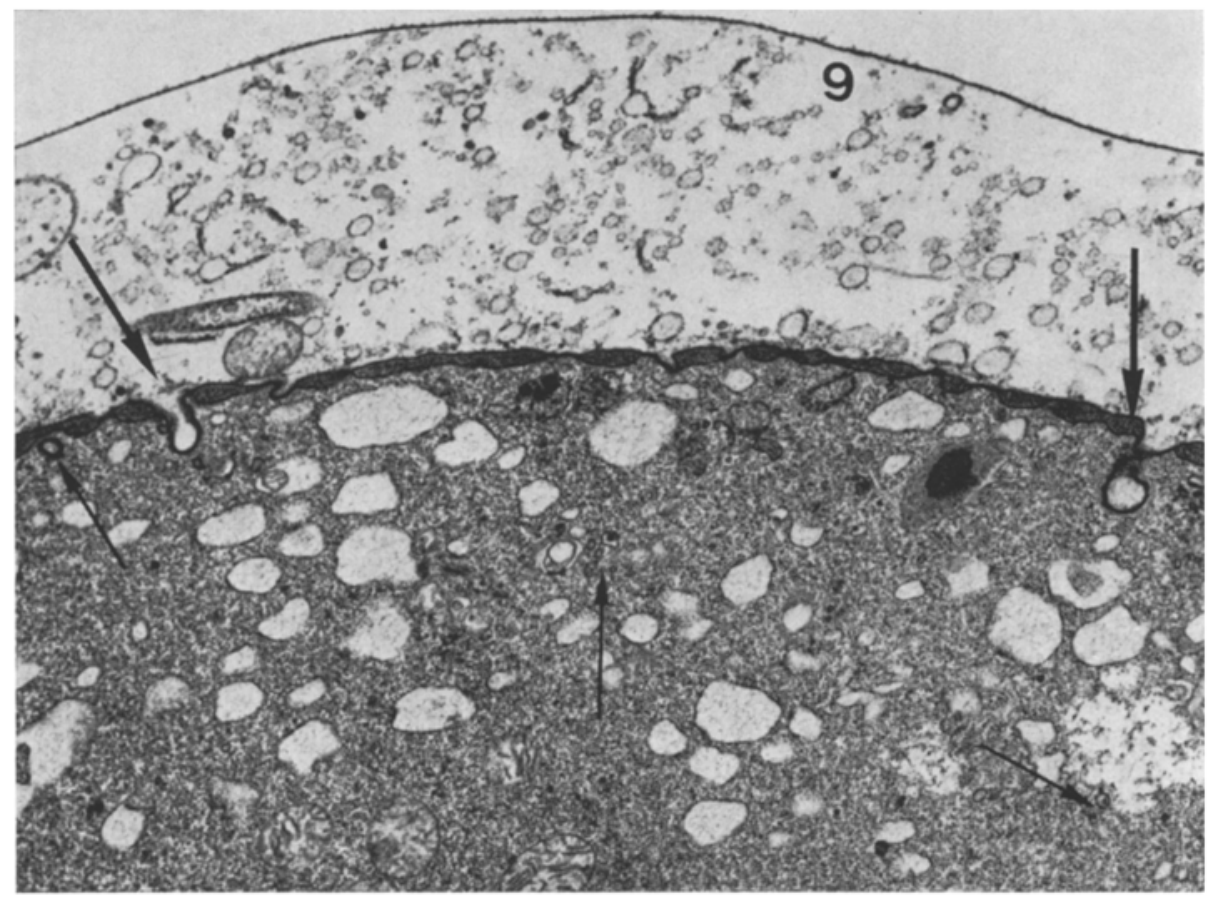

Abb. 11: Pinocytotische Aktivität der Oocyten- und Follikelzellmembranen im Stadium III. Die großen Pfeile deuten auf tiefe Einsenkungen in die Eizelle. Im Rindencytoplasma befinden sich Mikrovesikeln mit doppelten Membranen (kleine Pfeile). 9 Follikelzelle (19500:1)

Während in den frühen Entwicklungsstadien die Oocytenmembran exakt parallel zur inneren Follikelzellmembran verläuft, ohne irgendwelche Umbildungen zu zeigen, treten im Stadium III erstmals Zellhafte in Form von Zonulae adhaerentes mit einer Intercellularfuge von $10-20 \mathrm{~nm}$ auf. Entsprechend dem Zellwachstum vergrößert sich von nun an die Oocytenoberfläche. Der Intercellularspalt wird in unregelmäßigen Abständen vertieft, indem sich die Oocytenmembran in das Ooplasma einbuchtet, und die Follikelzellmembran hervorgewölbt wird. Der freigewordene Raum füllt sich mit fädig-granulärer Intercellularsubstanz. Große Pinocytose-Vesikeln treten gehäuft auf (Abb. 11). Sie werden von der Follikelzellmembran in die Oocyte eingesenkt und dann abgeschnürt. Diese von zwei Elementarmembranen umhüllten Pinosome wandern 
wahrscheinlich ins Zellinnere und werden teils von großen ER-Zisternen aufgenommen, teils zu Multivesikularkörpern aufgebaut.

Ein zuverlässiges Charakteristikum dafür, daß die Eizelle sich in der praevitellinen Phase befindet, ist das Auftreten von Mikrovilli im Zellzwischenraum. Sie entwachsen dem stark gewundenen Oolemm und bleiben infolge des Platzmangels oberflächenparallel $z$ wischen den Membranen liegen.

Ebenfalls auf erhöhte Stoffwechselaktivitäten und Verankerungen mit den ernährenden Follikelzellen läßt die Oocytenmembran des "Oocytenstiels" schließen. Sie ist extrem fest mit der Basallamina und den angrenzenden Follikelzellmembranen verzahnt. Solche innigen Verbindungen bleiben solange bestehen, bis sich die Oocyten vom Follikelepithelstrang oder Keimepithel gelöst haben.

\section{Stadium IV}

Stadium IV ist gegenïber allen anderen Entwicklungsstufen eindeutig durch die äußere Gestalt charakterisiert. Die Oocyte trägt acht, durch tiefe Einschnitte entstandene, höckerartige Vorwölbungen. Jeder der Höcker wird von jeweils 1-2 Follikelzellen überzogen. Auf der bisher glatten Oberfläche der Eizelle bilden sich jetzt Oocytenanhänge, die vor dem Gipfel der Vorwölbungen ringförmig angeordnet sind. Die Nucleolus-Vakuole zerfällt weiter in kleinere Untereinheiten. Die Vesikulation des Cytoplasma hat den Höhepunkt überschritten; es erscheinen vermehrt Dotterelemente. Die Oocyte löst sich vom Follikelepithelstrang (Abb. 12).

Im Stadium IV treten nach wie vor die Dotterkern-ähnlichen konzentrischen Membransysteme des Ergastoplasma auf. Die Zahl der Doppelmembranen erhöht sich nicht wesentlich. Vereinzelt sind degenerierende Mitochondrien und eingeschlossene Dotterelemente im Zentrum zu beobachten.

Als weitere Differenzierungen des rauhen ER erscheinen Membranvernetzungen, deren weiträumige Zisternen den granulär-fädigen Inhalt der cytoplasmatischen Vakuolen und darïber hinaus Membrankanälchen des glatten ER aufweisen. Seltener als die konzentrischen ER-Systeme sind wellenförmig angeordnete Membranstapel mit bis $\mathrm{zu}$ acht Doppelmembranen. Sie sind stärker in das übrige ER integriert, was die vielen offenen Verbindungen zu den Zisternen zeigen. Die Hohlräume zwischen den Elementarmembranen gehen größtenteils ineinander über und erweitern sich zu Vakuolen (Abb. 13).

Annulate lamellae sind bisher in den Eizellen folgender Molluskenarten gefunden worden: Spisula (Swift, 1956; Rebhun, 1961), Barnea (Pasteels \& de Harven, 1962), in den Gastropoden Otala (SwifT, 1956; Rebhun, 1961), Bithynia und Planorbarius (Bоттке, 1973) und in Alloteuthis (BotTke, 1974). Für die Käferschnecke Chatopleura apiculata ist die konzentrische Variante von ANDERson (1969) beschrieben worden.

Die Oocyten von $L$. cinereus zeigen im Stadium IV ein mannigfaltiges Bild an Möglichkeiten, wie die Membranen der annulate lamellae zueinander arrangiert sein können. Der Ursprung der ausgedehnten Membranfelder ist in den Röhren des granulären ER zu suchen, die selten ab Stadium I, häufiger jedoch ab Stadium III die typi- 


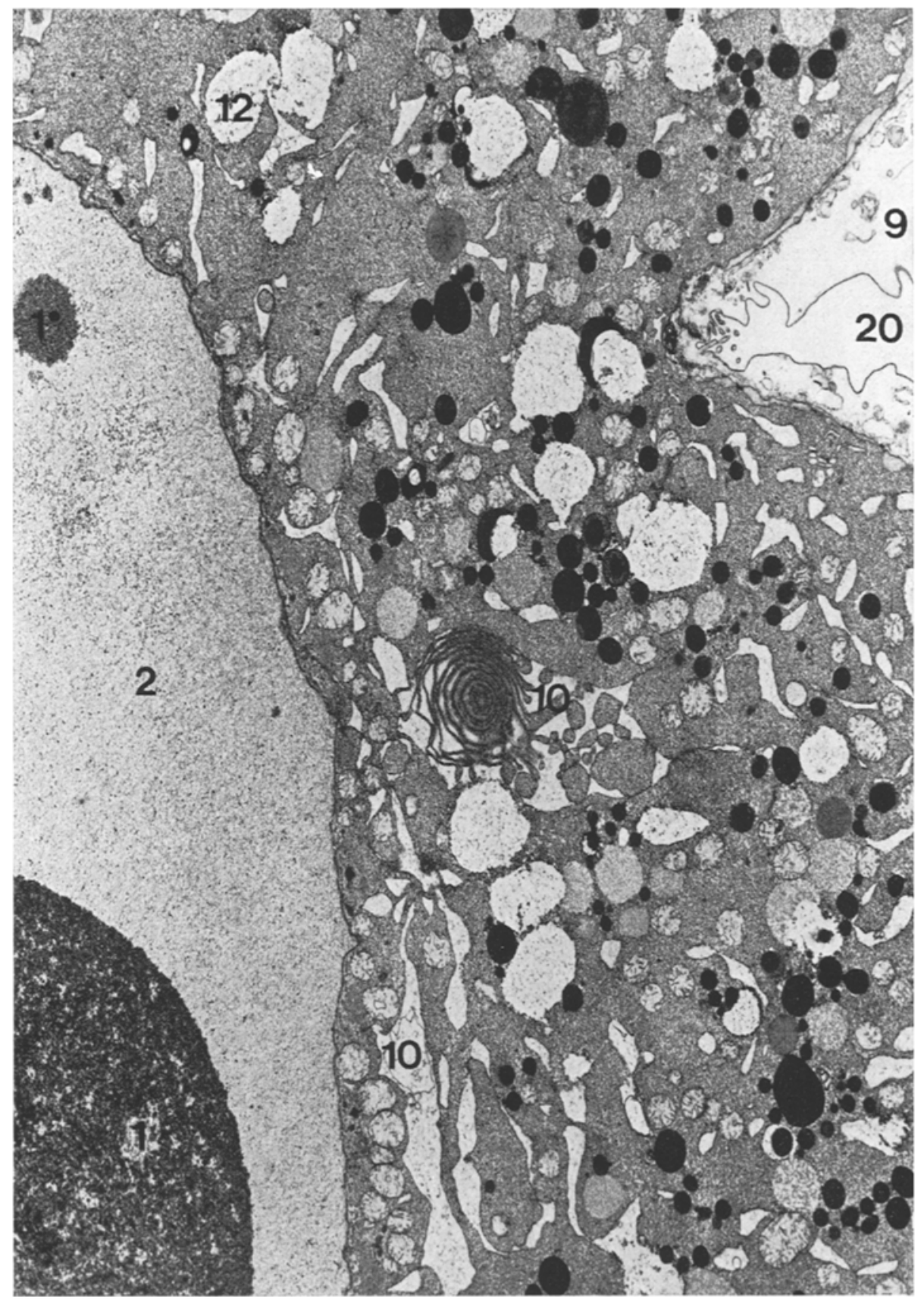

Abb. 12: Oocyte im Stadium IV. 1 Nucleolus; 1 Paranucleolus; 2 Caryoplasma; 9 Follikelzelle; $10 \mathrm{ER} ; 12$ cytoplasmatische Vakuole; 20 Incision $(4940: 1)$ 

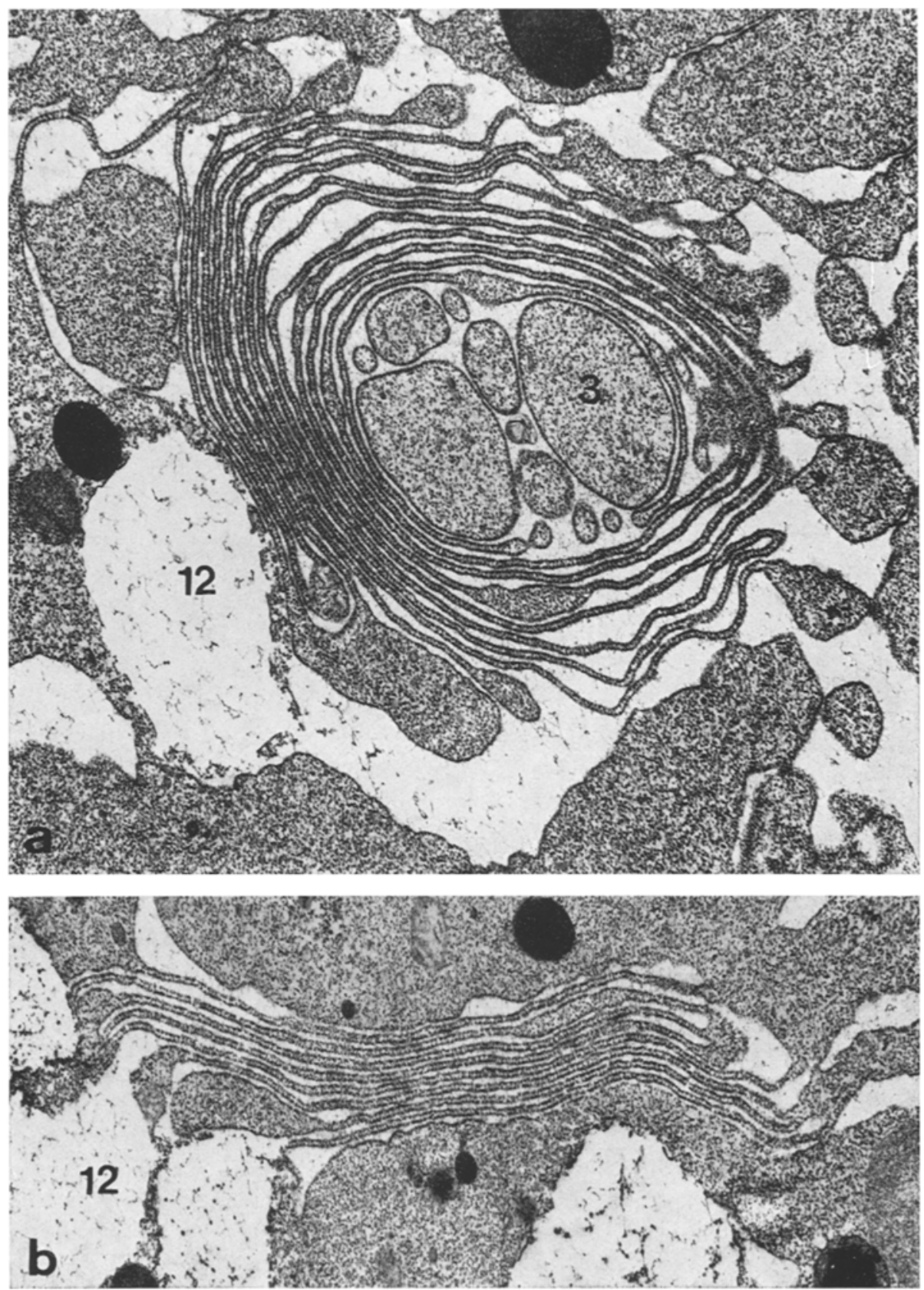

Abb. 13: Membranstapel des granulären ER. a Konzentrischer Membrantomplex mit eingeschlossenen Cytoplasmaportionen (3) (16 250:1). $b$ Gestreckter ER-Stapel mit Verbindungen zum weitläufigen Retikulum und zu den cytoplasmatischen Vakuolen (12) (12350:1) 

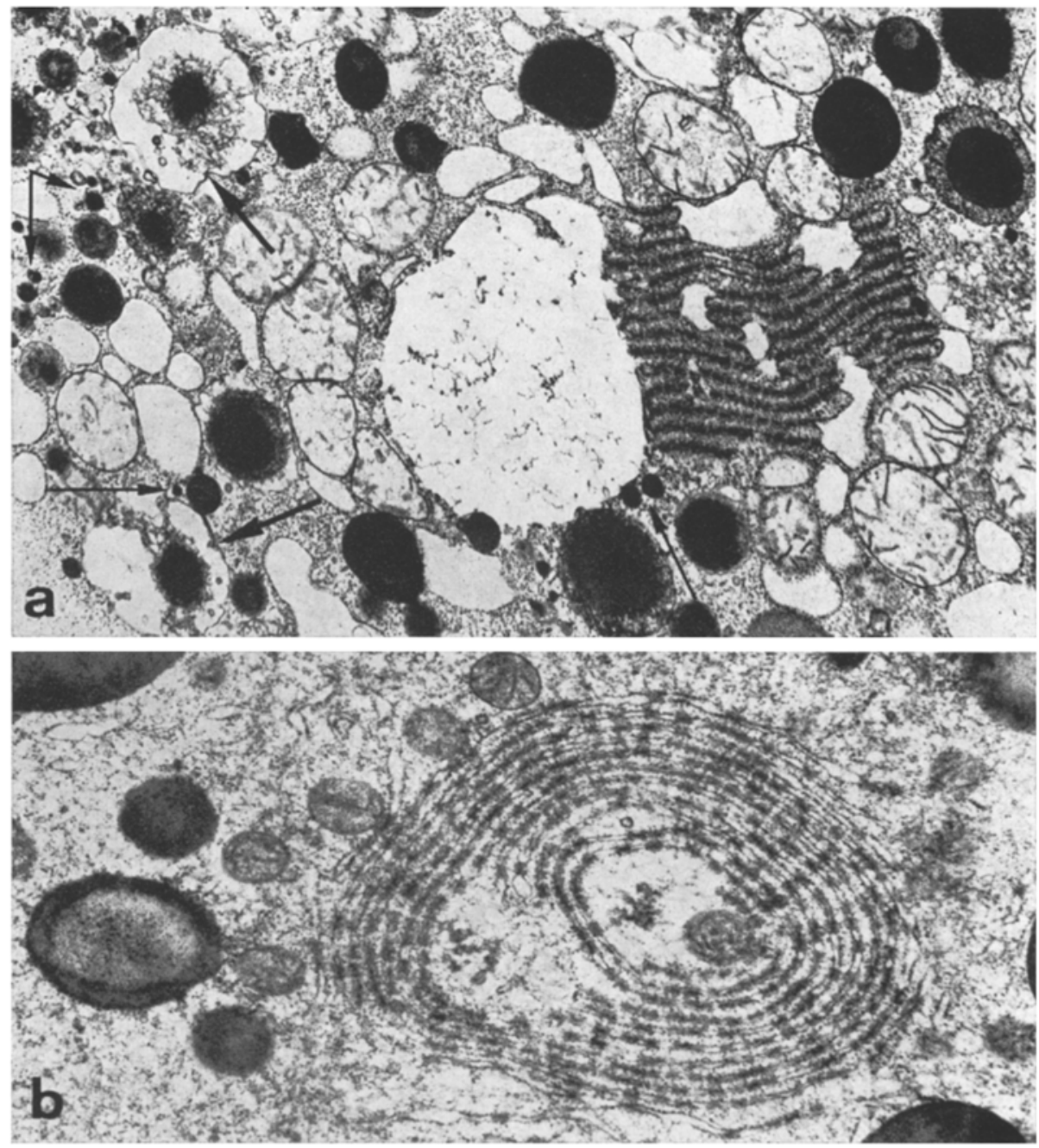

Abb. 14: Annulate lamellae im Stadium IV. a Gestreckter Lamellenkomplex, der in eine Cytoplasmavakuole mündet. Die Pfeile weisen auf Primordialdotter und Cytosomen (13000:1). $b$ Konzentrisch gelagerte Porenmembranen (16790:1)

schen, seriiert auftretenden Annuli ausbilden. Ausgehend von einem einzigen ER-Kanälchen, das sich in zunehmendem Maße in kurze Mäander legt, entsteht ein Membranstapel, der sich durch den Anschluß neu hinzukommender, sich parallel anordnender Membranzisternen vergrößert. Die einzelnen Membranen nehmen unabhängig voneinander an Länge zu, bleiben aber in der Regel durch unterschiedlich große Zisternen und Kanäle an den Stapelenden in direktem Kontakt. Anastomosierende Membranerweiterungen im Inneren der Stapel, die zur Bildung von weitlumigen Zisternen führen, treten häufig auf. 
Ob konzentrisch, halb geschlossen, wellenförmig, eben oder verzweigt, die Stapel stehen immer mit dem weitläufigen ER-System der Eizelle in Verbindung. An einem ihrer Endstücke öffnen sich die Membranzisternen in eine der großen cytoplasmatischen Vakuolen und stellen somit funktionell ein $Z$ wischenglied innerhalb der Transportkette vom Endoplasmatischen Retikulum zu den Dottervorstufen dar. Annulate lamellae einer Doppelmembranzahl von 1 bis 18 können gleichzeitig in ein und derselben Oocyte vorkommen. Quer - und längsgeschnittene Stapel lassen erkennen, daß die Membranlagen nicht unbedingt in geregeltem Muster und absolut parallel angeordnet sind. Der Triglycerid-Nachweis ist besonders für die Membranen und die umgebenden Vakuolen und Zisternen positiv (Abb. 14).

Der Nucleolus des Stadium IV bleibt nach wie vor in seinem Bild vielgestaltig. Caryoplasmatische Vakuolen, verschieden dichte Bereiche der pars amorpha, abgeschnürte Nucleolargrana und größere Gruppen von Ribosomen lassen Rückschlüsse auf die andauernden Stoffwechselvorgänge im Cytoplasma zu. Doch scheinen sich einzelne Nucleoli durch Zerfall der intranucleolären Vakuolen zu homogenisieren. Die Mehrzahl der Kernkörper wandert aus dem Kernzentrum zur Peripherie. Die Kernhülle beginnt dort die Oberfläche zu vergrößern, wo sich der große Nucleolus ihr am dichtesten genähert hat. Gegenüber den Paranucleoli liegen perinucleäre Zisternen, wie sie schon im Stadium III auftraten. Der circumnucleäre Cytoplasmasaum hat beträchtlich an Kontrast verloren. Die Ribosomendichte unterscheidet sich nicht von der des übrigen Cytoplasmakörpers. Nur noch wenige, kleine elektronendichte Komplexe liegen in unmittelbarer Nähe der Kernhülle.

Erste Anzeichen für den Beginn der Vitellogenese geben die cytoplasmatischen Vakuolen des späten Stadiums II. Die Zerklüftung des Cytoplasma von der Peripherie der Oocyte her, hat ihre Ursache in der Ausbildung der drei für das Stadium III charakteristischen Vakuolentypen. Während schon zu Ende dieser praevitellogenetischen Entwicklungsphase kondensierte globuläre Dotterkörner unterschicdlicher Inhalte aufraten, ist doch im Stadiun IV der örtiche wie zeitliche Abschnitt der eigentlichen Dottersynthese zu sehen. Nur in diescm Entwicklungsintervall können die verschiedenen Dottervorstufen bis zum vollständigen Aufbau in Form von Dotterschollen verfolgt werden. Im greichen Maße wie sich die Zahl der Mitochondrien als Dottervorstufen und der Nucleolargrana kontinuierlich erhöht, schwindet der Raum, den die cytoplasmatischen Vakuolen eingenommen haben. An seine Stelle treten Dotterkörner variabler Größe und Reife. Ihre endgültige Ausstattung mit Reservesubstanzen erfolgr erst in den ausgereiften Oocyten, so daß sich schließlich zwei Dottertypen, Proteindotter und Lipiddotter, unterscheiden lassen.

\section{Protein-Dotter}

Als Frühstadien dieses Dottertyps sind drei Dottervorstufen anzusehen: (1) dic vesikelenthaltenden Körper, wie sie bereits für das Stadium III beschrieben worden sind, (2) in Umwandlung begriffene Mitochondrien, (3) stark osmiophile Partikeln unterschiedlicher Größe.

Die Mitochondrien des Stadiums IV sind besonders vielgestaltig. Obwohl die 
kugelige Form vorherrscht, liegen noch schüsselförmige Mitochondrien aus dem vorhergegangenen Praevitellogenesestadium neben in Teilung begriffenen oder bereits geteilten Organellen. Ihre Zahl ist beträchtlich gestiegen. Die Cristae reduzieren ihre Länge, dichte Zusammenballungen formieren sich erst an der Peripherie des inneren Matrixraumes, dann auch im Zentrum. Das Mitochondrium wirkt aufgebläht, die Cristaemembranen zerfallen. Nur die Pediculi cristae erscheinen noch als runde Querschnitte. Teile der intramitochondrialen Membranen lassen auf Vesikelbildung schließen. Konzentrische Membranschlüsse kommen häufig vor. Es liegt nur noch eine Membran dem Körper auf.

Die osmiophilen Zentralkörper vergrößern sich, sind membranlos, enthalten neben einem dichteren feingranulierten Zentrum größere Granula und haben einen zentrifugal gerichteten äußeren Kranz aus kondensierten Substanzen, in die Mikrovesikeln eingelagert sind. Von diesem Zeitpunkt an können bei gleicher Größe der Cytosomen zwei Untergruppen peripherer Substanzen unterschieden werden: Eine Gruppe von Dottervorstufen hat auf den Zentralkörper eine dünne Schicht regelmäßig radialstrahlig angeordneter Ausläufer aufgelagert, deren Spitzen in ein fädiges Geknäuel übergehen. Die zweite Gruppe bildet nur ein bedeutend dichter gepacktes Netzwerk aus, das sich direkt an die Peripherie des Zentrums anschließt. Diese Cytosomen sind von einer Plasmamembran umgeben, die fingerförmige Ausstïlpungen in das Cytoplasma entsendet und stets Vakuolen, Mikrovesikeln und ergastoplasmatische Zisternen kontaktiert (Abb. 9, 10, 14, 15).

Im weiteren Verlauf der Vitellogenese strukturieren sich die peripheren Dottersubstanzen zu konzentrischen Lamellen um, die nicht streng parallel, sondern gewellt und mit unterschiedlichen $Z$ wischenräumen angeordnet sind. Diese, sowie die vorher beschriebenen Strukturen lassen keinen Zweifel offen, daß sie Kondensationsprodukte der zisternalen und vesikulären Substanzen darstellen und im Cytosom in Form des heranwachsenden dichten Zentralkörpers als Reservestoffe eingelagert werden. Das Internum bleibt homogen granuliert, seine Oberfläche bekommt eine elektronendichtere Hülle, der sich die stetig verdichtende, flockige Rindenschicht auflagert. Die Membran glättet sich und schmiegt sich dem Cytosom eng an. Parakristalline Strukturen sind in diesem Dotterstadium noch selten (Abb. 15).

Neben der Mitochondrien-Transformation findet in den Oocyten des Stadiums IV eine weitere Art der Dotterbildung statt. Es handelt sich hier um die Ausbildung stets kugelig-ellipsoider Dotterpartikeln, die überall im Grundcytoplasma anzutreffen sind. Sie sind von Beginn an von einer Membran umgeben, die auf der Außenseite keine Ribosomen trägt und daher sehr transparent dünn erscheint. Diese Dotterkugeln liegen in das ribosomenreiche Plasma eingebettet und treten daher nur an wenigen Stellen direkt mit den cytoplasmatischen Vakuolen, ergastoplasmatischen Zisternen und Vesikeln, Mitochondrien und Golgi-Vesikeln in Verbindung. Sie haben entsprechend den Transformationsstufen eine recht komplizierte Genese.

Das membranöse Grundmaterial stellen wohl primär die kleinen pinocytierten Vesikeln zur Verfügung, die teilweise das Aussehen von coated vesicles haben. Sie entnehmen dem eiweißreichen Cytoplasma Substanzen, die bei verschiedenen Fixierungen in der Regel gleichmäßig dicht, fein granuliert sind. Die Ablagerung der Reservestoffe beginnt ab einer Größe der Vesikeln von $60 \mathrm{~nm}$. Die Vesikeln zeigen ein stark osmio- 


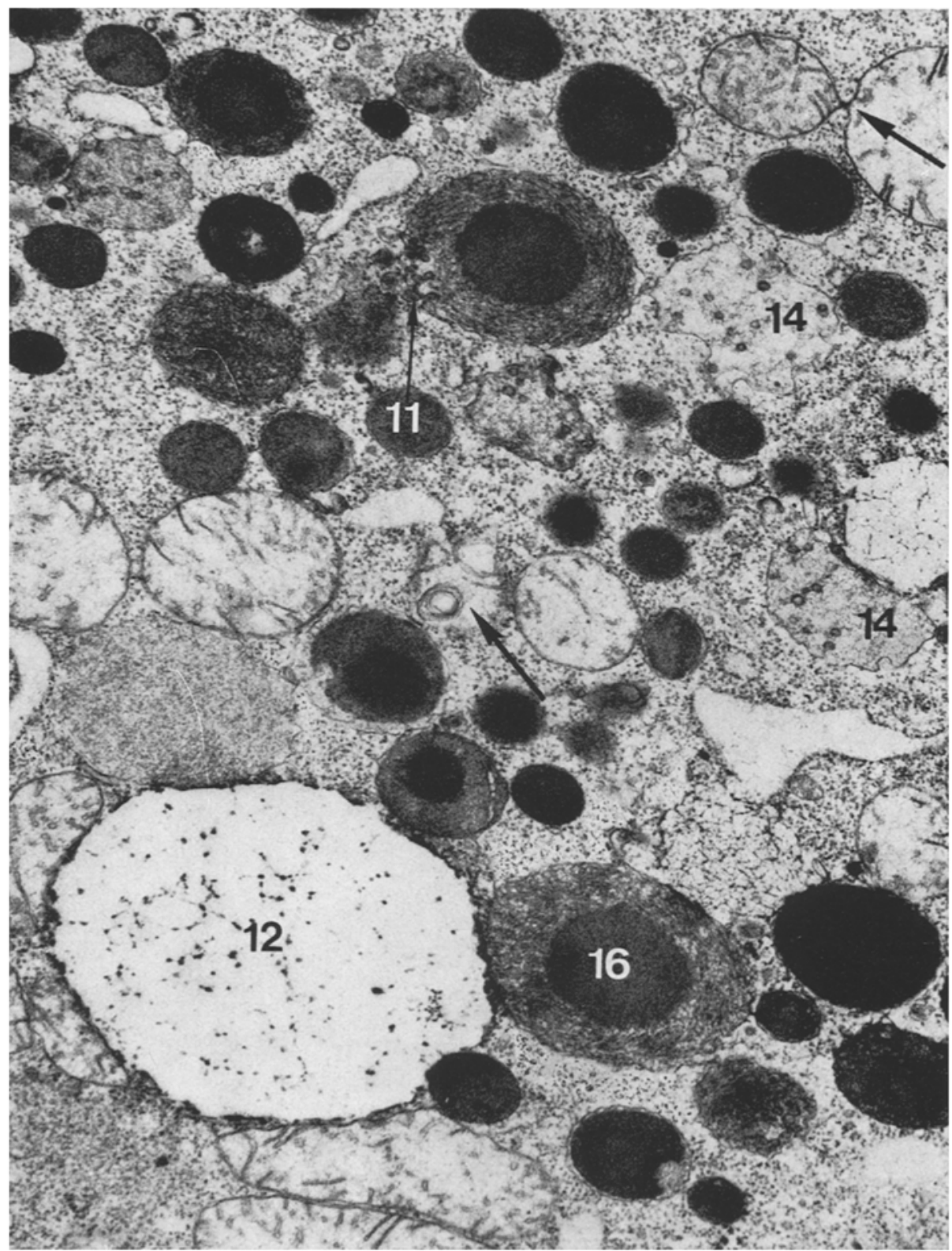

Abb. 15: Proteindottervorstufen mit unterschiedlichem Reifegrad (alle stark osmiophilen Kompartimente). Die Umstrukturierung der Mitochondrien ist noch nicht beendet (Pfeile). 11 Mikrovesikeln; 12 Cytoplasmavakuole; 14 multivesikulärer Körper; 16 fortgeschrittenes Dotterstadium mit Myelinstrukturen (22100:1) 


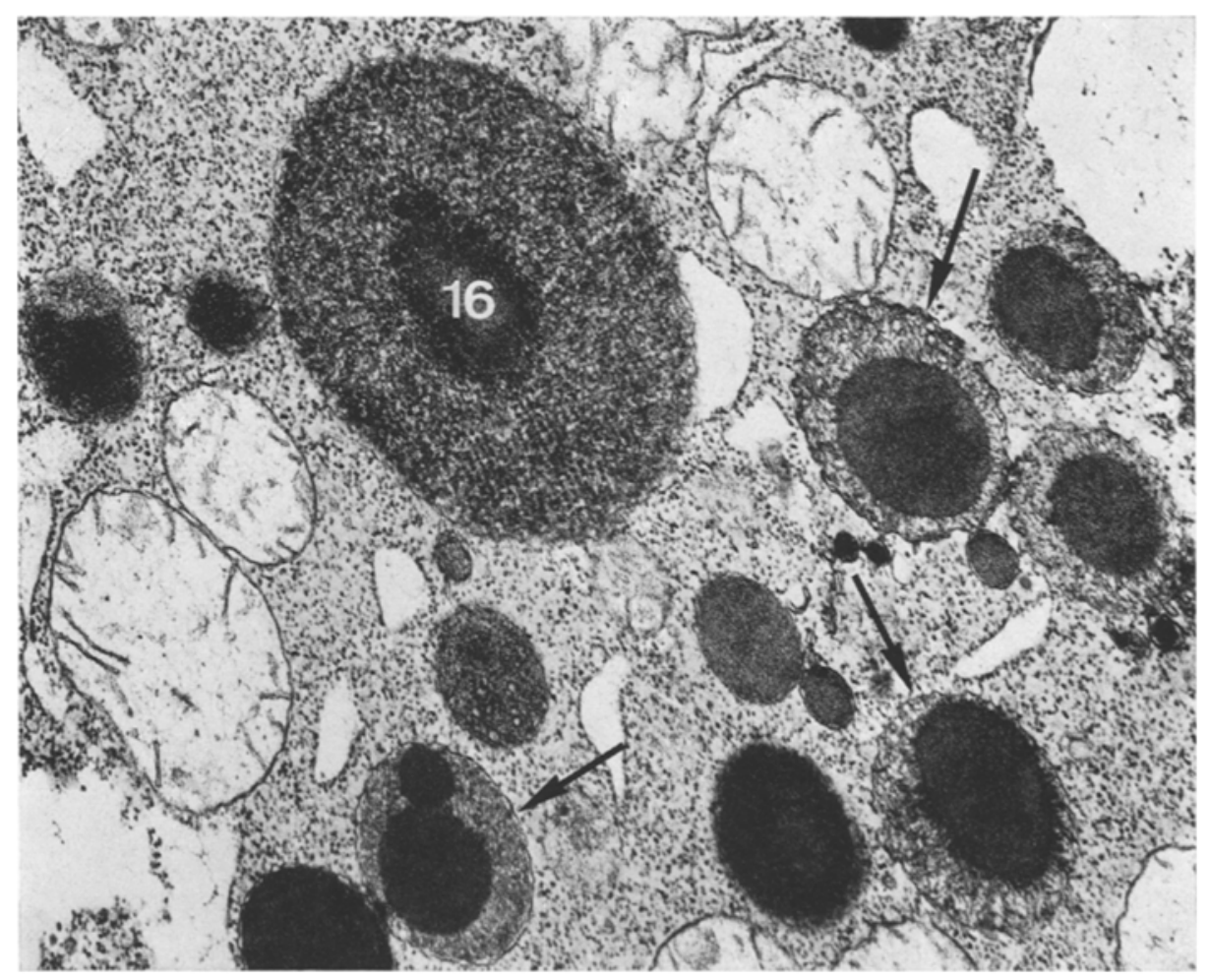

Abb. 16: Komplexcytosomen (Pfeile) und unreifer Proteindotter (16) mit teilweise radiärstrahliger oder parakristallin strukturierter Rindenschicht (42050:1)

philes Zentrum mit einer weniger kontrastierten Hülle, die sich entweder nach kurzer Zeit auf die Stärke der Cytoplasmamembran reduziert oder zu einer Kappe bzw. äußeren Hüllschicht heranwächst und bis zum Stadium der ausgereiften Dotterpartikel bestehen bleibt.

Parallel zu den sich aufbauenden Vesikeln sind bis zu 1,5 $\mu \mathrm{m}$ große Zisternen entstanden, die ebenfalls von einer ribosomenlosen Plasmamembran umschlossen sind. Feinfädige Niederschläge, die am Anfang noch flockige Wolken innerhalb einer im elektronenmikroskopischen Bild homogen hellgrau erscheinenden Matrix bilden, verteilen sich schließlich über das ganze Volumen dieser Dottervorstufen. Der Inhalt verdichtet sich auf verschiedene Weise. Es können mehrere Kondensationskerne vorhanden sein, die elektronendichte Granula erzeugen oder das gesamte Dottermaterial kondensiert bis auf einen Restkörper (Abb. 16).

$\mathrm{Ab}$ einer Größe von ca. $2 \mu \mathrm{m}$ lassen sich beide Dottertypen auf Grund der Elektronendichte, Ausbildung des Restkörpers und der beginnenden Schichtung nicht mehr unterscheiden. Selten sind Myelin-Figuren an der Peripherie des dichteren Teils zu sehen. Bei günstiger Schnittführung treten kristalline, parallel geordnete Dotterprotein-Strukturen hervor. Liegen zufällig zwei Dotterkörper eng zusammen, können 
ihre Hïllmembranen miteinander verschmelzen. Der Triglycerid-Nachweis liefert keine Anhaltspunkte, daß hier Lipid-Dotter entsteht. Diese beiden Dotterpartikeln bestehen demnach vornehmlich aus Proteinen.

\section{Lipid-Dotter}

Daß den Mitochondrien eine zentrale Bedeutung innerhalb der Vitellogenese zukommt, beweist ein anderer Aspekt ihrer Transformationsfähigkeit. Einige Mitochondrien scheinen zu den nur teilweise von Membranen ausgekleideten Cytoplasmavakuolen zu wandern, vergrößern ihr Volumen, bauen Cristae ab und öffnen die innere und äußere Mitochondrienmembran, wenn sie an die Vakuole gestoßen sind. Mehrere so entstandene bzw. vergrößerte Flüssigkeitsräume legen sich aneinander und bilden ein vakuoläres Verbundsystem, an das weitere ER-Zisternen und sich auflösende Mitochondrien angeschlossen werden (Abb. 17).

Daß es sich um Vorstufen des Lipid-Dotters handelt, zeigt das weitere Schicksal der Vakuolen. Obwohl sie unterschiedlichen Ursprungs sind (Typ 1-3 des Stadiums III), und während der Vitellogenese nicht mehr eindeutig in die drei Gruppen unterteilt werden können, bilden diese Vakuolen ausnahmslos unregelmäßig geformte Dotterschollen.

Wie die Abbildungen zeigen, lagert sich Dottermaterial entweder an der Innenfläche eines Membranstückes auf oder es ist an der Oberfläche unbegrenzter Vakuolenbereiche kondensicrt. Dabei lösen sich die feinkörnigen, zu Fäden verbundenen Substanzen in ihre Untercinheiten auf und werden am Rande der Dotterbildungszone angelagert. Auf diese Art und Weise formieren sich teils runde, teils gelappte Komplexe kontrastreichen amorphen Lipids. Die Fette werden nicht kontinuierlich, sondern schubweise abgegeben. Auch verlassen sie wahrscheinlich nicht aktiv die Dottervakuole, sondern werden vom nachfolgenden Tropfen in das Cytoplasma geschoben. Die Lipidschollen bleiben zu Gruppen vereint liegren. Meist erzeugt eine große Vakuole an mehreren Orten gleichzeitig Kondensate, die dann in Form einer Kugelklappe der jeweiligen Bildungszone aufsitzen. Ist die Dottersynthese beendet, verschwinden die Umrisse der Vakuolen, und cytoplasmatische Ribosomen erscheinen zusammen mit Grundcytoplasma in dem entstandenen Freiraum (Abb. 18).

Das charakteristische Merkmal der äußeren Gestalt dieses Stadiums IV sind tiefe Einschnürungen der Oocytenoberfläche bis in Kernnähe und acht daraus resultierende Aufwölbungen des Oocytenplasma. Dic einzelnen Stempel werden durch mehr oder weniger enge Ringfurchen gegeneinander abgesetzt und von meist einer Follikelzelle umspannt. Dic Kontaktstellen der Follikelzellen liegen immer am tiefsten Punkt der Einkerbung und sind als breite, bandförmige Zonulae adhacrentes ausgebildet. Beidseits der Zellhafte liegen starke Fibrillenbündel der jeweiligen Follikelzelle, die als kontraktile Elemente wirken (Abb. 12). Dadurch ist jede Zelle mit einem Ringmuskelähnlichen Zugband ausgerüstet, das das Zusammenschnüren der Cytoplasmamassen der Eizelle ermöglicht. Da im Oocyteninneren keine kontraktionsfähigen Strukturen im Bereich der Incisionen nachgewicsen werden können, hat jede Follikelzelle nur die Nachbarzelle als Antagonisten zur Verfügung. Die Oocyte selbst bleibt passiv. Das 

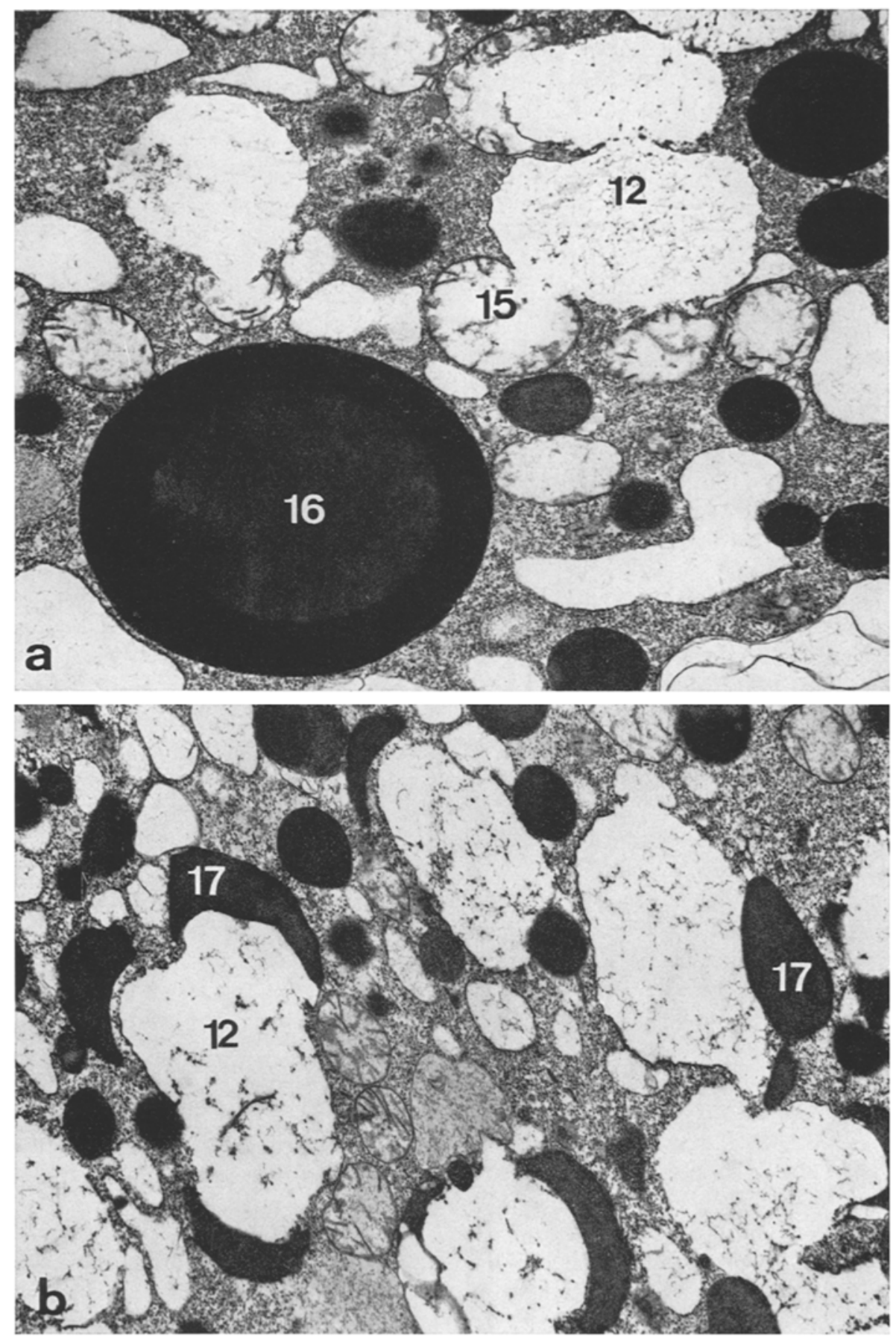

Abb. 17: a Im frühen Stadium der Lipiddotter-Bildung stehen Mitochondrien mit Cytoplasmavakuolen in Verbindung (14300:1). $b$ Kappenförmige Kondensate aus vornehmlich sauren Fetten an der Oberfläche der Dottervakuolen $(13650: 1)$. 12 Cytoplasmavakuole; 15 Mitochondrium; 16 reifer Lipoproteindotter; 17 Lipiddotter 
Grundcytoplasma, sowie alle funktionellen Elemente der Vitellogenese wie Vakuolen, ER-Stapel und -Zisternen, Lipidkörper und Proteindottersphären bleiben unverändert in Lage und Gestalt. Die Follikelzellen bilden in ihrer Gesamtheit ein grobmaschiges Netz aus zugfähigen Elementen, die die Funktion haben, die Oocytenoberfläche zu zerklüften und damit zu vergrößern. Mit dieser Flächenerweiterung ist natürlich eine Vergrößerung der Follikelzelle selbst verbunden. Sie nimmt große Flüssigkeitsmengen auf, so daß das Cytoplasma größtenteils leer erscheint.

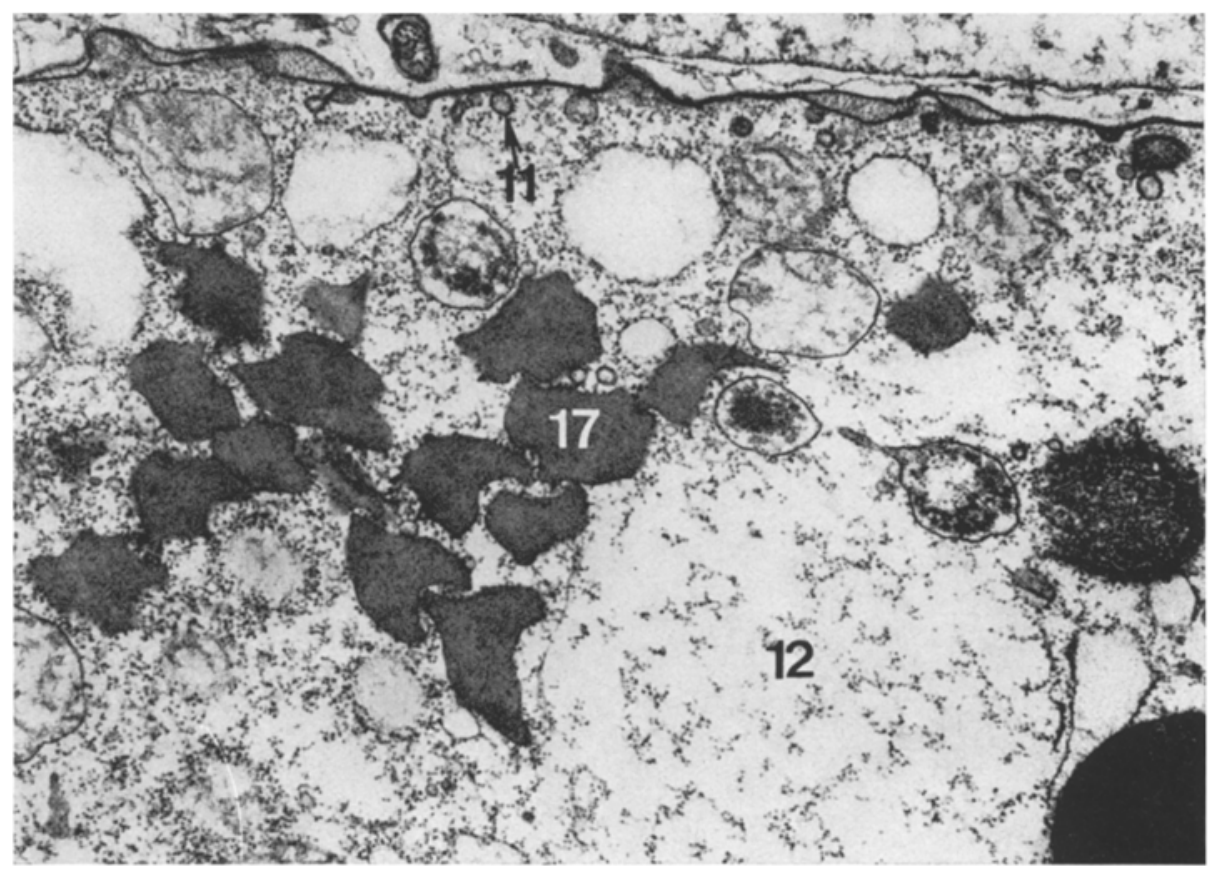

Abb. 18: Bereich einer Dottervakuole (12) nach Abgabe der Fettsubstanzen (17). 11 Pinosom (19500:1)

Diese Einsenkungen der Oocytenmembran haben einen hohen Anteil am Stoffaufnahme- und -transportgeschehen. Neben der beträchtlichen Oberflächenvergrößerung laben sie möglicherweise die Funktion, daß die aus dem Gonocoel über Makropinocytose der Follikelzellen aufgenommenen Nährstoffe auf kürzestem Wege dem Zentrum der inzwischen weit über $100 \mu \mathrm{m}$ großen Oocyte zugeführt werden.

Zu Ende des Stadiums IV entspannen sich die peripheren Fibrillenbänder der Follikelzellen wieder; das Oocytenvolumen ist gewachsen, die Intensität der Dotterbildung hat ihren Höhepunkt überschritten. Die Incisionen verlieren an Tiefe und die Eizelle erhält ihre kugelige Form zurück.

Wahrscheinlich einmalig für unreife Eizellen ist das Vorkommen von rootlets in den Entwicklungsstadien IV bis V bei L. cinereus. Die langen, flamentösen Strukturen bilden kräflige, regelmäßig quergestreifte Fasern, die annähernd parallel, gabelförmig 
verzweigt oder sich überkreuzend im corticalen Cytoplasma zu finden sind. Stets liegen sie gestreckt im Bereich der langen Mikrovilli unterhalb der Oocytenanhänge. Für den hüllenlosen Teil der Oocyten sind sie nicht nachweisbar.

Eine Verbindung zur Oocytenmembran oder zu oocytären Organellen läßs sich nicht feststellen. Die tatsächliche Länge der Mikrofilamente (über $4 \mu \mathrm{m}$ ) kann nicht angegeben werden; ihr Ursprung ist unbekannt. Im terminalen Bereich, kurz unter der Oocytenoberfläche verlassen lange Mikrotubuli den Verband und liegen teilweise vernetzt im Cytoplasma. Die zwischen 60 und 100 nm dicken Fasern spleißen sich auf (Abb. 19).

Die Periode der Querstreifung liegt bei $60 \mathrm{~nm}$. Jedes Querband ist wiederum in Scheiben zoniert, die $12 \mathrm{~nm}$ voneinander entfernt sind. Interessant ist, daß in unmittelbarer Nähe der Filamentbündel zahlreiche Mikrovesikeln anzutreffen sind, die den Dictyosomen entstammen. Die ca. $40-60 \mathrm{~mm}$ großen Vesikeln enthalten wenig dichtes, fibröses Material.

\section{Stadium V}

Die laichreifen Eizellen sind annähernd kugelrund, haben einen Durchmesser von 160-200 $\mu \mathrm{m}$ (ohne Oocytenhüllen: 110-150 $\mu \mathrm{m}$ ) und liegen frei im Gonocoel. Die Vitellogenese ist weitgehend abgeschlossen. Das Ooplasma ist angefüllt mit sphärischen Dotterkugeln und Lipid-Schollen. Die Kernhülle setzt die bereits im vorhergegangenen Stadium begonnene Oberflächenvergrößerung durch Einfaltungen fort. Der Durchmesser des Kernes erreicht bis zu $90 \mu \mathrm{m}$, der meist exzentrisch liegende Nucleolus kann bis zu $20 \mu \mathrm{m}$ groß werden. Die Oocytenhüllen haben sich weiter zu becherförmigen Schalenanhängen differenziert, wie sie von LYNGNEs (1924) beschrieben sind. Ovarialoocyten entfalten jedoch diese Anhänge aus Platzmangel nicht. Es löst sich außerhalb der Oocytenmembran eine häutige Struktur ab, die als zweite primäre Hülle oder "Dotterhaut" bzw. "Vitellinmembran" bezeichnet werden kann.

\section{Genese der Oocytenbüllen}

Die vorangegangenen lichtmikroskopischen Untersuchungen haben von der $\mathrm{Me}$ thode her keine befriedigende Beantwortung der Fragen zur Genese der komplizierten Anhänge der Oocyten von L. cinereus erlaubt. Die von Selwood (1970) erhaltenen Befunde bei Sypharochiton sind nicht direkt auf Lepidochitona übertragbar. An dieser Stelle nun sollen die Aspekte der oocytären Oberflächendifferenzierungen in Form der Mikrovilli (vergleiche Stadium III), die Pinosombildung, das Verhalten der Interzellularfuge und die Einlagerung der Hüllsubstanzen bis hin zur Entstehung der bereits von SchweIKart (1904) beschriebenen Eizellhüllen an Hand elektronenmikroskopisch gewonnener Ergebnisse erörtert werden.

Die Oocytenmembran des Stadiums IV bleibt nach wie vor über Zonulae adhaerentes in innigem Kontakt mit den Follikelzellen. Tiefe Membraninvaginationen, wie für Insekten-, Fisch- und Froschoocyten als "pinocytotic pits" beschrieben (Bier \& Ramurty, 1964; Droller \& Roth, 1966; Dumont \& Wallace, 1972), sind 


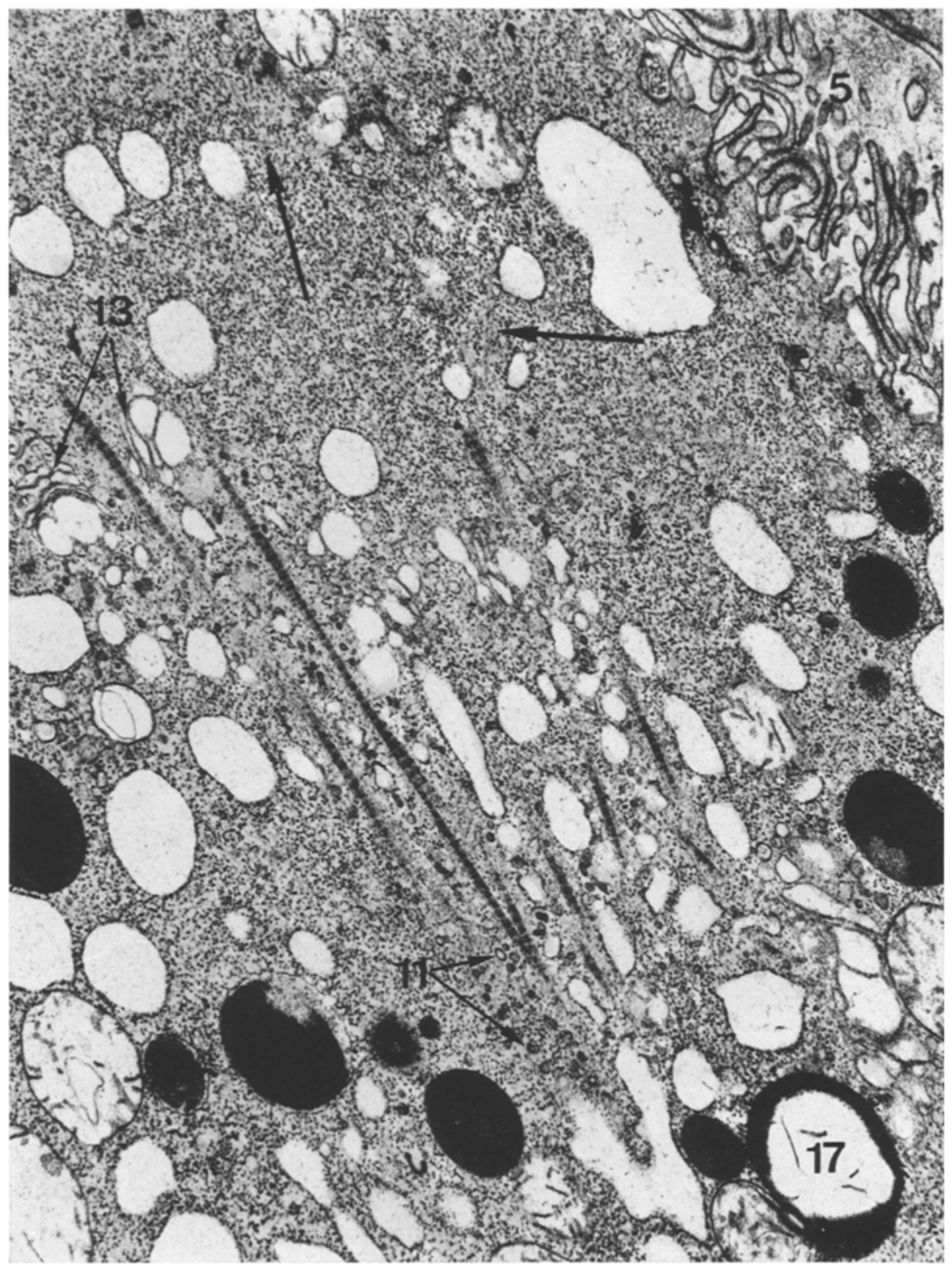

Abb. 19: Unterhalb der Mikrovilli (5) liegen gebänderte rootlets im Rindencytoplasma. Die Faserbündel verzweigen sich unregelmäßig und entsenden Mikrotubuli (Pfeile). 11 Mikrovesikeln; 13 Golgi-Komplexe; 17 Lipiddotter-Vakuole (18 190:1) 
nicht so weit in das Oocytoplasma vorgetrieben. Die abgeschnürten Pinosome sind im Corticalplasma häufig. Sie finden sich regelmäßig in den Bereichen der Ansammlungen von Mikrovilli vor den Schlauchöffnungen oder bereits innerhalb der Membranen auf dem Weg zu den distalen Endstücken. Ihre Ausschleusung in den Intercellularraum kann angenommen werden, ohne daß diese Phase eindeutig beobachtet worden ist.

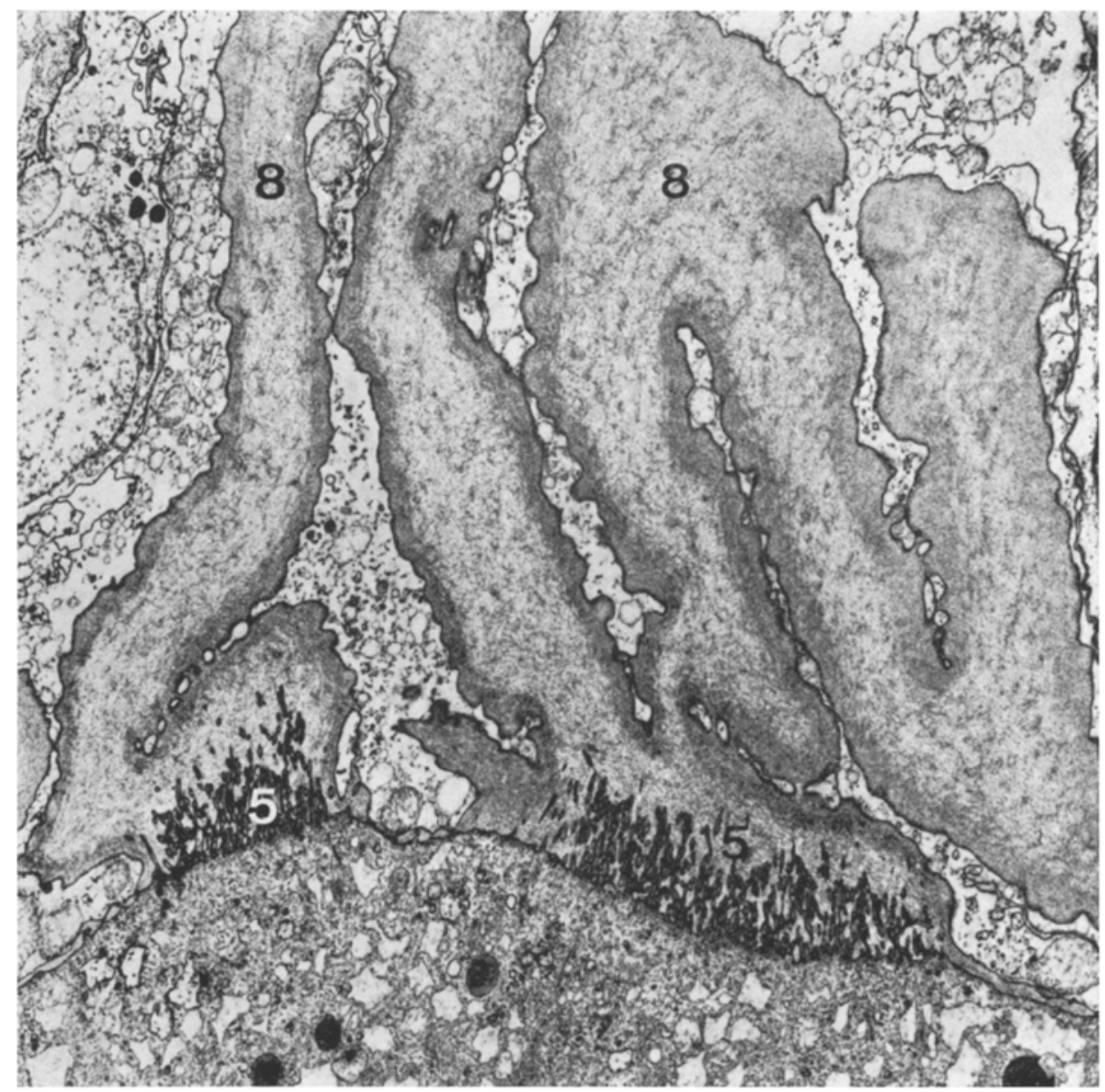

Abb. 20: Aufgerichteter Oocytenanhang (8) im Stadium IV nach Osmium-Fixierung. Die beiden Gruppen von Mikrovilli (5) deuten an, daß der Hüllenanhang ringförmig den Hervorwölbungen der Eizelle aufsitzt (4500:1)

Die im Stadium III noch niedergedrückten Mikrovilli haben inzwischen soviel amorphes extracelluläres Material abgeschieden, daß sie sich aufrichten und verlängern können. Dabei werden wohl erst 1-2 ooplasmatische Makrovilli in das Lumen geschoben, um die sich eine Vielzahl von dichtgepackten Mikrovilli schart. Die Mikrovilli sind in der Regel einfach gestreckt, doch können ebenso gebogene und verästelte For- 
men vorkommen. Im Tangentialschnitt läßt sich keine Musterbildung in Bezug auf ihre räumliche Anordnung erkennen.

Haben die lichtmikroskopischen Präparate des Stadiums IV lediglich auf den Scheiteln der oocytären Hervorwölbungen in der Mitte einer Follikelzelle die Ausbildung von Eizellhüllen erkennen lassen (Richter \& Gö't'TING, 1974), läßt sich auf den Ultradünnschnitten eine weitere Bildungszone nachweisen. Regelmäßig entstehen kleinere Hüllenteile gleichen Aufbaus unmittelbar links und rechts der Incisionen, die bei

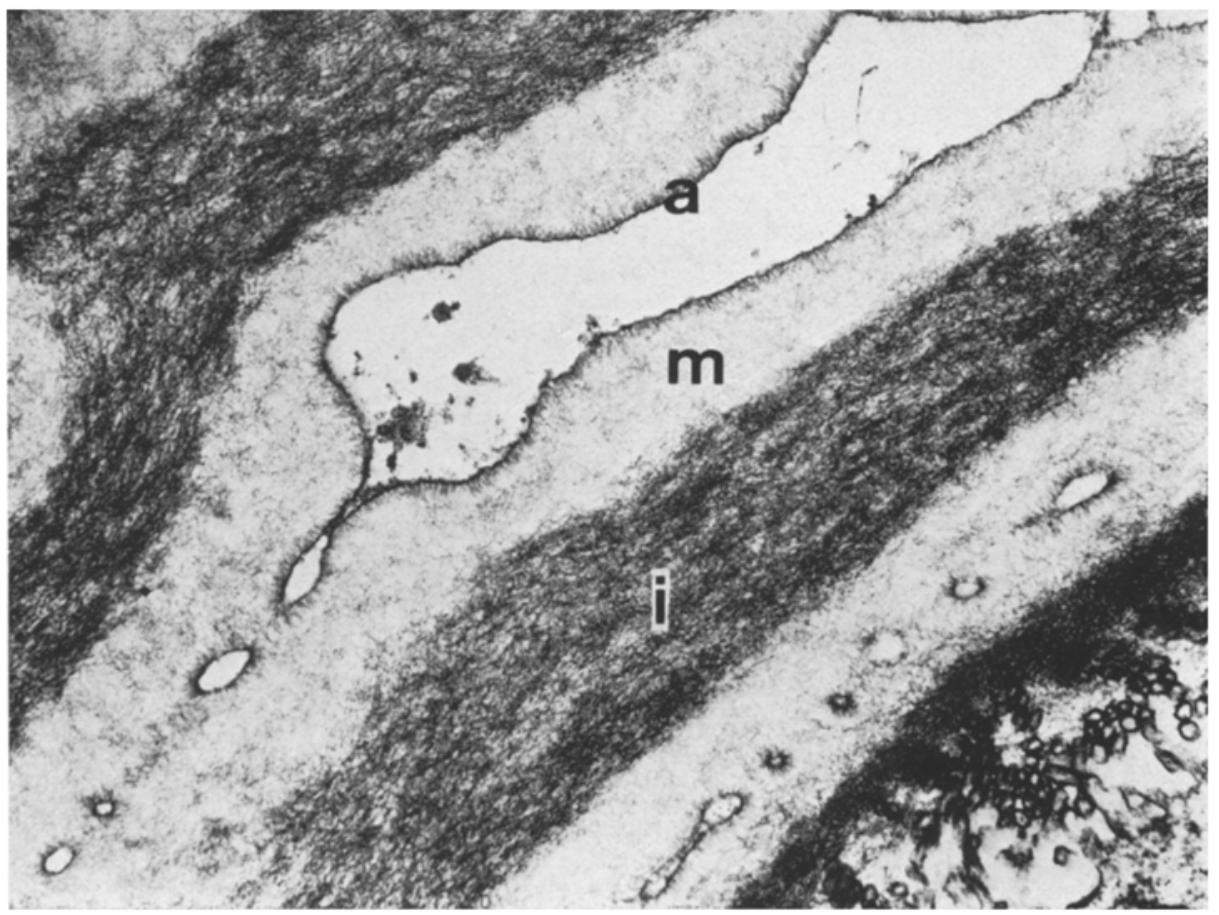

Abb. 21: Schichtenfolge der Oocytenanhänge nach Glutaraldehyd-Fixierung. a äußere, m mittlere, $\mathrm{i}$ innere Schiche $(13000: 1)$

den reifen Oocyten die Verbindungen zu den acht großen becherförmigen Anhängen herstellen. In ihrem Anfangsstadium schieben sich die Hüllenfortsätze nahezu parallel zur Oocytenoberfläche in die Intercellularfuge hinein. Nur in Ausnahmefällen finden sie so viel Platz, um sich aufgerichtet zwischen Nachbaroocyten und Follikelstränge zu drücken (Abb. 20).

Morphologisch lassen sich bei den Hülen der Eizellen von $L$. cinereus drei Schichten unterscheiden, wobei sich das ganze intercelluläre Material aus vernetzten feinen Mucopolysaccharid-Fibrillen zusammensetzt. Die Schichtung entspricht einer variablen Ordnung bzw. Dichte der fädigen Substanzen. Die nach Wohlfarth-BottermanN und Sjöstrand mit Osmiumtetroxid fixierten Hüllen lassen gleitende Übergänge zwischen den Schichten erkennen, während die Anwendung von Glutaraldehyd mit 


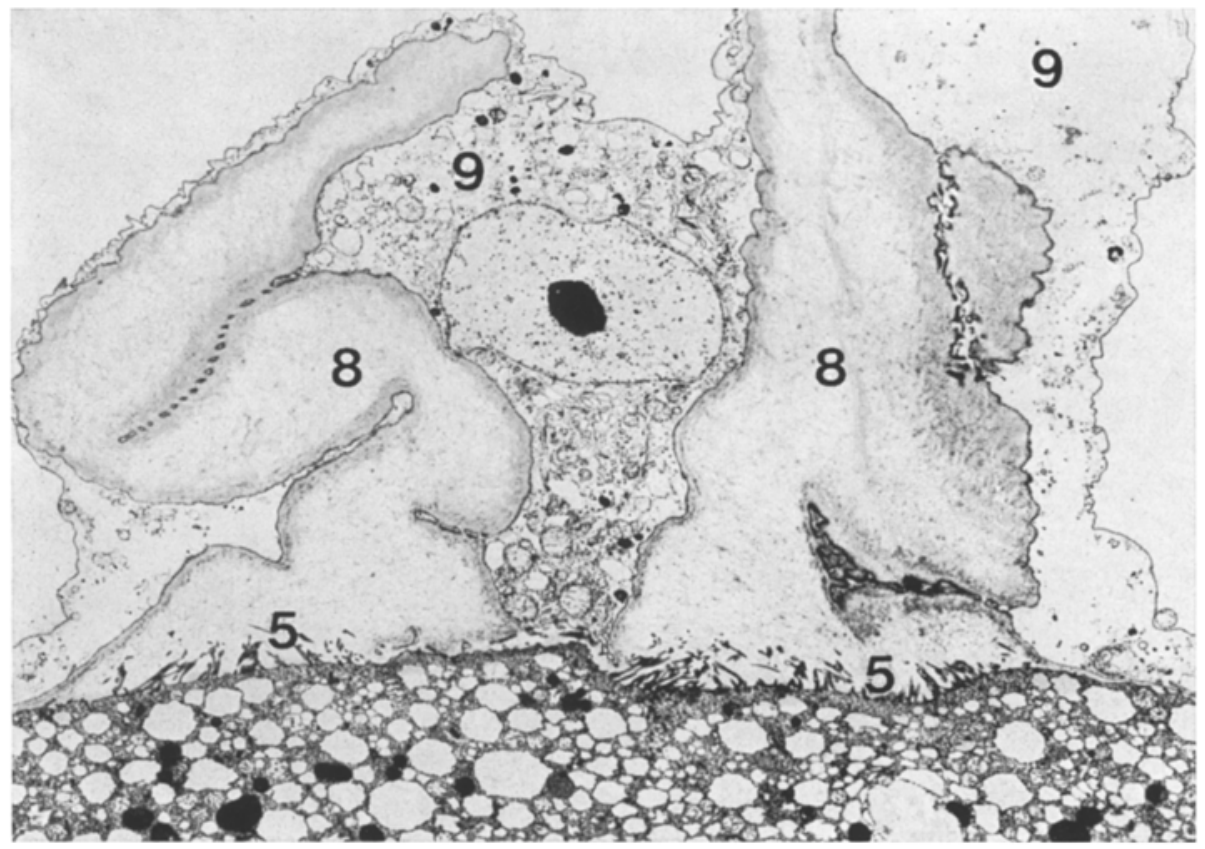

Abb. 22: Anschnitt eines becherförmigen Oocytenanhanges (8) im Stadium V. Die Mikrovilli (5) werden zurückgebildet; der Cortex löst sich von der Oocytenoberfläche; die Membranen der Follikelzellen (9) sind noch unversehrt (2940:1)

anschließender Schnittkontrastierung stärker die innere von den äußeren differenziert (Abb. 21).

Die innere Hüllschicht wird ausschließlich von der Oocyte selbst durch die Mikrovilli abgeschieden und stellt somit eine primäre Eizellhülle dar.

Sie ist sehr voluminös und umgibt die Eizelle nicht als zusammenhängende Hülle, sondern findet sich im Bereich der cytoplasmatischen Aufwölbungen und Incisionen speziell nur an den Orten, wo Mikrovilli ausgebildet sind, und erstreckt sich dort von der Oocytenmembran bis in die Spitzen der Anhänge. Bei geringer elektronenmikroskopischer Vergrößerung stellt sich dieser Cortexteil als aufgelockert und schwammig dar. Die Feinstruktur der aus vornehmlich sauren Mucopolysacchariden aufgebauten inneren Schicht zeigt das Bild perlschnurartig aufgereihter Untereinheiten, die durch die Fixierung unterschiedlich vernetzt sind.

Der inneren Schicht ist eine Mittelschicht aufgelagert, die nach $\mathrm{OsO}_{4}$-Fixierung homogener und dichter in ihrer Konsistenz ist. Dieser Hüllenteil wird im frühen Stadium der Genese bereits in den Intercellularspalt zwischen Oolemm und innerer Follikelzellmembran sezerniert (saure und neutrale Mucosubstanzen liegen dort in Mischung vor) und begleitet auch später als unterschiedlich dicke Schicht die nun sich ausdehnende Follikelzellmembran. Im Bereich der Fortsätze setzt sich die Mittelschich! hauptsächlich aus neutralen Mucopolysacchariden zusammen. Der Übergang von den sauren zu den neutralen Kohlenhydraten erfolgt jedoch nicht abrupt. 


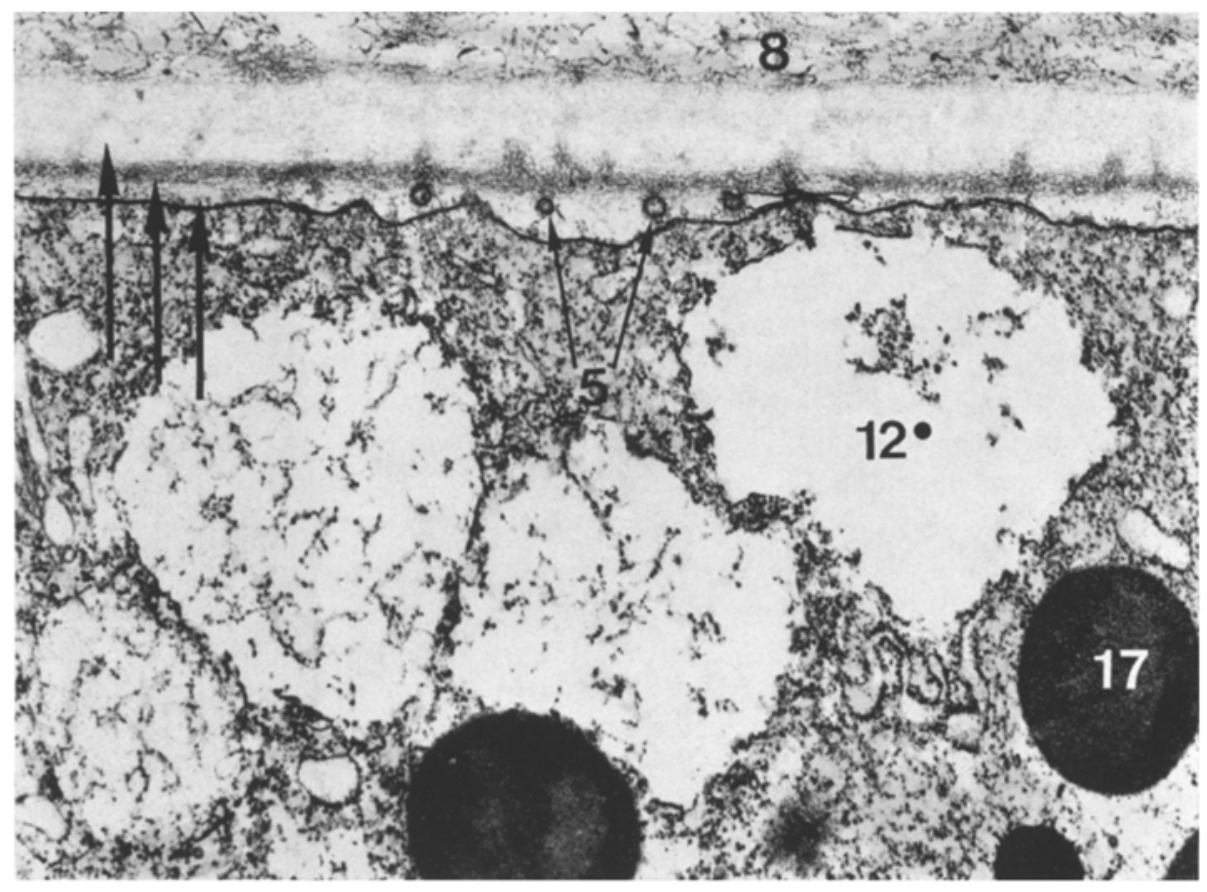

Abb. 23: Rindenvakuolen (12•) unmittelbar unter der Oocytenmembran der reifen Eizelle. Bildung der 3schichtigen Vitellinmembran (Pfeile). 5 Mikrovilli; 8 innere Schicht des Oocytenanhanges; 17 abgerundeter Lipidtropfen $(21410: 1)$

Die äußere Hüllschicht ist im Vergleich zu den beiden inneren extrem dünn (20 bis $30 \mathrm{~nm})$. Sie tritt im Längsschnitt als liniierter Saum aus kurzen Fibrillen auf, deren Enden zur Follikelzellmembran hin verschmelzen. Im Tangentialschnitt erscheinen dic osmiophilen Tonofilamente zu Röhren arrangiert, die in Reihen angeordnet sind und sich zum Inneren des Hüllenanhanges öffnen. Die Außenschicht schließt sich unmittelbar der inneren Follikelzellmembran an.

Der im Stadium IV begonnene Schalenaufbau wird im Stadium V fortgesetzt. Die Anhänge nehmen weniger an Länge als an Volumen zu, indem in die innere lockere Schicht große Mengen von sauren Mucopolysacchariden eingelagert werden. Die Hüllen orientieren sich während der ovarialen Phase entweder parallel zur Oocytenmembran, oder sie schieben sich in Schleifen gelegt senkrecht zur Oocytenoberfläche in das Ovarlumen. Nur die intakte äußere Follikelzellmembran hindert sie daran, sich zu entspannen, um die artspezifischen, kompliziert gebauten Oocytenanhänge zu entfalten (Abb. 22).

Die Schichtenfolge wird beibehalten. Ablagereife Eizellen reduzieren allmählich den Mikrovillisaum. Durch das Zurückweichen der Zellausläufer und durch einen Prozeß des Abstoßens der gesamten Oocytenhülle entsteht langsam eine Zone kontrastarmer, amorpher Intercellularsubstanz, in der die Spuren der eingeschmolzenen Mikrovilli als dichter strukturierte Stempelchen zurückbleiben (Abb. 23). Länge und Zahl der 
Mikrovilli nehmen nun rasch ab. Zwischen ihnen kondensiert sich eine Masse fein fibrillären Materials, das in seiner Beschaffenheit osmiophiler und dichter gepackt ist als die Substanzen der drei vorher abgesonderten Hüllschichten.

Diese letzte Schicht bleibt nicht homogen, sondern zoniert sich in eine äußere und innere kontrastarme Lage und eine dichte $Z$ wischenlamelle. Ihre Fibrillen laufen mehr oder weniger parallel und sind zu einer Textur zusammengefügt. Das innere Kondensat nimmt die nur noch spärlich vorhandenen Mikrovillireste auf. Die Genese und histochemischen Befunde sprechen dafür, daß hier eine weitere typische primäre Oocytenhülle vorliegt, die ausschließlich von den Mikrovilli abgeschieden wird und ebenfalls zum Teil aus sauren Polysacchariden zusammengesetzt ist.

Im weiteren Verlauf der Oogenese hebt sich auch diese Kugelschale immer weiter von der Oocytenoberfläche ab. In den $Z$ wischenraum fließen gallertige Substanzen von unbekannter chemischer Zusammensetzung ein. Zu diesem Zeitpunkt ist die Eizelle, was ihre Ausstattung an Reservestoffen und Schutzhüllen anbelangt, auf eine Ausschleusung durch die Ovidukte vorbereitet.

Rindenvakuolen treten bei $L$. cinereus erst sehr spät im Oocytenstadium V in Erscheinung. Ihr Vorkommen beschränkt sich auf einen schmalen Saum des corticalen Cytoplasma, wo sie in 1 bis 2 Reihen dicht unter der Oocytenmembran liegen. Sie lassen sich strukturell mit den Vakuolen des praevitellogenetischen Stadiums III vergleichen, bilden jedoch keine zusammenhängenden Komplexe. Intravakuoläre Kondensationsfiguren fehlen. Der Inhalt ist weniger fibrillär als granulär und besteht vorwiegend aus sauren Mucopolysacchariden.

Die umfangreichen Stapelkomplexe der annulate lamellae verringern während des Stadiums V Länge und Zahl der Porenmembranen, bis schließlich nur noch Reste von ihnen hauptsächlich im Rindencytoplasma angetroffen werden. Die Poren lösen sich von den Enden der Stapel her auf.

Die konzentrischen ER-Systeme degenerieren ebenfalls. Der Membranabstand vergrößert sich, oder benachbarte Membranen verschmelzen zu Myelin-ähnlichen Figuren. Die kurzen Röhren und gebogenen Kanäle des glatten ER sind auf das gesamte Ooplasma verstreut. In einigen reifen Oocyten liegen die Membranen eng an Dottersphären geschmiegt.

Charakteristisch für die reife Oocyte sind große Mengen elektronenmikroskopisch leerer Bläschen, die überall zwischen den Dotterpartikeln vom Kern bis zur Oocytenmembran angetroffen werden. Diese endoplasmatischen Vesikeln haben sich wahrscheinlich früher von der Kernhülle abgelöst oder direkt aus dem Retikulum entwickelt (Vesikulation der annulate lamellae).

Zwei Drittel der Kernhülle des vollreifen Oocytenstadiums bleiben annähernd gleichmäßig kugelflächig, während der zusammenhängende Bereich von einem Drittel stark gefaltet wird. In den tiefen Ausbuchtungen, die zur Vergrößerung der Kernoberfläche führen, liegen oft die Paranucleoli. Flachschnitte durch die Kernhülle zeigen typische Kernporen mit zylindrischen Annuli. Stets ist im Zentrum ein Zentralkorn zu sehen. Die Porenkomplexe sind in Form von Parallelreihen mit einem Abstand von 10-20 nm angeordnet. Der Abstand zwischen den Poren einer Reihe ist variabel. Das Caryoplasma ist homogen granulär, mit einzelnen fibrillär angereicherten Zonen und enthält viele Nucleolargrana von 0,2 bis $3,0 \mu \mathrm{m}$. 

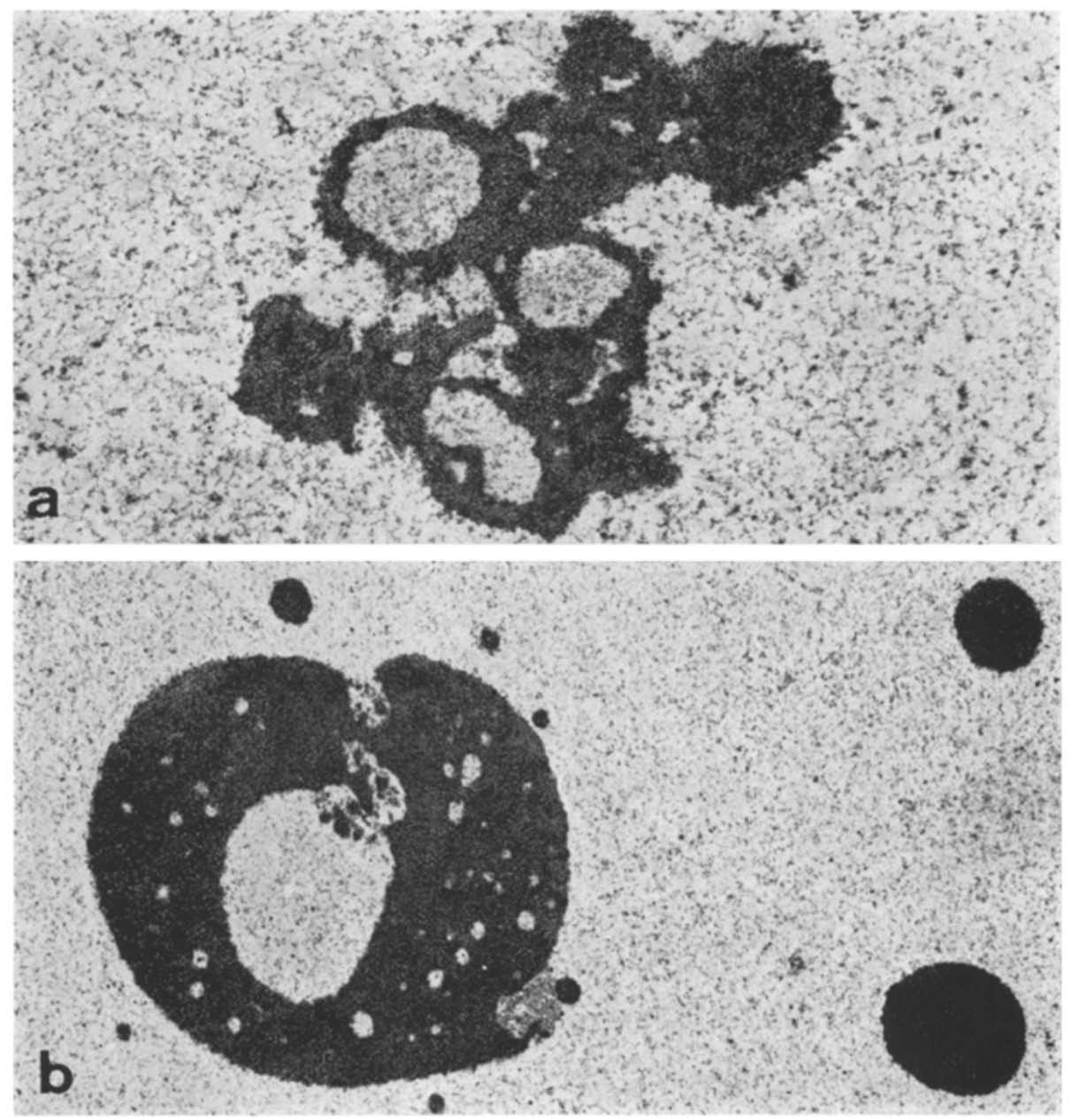

Abb. 24: Nucleolus-Aktivität im späten Stadium V. a Zerfall eines Nebennucleolus (11050:1). $b$ Zerfall eines Hauptnucleolus $(4760: 1)$

Die Hauptnucleolen zeigen weiterhin zentrale und multilokale Auflösungserscheinungen, schleusen aber trotz fortgeschrittener Entwicklung der Oocyte weitere Paranucleoli aus. Dieser Prozeß erreicht seinen Höhepunkt zum Ende der Dotterbildung. In ablagereifen Oocyten zerfällt der Nucleolus derart, daß die pars amorpha und caryoplasmatischen Alveolen einen schwammigen Komplex bilden. Chromatin lagert sich zusammen, Chromosomen-äbnliche Aggregate formieren sich. Diese chromosomalen Strukturen sind anders als die Sekundär-Nucleolen aus dicht gelagerten kontrastreichen Substanzen aufgebaut, die in eine weniger dichte, gleichmäßig granulierte Matrix eingebettet sind (Abb. 24). Die Oocyte wird auf das Ende der meiotischen Prophase vorbereitet. 
Die bei der Beschreibung der Entwicklungsstadien III und IV aufgezeigten Möglichkeiten der Speicherung von Reservesubstanzen in den Oocyten von $L$. cinereus führen schließlich zur Ausbildung von zwei Dotterkörpern: Lipiddotter und Lipoproteindotter. Trotz der Polysaccharid-Kontrastierung mit Ruthenium-Rot, sind außer einer unbedeutenden Zahl von Glycogenrosetten, Kohlenhydrate in konzentrierter Form nicht eindeutig nachzuweisen. Daß saure Mucopolysaccharide in den Corticalvakuolen, den Bereichen der ER-Stapel und diffus verteilt im gesamten Cytoplasma gespeichert werden, bestätigen die lichtmikroskopischen Nachweis-Färbungen. Auf Polysaccharid-Dotter kann daraus jedoch nicht geschlossen werden.

Im folgenden sollen die beiden Dottertypen im endgültigen strukturellen und inhaltlichen Aufbau vorgestellt werden:

\section{Lipid-Dotter}

In den frühen Oocytenstadien I bis III und zur Zeit der Dotterbildung im Stadium IV liegen die Fettschollen unregelmäßig gelappt im Cytoplasma. Im Stadium V runden sie sich je nach Reifegrad etwas ab. Oft treten sie mit Proteindotter-Sphären in Verbindung.

Die Lipidansammlungen stellen sich nach Osmium-Fixierungen als weitgehend homogen ausgefuillte, mitteldichte Alveolen dar. Mit Glutaraldehyd fixierte Fette sind neben den Rindenschichten des Lipoprotein-Dotters die elektronendichtesten Zellbestandteile. Diese Fixierung läßt substantielle Untereinheiten in Form von kleinen kontrastreicheren Partikeln erkennen. Weniger dichte Areale deuten darauf hin, daß Stoffgruppen während der Entwässerung ausgewaschen worden sind. Nachdem sich die Lipidkomplexe abgerundet haben, scheint ein Wandel in der Konsistenz einzutreten. Von nun an können sie durch die Fixantien nicht mehr vollständig gefällt werden; das Einbettungsmedium dringt nicht durch, und der Inhalt wird beim Ultradünnschnitt oft "gechattert". Auf Grund der histochemischen Nachweisreaktionen liegen keine neutralen Triglyceride, sondern Phospholipide oder andere saure Fettsubstanzen vor.

\section{Lipoprotein-Dotter}

Obwohl schon im Stadium IV Lipoproteindotter vorliegt, erfolgt der eigentliche Reifeprozeß dieses Dotters erst im Stadium V. Parallel zur fortschreitenden Einlage-rung der Eiweiße nimmt die stets membranumgebene Dotterpartikel weitere Reservestoffe auf. Dies können sowohl Polysaccharide als auch verschiedene Lipide sein. Die Fette, die zur Kombination des Lipoprotein-Komplexes führen, gehören in die Gruppe der Neutralfette.

Während das proteinhaltige Internum der Dottersphären nach wie vor in der Regel homogen bis wolkig erscheint, ist die lipidhaltige Oberflächenschicht von granulärer Zusammensetzung. Die Auflagerung der Außenschicht beginnt an einer Stelle, an der später eine im Längsschnitt U-förmige, im Tangentialschnitt runde "Offfnung" liegen wird. Die Fettsubstanzen scheinen dabei an der Innenseite der Hüllmembran entlang transportiert zu werden, so daß die Dotterkugeln anfangs einen dichten halb- 


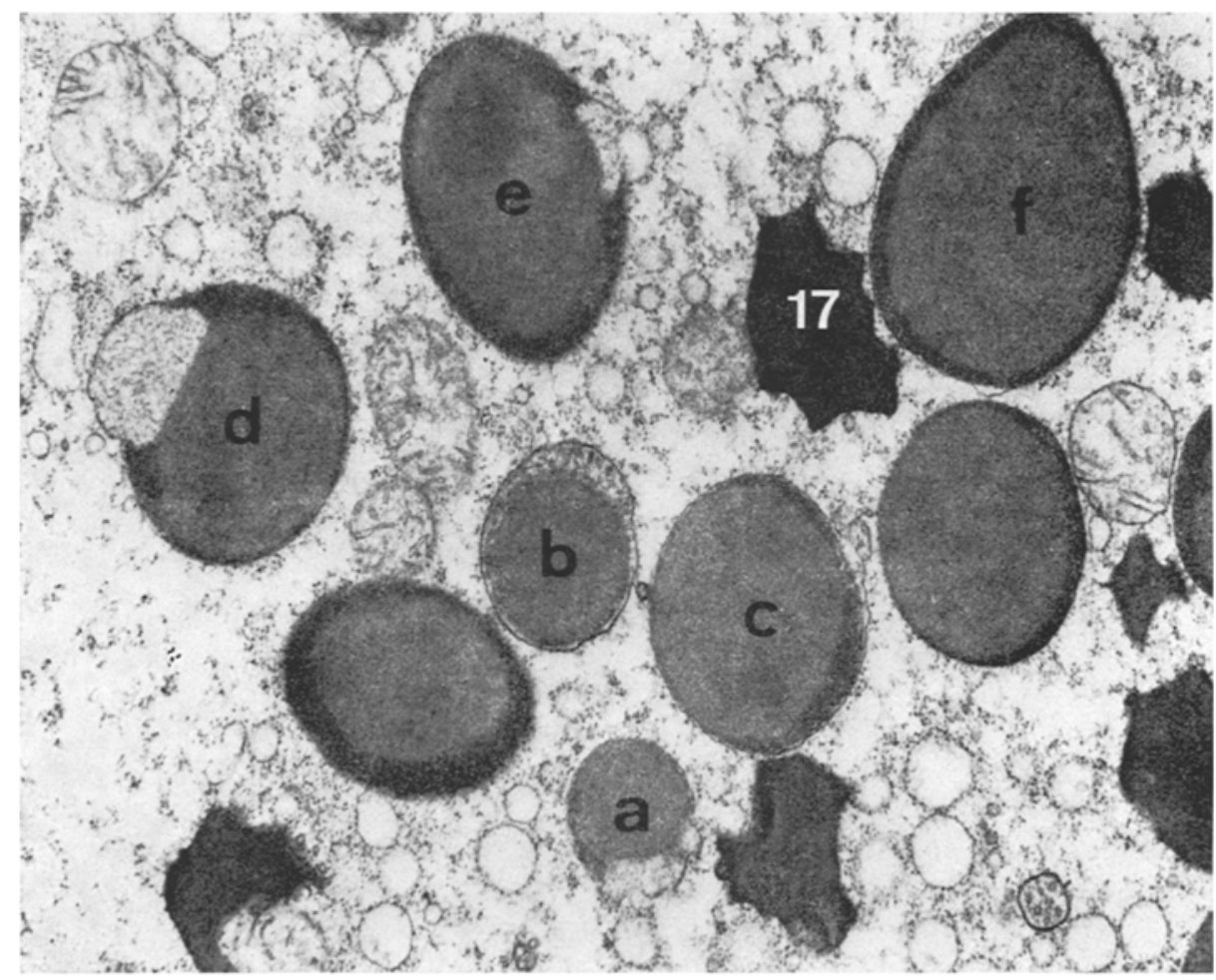

Abb. 25: Mögliche Reihenfolge der Entwicklungsstadien eines Lipoprotein-Dotterkörpers (a-f). 17 Lipiddotter $(16220: 1)$

mondförmigen Belag aufweisen. Diese Asymmetrie bleibt solange bestehen, bis der Dotter einen hohen Reifegrad erreicht hat und die Offnung verschwindet. Die Offnung ist keinesfalls ein Loch in der Membran, sondern lediglich eine Aussparung in der Rindenschicht. Die Hüllmembran wölbt sich an diesem Ort oft blasenförmig in das Cytoplasma und schließt eine Portion amorphen Materials ein (Abb. 25).

Wie der Triglycerid-Nachweis erkennen läßt, gelangt dieses Neutralfett jedoch nicht direkt durch die Offnung in die Partikel. Dieser Bereich ist Triglycerid-negativ. Auch lassen sich Triglycerid-Einlagerungen erst relativ spät in der Genese des Lipoprotein-Dotters nachweisen.

Eine weitere Stoffaufnahme durch die Membran ist über die Anlagerung der zahlreichen cytoplasmatischen Vesikeln gegeben. Diese kleinen elektronenmikroskopisch leeren Zisternen können als Dottervesikeln angesehen werden, wenn sie sich zur Oberfläche des Lipoproteindotters geöffnet haben. Ihr Inhalt ist unbekannt (HumPHREYs, 1962).

Parakristalline Strukturen sind für verschiedene Tierklassen nachgewiesen worden. Doch handelt es sich in den meisten Fällen um Musterbildungen innerhalb der Proteinkörper des Dotterzentrums. In den Lipoproteinpartikeln der Oocyte von $L$. 


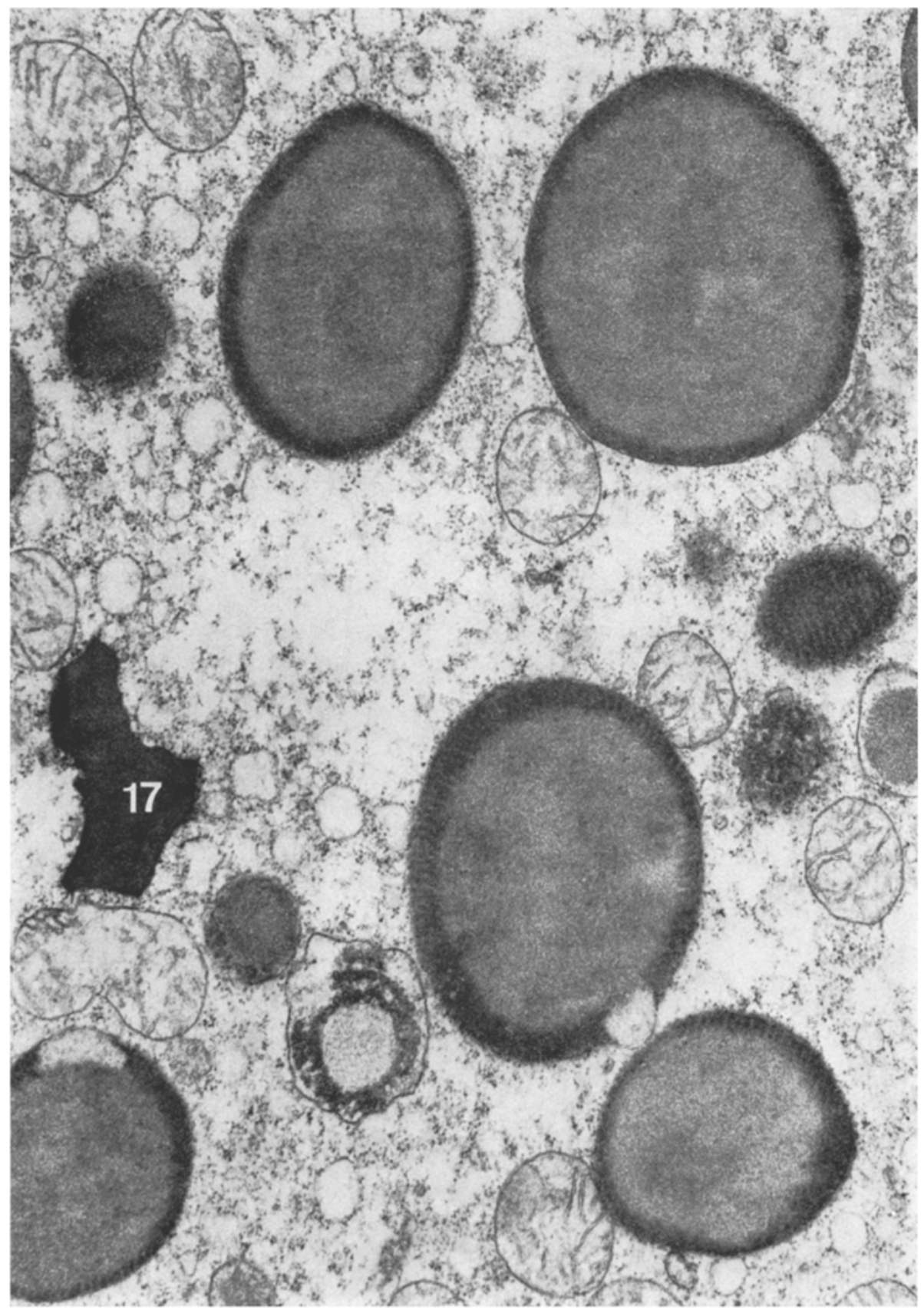

Abb. 26: Reifer Lipoprotein-Dotter mit parakristallin strukturierter Rindenschicht. 17 Lipidtropfen $(22100: 1)$ 
cinereus dagegen sind hoch geordnete kristalline Gefüge in der lipidhaltigen Rindenschicht angetroffen worden. Die Rindenschicht ist im Querschnitt radiärsymmetrisch gestreift und setzt sich aus abwechselnd hellen und dunklen Ringscheiben zusammen. Die Scheiben sind je ca. $30 \mathrm{~nm}$ dick, jedoch nicht streng ringförmig, sondern in sich gebogen, teilweise verzweigt oder annähernd parallel geschichtet. Sie ergeben ein unregelmäßiges Muster in tangential geführten Dünnschnitten (Abb. 26).

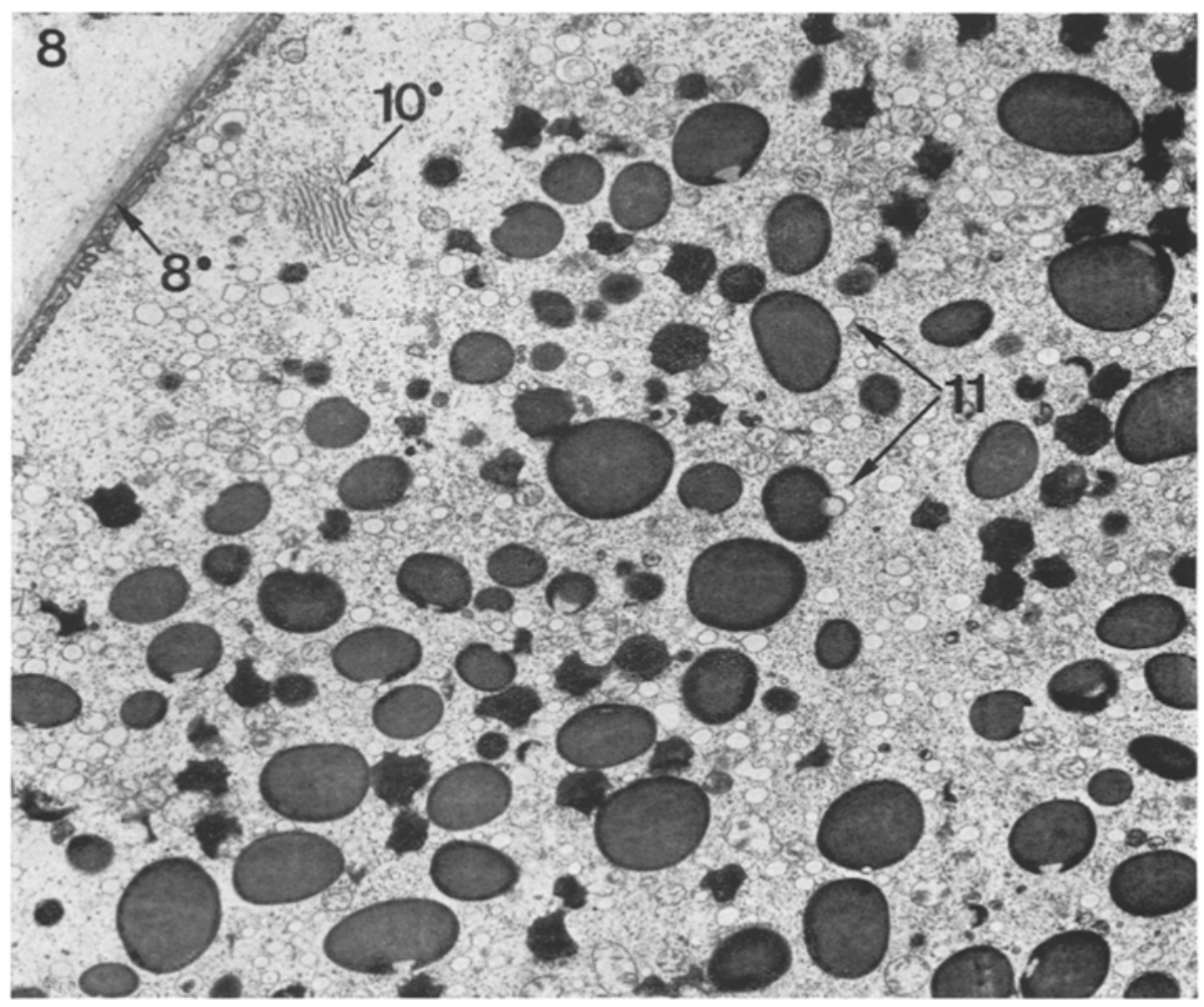

Abb. 27: Vertcilung von Lipid- und Lipoprotein-Dotter in der reifen Oocyte. \& Oocytenanhang; 8 Vitellinmembran; 10 annulate lamellae in Auflösung; 11 Dottervesikeln $(4940: 1)$

Die lipid- und proteinhaltigen Dotterelemente sind nach Analyse von Übersichtsvergrößerungen weitgehend gleichmäßig über den Querschnitt der vollreifen Oocyte verteilt. Nur der kernnahe Bereich und das unmittelbar unter der Oocytenoberfläche anstehende Corticalplasma zeigen geringere Dotterkonzentrationen. Die Differenzierung in einen animalen und vegetativen Oocytenpol ist demnach mit Hilfe der Dotterverteilung nicht möglich. Der totale Abschluß der Vitellogenese ist in keiner der betrachteten Oocyten des Entwicklungsstadiums $V$ beobachtet worden, d. h., die Einlagerung von Reservesubstanzen in die Komplex-Cytosomen hält während der folgenden oogenetischen Reifungsperiode an. Dotterbildungszentren sind nicht zu erkennen (Abb. 27). 


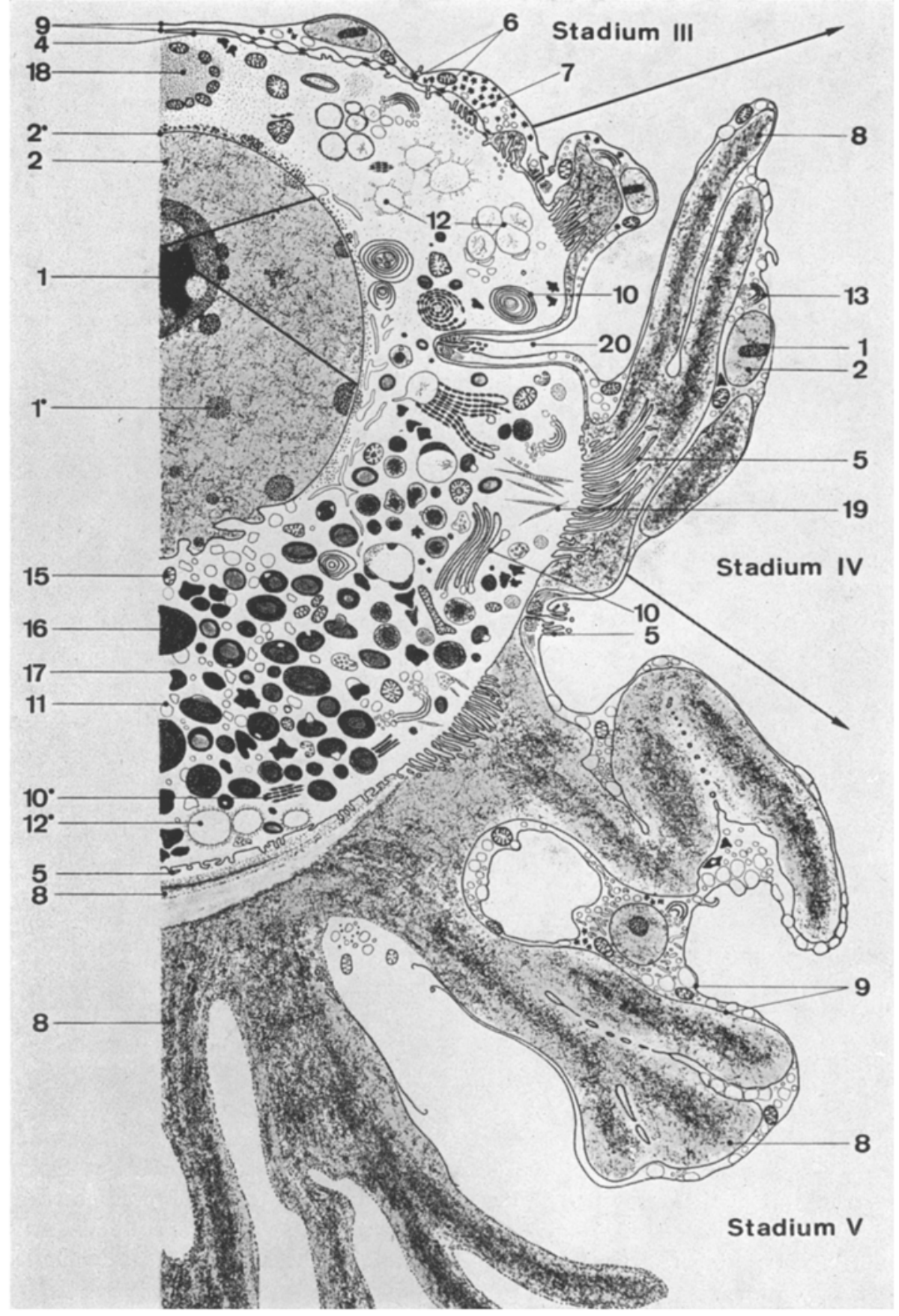

Abb. 28: Schematische Darstellung der Oogenese während der Entwicklungsstadien III-V (durch Pfeile markiert, die cytoplasmatischen Organellen sind vergrößert eingezeichnet). 1 Hauptnucleolus; $1 \bullet$ Nebennucleolus (Nucleolargranum); 2 Kern; $2 \bullet$ Kernhülle; 4 Oocytenmembran; 5 Mikrovilli; 6 Zellkontakt; 7 Intercellularspalt; 8 Oocytenhülle; 9 Follikelzellmembranen; $10 \mathrm{ER} ; 10 \bullet$ annulate lamellae; 11 Vesikel; 12 Cytoplasmavakuole; $12 \bullet$ Rindenvakuole; 13 Golgi-Komplex; 15 Mitochondrium; 16 Lipoproteindotter; 17 Lipiddotter; 18 Dotterkern (Balbiani-Körper); 19 rootlet; 20 oocytäre Incision 


\section{DISKUSSION}

Die $\mathrm{Nucl}$ e ol us - Vakuolen stellen den histochemischen Befunden nach caryoplasmatische Lakunen dar, die das Ergebnis zentraler oder multilokaler Auflösung der Pars amorpha sind (Krelbowna \& Koscielski, 1974). Die Zonierung mancher Nucleolen desselben Stadiums ist in den meisten der beschriebenen Mollusken-Oocyten anzutreffen: Lymnaea stagnalis (KIELBOWNA \& KoscIELSKI, 1974), Ilyanassa obsoleta (TAylor \& Anderson, 1969), Anodonta (BeAms \& SeKhon, 1966), Viviparus contectus (BoTTKE, 1973). Der elektronenoptische Befund bestätigt in diesem Punkt das lichtmikroskopische Bild des Nucleolus der Polyplacophora-Oocyte (Gabe \& Prenant, 1949; Richter \& Götting, 1974).

Hinsichtlich des Auftretens einer wachsenden Zahl nucleolärer Grana im Kernraum vom Stadium II ab kann davon ausgegangen werden, daß es sich hierbei um Sekundärnucleoli handelt, die vom Eunucleolus intern oder extern abgenabelt werden und zur Kernhülle wandern. Dies wird bestätigt durch den weitgehend gleichen Stoffbestand und den ultrastrukturellen Aufbau. Anderson (1969) faßt diese Grana als echte Nucleoli auf. Demnach müßten mehrere (bis über 100) chromosomale Nucleolusorganisatoren vorliegen. Als echte Nucleoli wären sie in die RNS-Synthese einbezogen, was DAS \& ALFERT (1973) auf autoradiographischem und histochemischem Wege für Urechis-Oocyten jedoch nicht nachweisen konnten. Beide Autoren, sowie ERB \& MAURer (1962) sehen ebenfalls im Hauptnucleolus den Erzeuger von ribosomalen RNS-Vorläufern, die als Grana in Richtung Cytoplasma transportiert werden.

Die Ribosomen-ähnlichen Partikeln haben in verschiedenen Nucleoli desselben Stadiums unterschiedliche Größe. Eine klare Klassifizierung in 150-200 Ả und 200 bis $300 A \vec{A}$ große Einheiten (NørRevang, 1968) kann für $L$. cinereus nicht vorgenommen werden. Nach Harris (1967) könnten diese Partikeln Proribosomen und proteingebundene Ribosomen darstellen.

Nucleolus-Extrusion in Eizellen ist mehrfach beschrieben worden (BRETSCHNEIder \& Raven, 1951; Bedford, 1966; Reverberi, 1967; Taylor \& Anderson, 1969). Die vorliegenden Untersuchungen bei den Polyplacophora lassen den Schluß zu, daß weder ein Zusammenbruch der Kernhülle, noch eine massive Ausschleusung nucleolären Materials stattfindet. Es kann davon ausgegangen werden, daß einzelne Partikeln die zahlreichen Kernporen passieren und sich im kernnahen Oocytoplasma der Stadien II bis IV zu unterschiedlich großen, elektronendichten Wolken organisieren, die oft zusammen mit Mitochondrien zur Zellperipherie wandern. Diese Aggregate sind vermutlich notwendige Vorstufen für die Vitellogenese.

Auffallend an den Mitochondrien der Stadien I und II sind geringe Länge und Anzahl der Cristae mitochondriales. Mit STEgner (1967) kann dies als Zeichen der oocytären Unreife gedeutet werden. Zur Zeit des Wachstums und der Proteinsynthese vergrößern sich die Organellen erheblich und durchlaufen umfassende Gestaltsänderungen. Derartige Umstrukturierungen von Mitochondrien während der Dotterbildung sind in vielen Mollusken-Oocyten anzutreffen: Planorbarius corneus (FAvard \& Carasso, 1958), llyanassa obsoleta (TAylor \& Anderson, 1969). Sie müssen aber nicht unbedingt zu Transformationsstufen und damit zur Bildung von Dotter führen (BOT'TKE, 1973). 
Obwohl Vesikeln enthaltende Körper in beinahe allen Eizellen vorkommen, differiert der Bildungsmodus der multivesikulären Körper erheblich. Die meisten Autoren nehmen an, daß sie de novo entstehen und Material sammeln, das von außen durch Mikropinocytose aufgenommen oder vom Golgi-Apparat bereitgestellt wird. Zumindest für das Stadium IV der Oogenese von L. cinereus lassen sich pinocytotische Vesikeln nachweisen. Andere multivesikuläre Einschlüsse stammen wahrscheinlich von Mitochondrien ab, wenn sie während der Vitellogenese auftreten. Eine funktionelle Beziehung zum Proteindotter kann bestätigt werden (PAsteels \& de Harven, 1962; Beams \& Sekhon, 1966; Terakado, 1974). Es gibt sowohl vollständig geschlossene als auch offene multivesikuläre Sphären mit eingerollten Membranrändern, die sicherlich keine Artefakte darstellen (PASTEels \& DE HARven, 19б2; KESSEL, 1966; NørRevang, 1968).

Eine zentrale Stellung innerhalb der Oogenese muß dem Golgi-A p pa r a eingeräumt werden. In den Eizellen der Käferschnecken entspricht den erhöhten Stoffeinlagerungen eine Vermehrung der Dictyosomen während der vitellogenetischen Phase (ANderson, 1969; Selwood, 1970). In Gastropoden scheinen die DaltonKomplexe ebenfalls verantwortlich für die Dotterformation zu sein (Bolognari, 1960; Recourt, 1961; Worley \& Moriber, 1961; Bottke, 1973; Terakado, 1974). Die unterschiedlich großen Vesikeln enthalten verschiedene Substanzen, deren Zusammensetzung im einzelnen unbekannt geblieben ist. Stets sind es Mikrovesikeln, die teilweise über weite Distanzen transportiert werden und vermutlich dem extraoocytären Hüllenaufbau, der Eiweißeinlagerung in die Cytosomen und der Formation multivesikulärer Körper dienen. Die Makrovesikeln dagegen bauen sich am Ort zu voluminösen Vakuolen auf, die als Basis der Lipid-Kondensation anzusehen sind.

Sowohl die Dictyosomen als auch die rootlets des Stadiums IV bilden eine enge Gemeinschaft mit den langen Mikrotubuli im Rindencytoplasma. Eine mögliche Transportfunktion während der Konstruktion der Hüllfortsätze ist nicht auszuschließen. Dazu kommt die Weiterleitung von Stoffen in Verlaufsrichtung der Oocytenmembran. Doch scheinen die Mikrotubuli in den hier untersuchten Oocyten nie so bedeutungsvoll zu sein, wie in den Eizellen von Anodonta in der Phase der Stielbildung (BEAMS \& SEKHON, 1966) und beim Bau der Corticalgranula von Mytilus. In der Eizelle von L. cinereus kommt das Moment der Verformung des trägen Cytoplasmakörpers hinzu. Die Mikrotubuli könnten als stabilisierendes, mechanisches Element der Einsenkung entgegenwirken.

Wesentliche Unterscheidungsmerkmale gegenüber anderen Oocyten weist das Oocytoplasma der Polyplacophora auf. Neben dem Balbiani-Körper stellen die cytoplasmatischen $\mathrm{V} \mathrm{ak} \mathrm{u} \mathrm{ol} \mathrm{e} \mathrm{n}$ ein wichtiges cytomorphologisches Strukturelement dieser Eizellen dar. Vakuolen solchen Ausmaßes wurden von Gabe \& Prenant (1949) im Entwicklungsstadium 3 von drei Chitonenarten beobachtet und ihre Bedeutung für die Dotterbildung erkannt. Cowden (1961) erwähnt keinerlei cytoplasmatische Zerfallserscheinungen bei Chiton tuberculatum. In den Eizellen von Sypharochiton sind sie gut ausgeprägt und mit der Bildung von Proteindotter in Verbindung gebracht worden (SEL wOOD, 1968). Sie wurden ebenfalls für Dentalium von Arvy (1950) nachgewiesen. ANDERson (1969) nennt selbst Vakuolen gleicher Ausprägung wie bei den anderen Chitonen in der praevitellogenetischen Phase "cortical granules", obwohl 
diese Eizellen nicht ausgewachsen sind, was das Fehlen jeglicher Dotterelemente anzeigt. Der Verlauf der Dotterbildung und die Genese der Rindenvakuolen bei L. cinereus zeigen jedoch, daß beide Vakuolengruppen nicht identisch sein können.

Bei $L$. cinereus liegen wahrscheinlich 3 Vakuolentypen vor. Während die vermutlich rein dictyosomalen Vakuolen stets von einer vollkommen geschlossenen Membran ausgekleidet werden, weisen die aus endoplasmatischen Vesikeln hervorgegangenen oder frei im Cytoplasma entstandenen Vakuolen durchbrochene Membranen, meist jedoch nur Membranbruchstücke auf. Da die Vakuolentypen oft gleichzeitig nebeneinander im Präparat vorliegen, ist die Möglichkeit einer spezifischen Fixierungslabilität nicht auszuschließen. Die einzelnen Vakuolen unterscheiden sich im Inhalt strukturell und wohl auch histochemisch, möglicherweise durch Stoffe unterschiedlicher osmotischer Werte. Während der Fixierung könnten die hoch osmotischen Vakuolen platzen und das periphere Cytoplasma strahlenförmig auseinanderdrücken. Die Membranbruchstücke könnten jedoch auch Reste der endoplasmatischen Vesikeln sein, die um die wachsende Vakuole gruppiert sind und deren Aufbau dienen. Eine weitere Interpretation besteht in der Annahme, daß makromolukulare Stoffe in diesen ribosomenfreien Räumen gesammelt werden. Viele Anzeichen sprechen dafür, daß eine Anzahl von Vakuolen saure Fette enthalten. Diese Lipide kondensieren sicherlich als Tropfen im Cytoplasma. Wahrscheinlich werden nach Abschluß der Fettdotterbildung die sich leerenden Vakuolen wieder durch Cytoplasma aufgefüllt.

D o t t e rke r n e oder Balbiani-Körper stellen eine äußerst mannigfaltige Gruppe cytoplasmatischer Differenzierungen dar, wenn sie über die gesamte Wachstumsphase oder bis in die ersten Teilungsstadien verfolgt werden. Innerhalb der verschiedenen Oogenesestadien lassen sich dagegen einige konsequent durchgehende morphologische, morphogenetische und cytochemische Übercinstimmungen finden (GöTTING, 1968; SCHMEKEL \& Fioroni, 1974).

Bei L. cinereus sind die Dotterkerne im Stadium II stark RNS- und Protein-haltig, zeigen basichromatische Reaktionen und enthalten keine Polysaccharide. Ein solch einfacher Dotterkern-Typ ist von der Schnecke Physa acuta (Terakado, 1974) und von Merlangius-Eizellen bekannt (Göttring, 1968). Morphogenetisch weist er jedoch auch Übereinstimmungen mit Xenopus (Balinsky \& Devis, 1963) auf. Das RNShaltige Material entstammt dem juxtanucleären Saum extrusierter Nucleolarpartikeln, was für die Mitochondrien keineswegs immer der Fall sein muß. Nachdem sich die Ribosomenwolken aufgelöst und die Mitochondrien verteilt haben, formieren sich die großen Vakuolen. Erst jetzt setzt die Vitellogenese cin.

Im Anschluß daran entwickelt sich ein zweiter Typ von Dotterkern, der nur die Ribosomen mit dem ersten Typ gemeinsam hat. Konzentrisch gestapelte, ergastoplasmatische Membranlagen umhïllen eine kleine Portion Ooplasma wie es für Mytilus edulis (Reverberr, 1966), Bembicium nanum (Bedford, 1966) und Mopalia muscosa (Anderson, 1969) beschrieben ist. Oocyten anderer Mollusken sind in der Entwicklung fortgeschritten und lagern im Zentrum Lipidtropfen ab: Ilyanassa obsoleta (TAYLor \& Anderson, 1969) und Bankia australis (Popham, 1975). Nur Mopalia muscosa formt nach ANDERSON sogar typische Proteindotter-Sphären. Bei $L$. cinereus verschwinden diese ergastoplasmatischen Dotterkerne im ausgereiften Oocytenstadium, indem alle Membranen zu Myelinfiguren zerfallen. Strukturell kann kein direkter Zusammenhang 
zur Dotterbildung gefunden werden, Lediglich die Verbindungen zu den Vakuolen deuten auf eine vitellogenetische Rolle hin.

Als drittes, stark basophiles Element tritt der Membrankomplex der annulate lamellae auf. Die stetigen Verbindungen zum glatten ER und damit zu den verschiedenen Dotterpartikeln lassen sie einesteils zu Syntheseorten, andernteils zu Kompartimenten der Stoffumlagerung werden (Nørrevang, 1968; Kessel, 1965).

Annulate lamellae, von den Autoren als Dotterkerne bezeichnet, kommen in Spisula und Otala (RebHun, 1956a, b) und Xenopus (Balinsky \& Devis, 1963) vor. Nach ReBHun bestehen die Porenmembranen aus glattem ER, während bei L. cinerews die Membranen mit Ribosomen besetzt sind. ANDERson (1969) erwähnt sie bei Chaetopleura apiculata, bezeichnet sie aber nicht als "yolk nucleus".

In den Oocyten von $L$. cinereus entstehen die annulate lamellae in Form von sehr kurzen Röhren de novo oder aus engen Kanälen des agranulären ER. Das Porenmuster und die Ausmaße der Annuli im Flachschnitt korrespondieren dennoch auffallend mit der Perforation der Kernhülle. Während die Literatur fast ausschließlich sphärische Komplexe angibt, überwiegen hier die gestreckten und verzweigten Membransysteme.

Die starke endoplasmatische Vesikulation in reifen Oocyten ist typisch für viele Keimzellen. Während Humphreys (1962) keine Auskunft über die Entstehung der Zisternen in Mytilus-Eiern gibt, könnte für L. cinereus eine Herkunft aus den Dictyosomen, der Kernhülle und ganz besonders aus dem Abbau der ER-Membransysteme abgeleitet werden. Die etwas unregelmäßigen Bläschen führen wahrscheinlich den Dotterkugeln restliche Reservestoffe zu.

Das Bild des reifen Dot te rs von L. cinereus ergibt sich aus der Synthese aller Beobachtungen über die organellären Veränderungen während der Oogenese. Diese Chitonenart ist innerhalb der Mollusken ein hervorragendes Beispiel dafür, daß zur Einlagerung der Reservestoffe fast alle Möglichkeiten ausgeschöpft werden. Der Fluß exogenen Materials aus den Haemalsinus über die Follikelzellen ist ebenso sicher anzunehmen, wie der endogene Aufbau verschiedener Stoffgruppen durch die oocytären Organellen. Alle Aktivitäten zusammen führen zum Bau von zwei Dottertypen, Lipid-Dotter und Lipoprotein-Dotter.

(1) Obwohl Fette und fettähnliche Stoffe bereits in den praevitellogenetischen Oocyten der Stadien I und II im corticalen Cytoplasma liegen, ohne daß ein morphogenetischer Zusammenhang mit oocytären Strukturen zu erkennen ist, erfolgt die Kondensation von $\mathrm{L}$ i p id-Dotte r erst im späten Stadium III. Dies ist auf die Beendigung der Vakuolisation zurückzuführen, an die sich wahrscheinlich eine Transformation von Mitochondrien anschließt. Den Beweis der Vermittlung modifizierter Mitochondrien bei der Lipid-Ablagerung in den Eiern von Rana pipiens brachte Ward (1962). Humphreys (1962) beschreibt Mitochondrien in Kontakt mit Lipidtropfen bei Mytilus. Für einen von Organellen unabhängigen Aufbau der Fette im Cytoplasma spricht bei weitem die Überzahl der Publikationen. In den Oocyten von L. cinereus jedoch, ist ihre Bildung hauptsächlich an die cytoplasmatischen Vakuolen gebunden. Diese Befunde stimmen dahingehend überein, daß gleichsam wie die Vakuolisierung von der Peripherie der Oocyte zum Zentrum fortschreitet, die Lipid-Kondensation den gleichen Verlauf nimmt (GöTting, 1966). 
(2) Als primäre Vorstufen des Lipoprotein-Dotters sind in erster Linie die transformierenden Mitochondrien zu sehen (typischer Primordialdotter bei Fischen und Amphibien). Verdichtung von Dottermaterial innerhalb der Mitochondrien fanden erstmals Favard \& Carasso (1958) in den Oocyten von Planorbarius. Ahnliche Prozesse zeigen die Bilder von Elbers (1957) und Recourt (1961) für Lymnaea und Humphreys (1962) für Mytilus. Die elektronenmikroskopischen Abbildungen von TERAKADO (1974) dürften in gleicher Weise zu interpretieren sein, obwohl der Autor nur Golgi-Vesikeln als Initiatoren angibt. Es handelt sich hier nicht nur um einen Kondensationsprozeß wie beim Lipiddotter, sondern um einen Transport von Proteinen durch die Membran der Cytosomen mit anschließender passiver Umund Ablagerung (WARTENBERG, 1973). Ultrastrukturell ähnlich differenzierte unreife Dotterkörner mit myelinisierten Restmembranen sind in Oocyten weit verbreitet: Ilyanassa, Viviparus, Physa, Spisula, Mytilus, Anodonta und Bankia.

Gegen eine Transformation spricht die Entwicklung des zweiten Typs von primärem Dotter, der aus pinocytotischen Mikrovesikeln oder de novo im Cytoplasma entsteht. Diese Dotterkugeln erscheinen ähnlich den dense bodies und sind annähernd mit denen der Anodonta-Oocyten vergleichbar (BEams \& Sekhon, 1966). Besonders in den Eizellen von Gastropoden sind die Mikrovesikeln als Derivate des Golgi-Apparates angesehen worden. Da es jedoch schwierig ist, ihre Herkunft eindeutig festzustellen, können auch hier Pinosome als Dottervorstufen nicht ausgeschlossen werden. Beide Dottertypen durchlaufen gemeinsam einen Reifungsprozeß, indem ein hoch verdichteter Cortex dem homogenen Internum aufgelagert wird. Die Abschlußmembran bleibt entgegen anderen Beobachtungen bei $L$. cinereus öfters im Bereich der "Öffnung" geschlossen (WARTENBERG, 1973). Diese Offnungen sind nur noch andeutungsweise als kontrastarme Vakuolen bei Mopalia muscosa und Sypharochiton ausgebildet. Erst in dieser späten vitellogenetischen Phase differenziert sich der Proteinkörper zum reifen Lipoproteindotter, wie er für Oocyten typisch ist. Assoziierte Dottervesikeln sind ein unverkennbares Strukturelement reifcr Oocyten (HumpHreys, 1962).

Proteindotter mit kristallinem Aufbau konnte bisher in den Oocyten und Eiern von Mollusken, Insekten, Crustaceen, Fischen und Amphibien gefunden werden. Hauptsächlich bestand jedoch das Zentrum der Dottersphäre aus einem biokristallinen Gefüge. Speziell für Mollusken sind parakristalline Proteine wiederholt beschrieben worden: Haliotis (Bolognari, 1960), Crepidula (Worley \& Moriber, 1961), Ilyanassa (Taylor \& Anderson, 1969), Physa (Terakado, 1974), Lymnaea (Elbers, 1957; Bluemink, 1969), Planorbarius (Favard \& Carasso, 1958), für Anodonta (Beams \& SeKhon, 1966) und für Alloteuthis (BottKe, 1974).

L. cinereus bildet zusammen mit Spisula sachalinensis (TAKahashi \& YAMAмото, 1972) dahingehend eine Ausnahme, daß nicht das Internum strukturiert ist, sondern die Rindenschicht der Dotterpartikel. Lepidochitona zeigt jedoch keine tangentialen, blättrigen Kristallstapel, sondern radiär zum Zentrum des Proteinkörpers angeordnete Leisten. Derartige Oberflächenstrukturen sind in oocytärem Proteindotter bisher nicht bekanntgeworden. Nach SELwOoD (1968) enthalten die follikulären Granularzellen ellipsoide Proteinschollen, deren Rinde gleichartig strukturiert ist. Die Abstände und das Muster der Leisten sind identisch. Die Tatsache, daß die Außenschicht kristallinen Charakter zeigt, und der Kern amorph bleibt, läßt eine Klassifizierung in 
zwei morphologische Proteindotter-Typen zu: einen Kern-Typ und einen Cortex-Typ (TAKAHAShI \& YamaMoto, 1972).

Die bisherigen elektronenmikroskopischen Untersuchungen an Mollusken-Oocyten deuten auf eine weitgehend endogene Vitellogenese hin. Eine Ausnahme scheinen nach Cowden (1968) oder O'Dor \& Wells (1973) lediglich die Cephalopoden zu sein. Pinocytotische Prozesse sind eindeutig von Selwood (1968) in den Oocyten von Sypharochiton während der Vitellogenese beobachtet worden. Bei Lymnaea stagnalis fanden ElbERs \& Bluemink (1960) Pinocytosebläschen, die durch einen Ringwall-förmigen Membranschluß zustande kommen und Eikapselflüssigkeiten enthalten. Die Pinosome können jedoch nicht auf ihrem Wege in das Endoplasma verfolgt werden, da sie sich mit gleichförmigen Zisternen des ER und Golgi-Vesikeln vermischen. Die von Doppelmembranen umgebenen Mikropinocytose-Vesikeln der Oocyten von Lepidochitona lassen sich gut bis in Kernnähe verfolgen, wo aus ihnen wahrscheinlich Dottervorstufen hervorgehen. Es kann von einer mittleren pinocytotischen Aktivität gesprochen werden, da pinocytotische Prozesse nur auf die Stadien III bis IV beschränkt bleiben und das Ergebnis wenige, oft sehr kleine Mikrovesikeln sind. Mit Sicherheit kann man davon ausgehen, daß sowohl eine endogene als auch exogene Komponente der Dotterbildung ausgeprägt ist.

In Zusammenhang mit der Aufnahme von Nährstoffen stehen die Differenzierungen der oocytären Oberfläche zur Zeit der Dottereinlagerung. Dazu gehören der Werdegang der Mikrovilli, die Sekretion der Intercellularsubstanzen und die Aufwölbung bzw. Einsenkungen der $\mathrm{O}$ o c y t e $\mathrm{n} \mathrm{m} \mathrm{e} \mathrm{m} \mathrm{b} \mathrm{r} \mathrm{a} \mathrm{n.} \mathrm{Entgegen} \mathrm{vielfältiger} \mathrm{Beob-}$ achtungen an Eizellen mit geringer Hüllenbildung, kann bei $L$. cinereus nicht nur von einer sekretorischen Funktion der Mikrovilli berichtet werden. Beide Phasen sind zeitlich und räumlich getrennt (im Stadium III eine Resorption an der gesamten Oberfläche über kurze Mikrovilli, im Stadium IV der Export von Hüllsubstanzen an ca. acht Stellen über sehr lange Mikrovilli). Ähnliche exopinocytotische Prozesse erfolgen an der Oocytenoberfläche des Cnidariers Bunodosoma (Dewel \& Clark, 1974). Die reife Oocyte zeichnet sich durch einen Mikovillibesatz einheitlicher Morphologie aus, wie er für Sypharochiton (Selwood, 1970), Mopalia und Chaetopleura (Anderson, 1969) angenommen werden kann. Ein solcher Formwechsel der Mikrovilli ist jedoch in diesem Maße bei den anderen Chitonen nicht zu verzeichnen. Die starken intercellulären Bindungen zwischen Eizelle und Follikelzellen über Zonulae adhaerentes werden auch bei den von ANDERSON untersuchten Arten hergestellt.

Root lets-Strukturen sind als Cilienwurzeln z. B. in Muschelkiemen (FAwCETT, 1961; STEPhens, 1975) ausgebildet. Cilien und deren Basalkörper in Oocyten sind bisher unbekannt. Lediglich DeweL \& CLARK (1974) beschreiben in fast reifen Oocyten und Eiern von Bunodosoma cavernata ungebänderte rootlets, die aus Mikrofilamenten zusammengesetzt sind. Neben der Querbänderung stellen die Befunde bei den Oocyten von $L$. cinereus eine Ausnahme dar, was die Zuordnung der einzelnen rootlets betriff. Parallele und verzweigte Faserbündel sind für Ciliaten nachgewiesen, sie stehen aber nie in ihrer Ausrichtung senkrecht aufeinander.

Eize 11 h üllen als Vitellinmembran kommen außer bei den Polyplacophora (L. cinereus, M. muscosa, C. apiculata) innerhalb des Stammes der Mollusken besonders an den Oocyten der Bivalvier vor. Beschrieben ist eine fibrilläre Hülle zwischen 
den oocytären Mikrovilli bei Mytilus (HumphreYs, 1962; ReverberI, 1967; Longo \& Anderson, 1969), bei Anodonta (Beams \& Sekhon, 1966), Barnea (Pasteels \& de Harven, 1962), Spisula (Rebhun, 1962) und Bankia (Popham, 1975).

Vitellinmembran sowie die Innenschicht der Anhänge scheinen Produkte der Golgi-Komplexe zu sein (Sewwood, 1970). Doch sind es bei $L$. cinereus nicht nur die Golgi-Vesikeln, sondern auch die Mikrotubuli und rootlets, die für einen Stofftransport aus der Oocyte heraus in Frage kommen könnten. Einige Dictyosomen, große Mengen an Mikrovesikeln und die quergestreiften rootlets bilden eine funktionelle Einheit. Dieser Organellenkomplex liefert möglicherweise das Hüllenmaterial und transportiert es zum Ort der Ablagerung oder ist für die Verankerung der Hüllfortsätze im Cytoplasma von Bedeutung. Zusamensetzung und Schichtenfolge der oocytären Hüllsubstanzen sind analog den Verhältnissen bei Sypharochiton septentriones (SELwOoD, 1970). Für Chiton tuberculatum (Cowden, 1961), M. muscosa und C. apiculata (ANDERSON, 1969) sind dieselben Stoffkomponenten nachgewiesen, jedoch nicht in Schichten getrennt. Die Befunde erlauben eine Klassifizierung in zwei Typen von Oocytenhüllen: Die innere Schicht der Oocytenanhänge und die Vitellinmembran oder Dotterhaut des späten Stadiums V stellen primäre Hüllen dar, während die äußerste Lage und Teile der mittleren Schicht wohl zu den sekundären Hüllen gerechnet werden können und als Chorion zu benentnen sind. SELWOOD differenziert nicht in primäre und sekundäre Hüllen, ANDERson spricht lediglich von Anhängen und einer Dotterhaut. Beide Autoren bezeichnen zusammen mit COWDEN die Oocytenanhänge als Chorion. Interessant ist die Beobachtung, daß bei Chiton tuberculatum und Sypharochiton die Hüllenfortsätze ohne strukturierten Inhalt, also hohl angelegt sind. Demgegenüber ist bei den Oocyten von $L$. cinereus, $M$. muscosa und C. apiculata der gesamte Intercellularraum kompakt mit fibrillären Materialien angefüllt.

\section{ZUSAMMENFASSUNG}

1. Die Wachstumsphase der Oocyten von Lepidochitona cinereus L. Läßt sich nach cytomorphologischen und histologischen Gesichtspunkten in füf Entwicklungsstadien einteilen.

2. Typische Oogonien in den Ovarien adulter Weibchen sind nicht eindeutig nachzuweisen. Es ist nod kein kugeliger Nucleolus ausgebildet; der Kern ist teilweise dicht mit Chromatinkörpern angefüllt. Diese Eizellen sind noch nicht vollständig durch Follikelzellen getrennt.

3. Die Oocyten des Stadiums I sind stets von Follikelzellen umgeben. Ribosomenähnliche Grana akkumulieren sich zum kugeligen Nucleolus oder sind auf dem Wege zur Emission durch die Kernhülle. Sie bilden einen osmiophilen juxtanucleären Saum. Das Oocytoplasma enthält wenige kleine Mitochondrien, einen kleinen Golgi-Apparat, einige Lipidschollen und einzelne Stränge des Endoplasmatischen Retikulums.

4. Charakteristisch für das Stadium II sind 1 bis 2 Dotterkerne (Balbiani-Körper), die sich aus einer dichten Wolke von Ribosomen und einer Schale aus Mitochondrien zusammensetzen. Der Nucleolus tritt in eine aktive Phase, zoniert sich in ein vaku- 
oläres Zentrum und einen homogenen Cortex und schnürt von nun an Nucleolargrana (Paranucleoli) ab.

5. Die vitellogenetische Phase wird im Entwicklungsstadium III durch die Vakuolisierung des Cytoplasma eingeleitet. Es können drei Vakuolentypen unterschieden werden, die ihren Ursprung entweder im Grundcytoplasma selbst, in Vesikeln des ER oder in benachbarten Golgi-Feldern haben können. Das ER entwickelt sich zu konzentrischen Membranstapeln.

6. Das Stadium IV ist gekennzeichnet durch cytoplasmatische Aufwölbungen mit gleichzeitigen Einsenkungen der Oocytenmembran, die auf die Tätigkeit des oocytären Follikelepithels zurückzuführen sind. Es werden möglicherweise drei Wege der Dottersynthese beschritten: (a) In der inneren Mitochondrienmatrix akkumulieren sich Substanzen, die zu Protein-Primordialdotter mit Myelinlamellen führen. (b) Pinocytotische Vesikeln beteiligen sich an der Genese von homogen strukturierten Eiweiß-Dotterkugeln. (c) Lipidschollen gehen aus cytoplasmatischen Vakuolen hervor, die mit den umfangreichen Stapeln der annulate lamellae in Verbindung gestanden haben. Beim Übergang zum Stadium IV scheidet hauptsächlich die Oocyte über Mikrovilli eine aus Mucopolysacchariden bestehende dreischichtige, kompliziert gebaute Oocytenhülle ab. Im Cytoplasma liegen rootlets, die im Aufbau Cilienwurzeln gleichen.

7. Im Stadium V erscheinen im cortikalen Cytoplasma Rindenvakuolen. Die Kernhülle faltet sich; die Nucleoli zerfallen. Die ausgereiften Protein-Dotterpartikeln enthalten ein homogenes Internum mit aufgelagertem parakristallin strukturiertem Cortex. Durch Anlagerung von Vesikeln und Lipidkörpern entsteht schließlich typischer Lipoproteindotter. Die Eizelle gibt eine weitere primäre Oocytenhülle, die Dottermembran ab.

Anmerkung. Die vorliegende Arbeit stellt einen Teil der Inaugural-Dissertation zur Erlangung des Doktorgrades im Fachbereich Biologie der Justus-Liebig-Universität Gießen dar. Herrn Prof. Dr. K.-J. Görting möchte ich für die Überlassung des Themas und für die Unterstützung während der Untersuchungen und den Herren Dr. E. Zirgelmeier und M. STURM (Biologische Anstalt Helgoland, Litoralstation, List/Sylt) für die Materialbeschaffung danken.

\section{ZITIERTE LITERATUR}

Adams, C. W. M., Abdulla, Y. H., Baylis, O. B. \& Weller, R. O., 1966. Histochemical detection of triglycerid esters with specific lipases and a calcium-lead sulfide technique. $\mathrm{J}$. Histochem. 14, 385-395.

Anderson, E., 1969. Oocyte-follicle cell differentiation in two species of Amphineurans (Mollusca), Mopalia muscosa and Chaetopleura apiculata. J. Morph. 129, 89-126.

ArNold, M., 1968. Histochemie. Springer, Berlin, 210 pp.

Arvy, L., 1950. Données histologique sur l'ovogénèse chez Dentalium entale Deshayes. Archs Biol., Liège 61, 187-196.

Balinsky, B. I. \& Devis, R. J., 1963. Origin and differentiation of cytoplasmic structures in the oocytes of Xenopus laevis. Acta Embryol. Morph. exp. 6, 55-108.

BeAms, H. W. \& Serhon, S. S., 1966. Electron microscope studies on the oocyte of the fresh water mussel (Anodonta), with special reference to the stalk and mechanism of yolk deposition. J. Morph. 119, 477-502. 
BEDFORD, L., 1966. The electron microscopy and cytochemistry of oogenesis and the cytochemistry of embryonic development of the prosobranch gastropod, Bembicium nanum L. J. Embryol. exp. Morph. 15, 15-37.

BIER, K. \& RAMURTY, P. S., 1964. Elektronenoptische Untersuchungen zur Einlagerung der Dotterproteine in die Oocyte. Naturwissenschaften 51, 223-224.

BLuemink, J., 1969. Verwandtschaft $z$ wischen Dotterkörnchen und Lysosomen. Zeiss Inf. 73, 95-99.

Bolognari, A., 1960. Yolk formation in oocytes of Patella coerulea L. and Aplysia depilans L. as observed in the electron microscope. Nature, Lond. 186, 490.

Bretschneider, L. H. \& Raven, C. P., 1951. Structural and topochemical changes in egg cells of Limnaea stagnalis $\mathrm{L}$. during oogenesis. Archs néerl. Zool. 10, 1-31.

BotTKE, W., 1973. Zur Ultrastruktur des Ovars von Viviparus contectus Millet (Gastropoda, Prosobranchia). II. Die Oocyten. Z. Zellforsch. mikrosk. Anat. 138, 239-259.

- 1974. The fine structure of the ovarian follicle of Alloteutbis subulata L. (Mollusca, Cephalopoda). Cell. Tiss. Res. 150, 463-479.

COWDEN, R. R., 1961. A cytochemical investigation of oogenesis and development to the swimming larval stage in the chiton, Chiton tuberculatum L. Biol. Bull. mar. biol. Lab., Woods Hole 120, 313-325.

- 1968. Cytological and histochemical studies of oocyte development of follicular epithelium in the squid, Loligo brevis. Acta Embryol. Morph. exp. 10, 160-173.

Das, N. K. \& Alfert, M., 1973: Prenucleolar bodies of Urechis oocytes. J. Cell Sci. 12, 781-797.

DEWEL, W. C. \& ClARK, W. H., 1974. A fine structural investigation of surface specialisations and the cortical reaction in eggs of the cnidarian, Bunodosoma cavernata. J. Cell Biol. 60, 78-91.

Droller, M. J. \& Roth, F. F., 1966. An electron microscope study of yolk formation during oogenesis in Lebistes reticulatus Guppyi. J. Cell Biol. 28, 209-232.

Dumont, J. N. \& Wallace, R. A., 1972. The effect of vinblastine on isolated Xenopus oocyte. J. Cell Biol. 53, 605-610.

ELBERS, P. F., 1957. Electron microscopy of protein crystals in ultrathin sections of the egg of Limnaea stagnalis. Proc. K. ned. Akad. Wet. (C) 60,96-98.

- \& Bluemink, J. G., 1960. Pinocytosis in the developing eggs of Limnaea stagnalis. Expl Cell Res. 21, 619-622.

ERB, W. \& MAUrer, W., 1962. Autoradiographische Untersuchungen über den Eiweißstoffwechsel von Oocyten und Eizellen. Z. Naturforsch. (b) 17, 268-273.

Favard, P. \& Carasso, N., 1958. Origine et ultrastructure des plaquettes vitellines de la Planorbe. Arch. Anat. microsc. Morph. exp. 47, 211-234.

Fawcett, D. W., 1961. Cilia and flagella. In: The Cell. Ed. by J. Brachet and A. E. Mirsky. Academic Press, New York, 2, 217.

Gabe, M. \& Prenant, M., 1949. Contribution à l'histologie de l'ovogénèse chez les polyplacophores. Cellule 53, 99-116.

Garnault, P., 1888. Recherches sur la structure et le development de l'oeuf et de son follicule chez les chitonides. Archs. Zool. exp. gén. (Ser. 2) 6, 82-116.

GläTZER, K. H., 1971. Die Ei- und Embryonalentwicklung von Corydendrium parasiticum mit besonderer Berücksichtigung der Oocyten-Feinstruktur während der Vitellogenese. Helgoländer wiss. Meeresunters. 22, 213-280.

GötтrNG, K.-J., 1966. Zur Feinstruktur der Oocyten mariner Teleosteer. Helgoländer wiss. Meeresunters. 13, 118-170.

- 1968. Zur Feinstruktur der Dotterkerne in den Oocyten mariner Teleosteer. Zool. Anz. (Suppl.) 32, 161-168.

HarrIS, P., 1967. Structural changes following fertilization in the sea urchin egg: Formation and dissolution of heavy bodies. J. exp. Cell Res. 48, 569-581.

HuMPhREYS, W. J., 1962. Elektron microscope studies on eggs of Mytilus edulis. J. Ultrastruct. Res. 7, 467-487.

KesSEL, R. G., 1965. Intranuclear and cytoplasmic annulate lamellae in tunicate oocytes. J. Cell Biol. 24, 471-488. 
- 1966. Electron microscope studies and the origin and maturation of yolk in oocytes of the tunicate, Ciona intestinalis. Z. Zellforsch. mikrosk. Anat. 71, 525-544.

KielbownA, L. \& Koscielski, B., 1974. A cytochemical and autoradiographic study of oocyte nucleoli in Limnaea stagnalis L. Cell Tiss. Res. 152, 103-111.

KNORRE, H. von, 1925. Die Schale und die Rückensinnesorgane von Cbiton cinereus und die ceylonischen Chitonen der Sammlung Plate. Jena. Z. Naturw. 54, 469-632.

Longo, F. J. \& Anderson, E., 1969. Cytological aspects of fertilization in the lamellibranch, Mytilus edulis. I. Polar body formation and development of the female pronucleus. J. exp. Zool. 172, 69-95.

Loven, S., 1856. Über die Entwicklung von Chitonen. Ann. Mag. nat. Hist. 17, 413-416.

Lyngnes, R., 1924. Zur Kenntnis der Eihüllen der Chitonen. Skrift. VidenskSelsk. Christiania 20, $1-19$.

Monis, B. \& Zambrano, D., 1968. Ultrastructure of transitional epithelium of man. Z. Zellforsch. mikrosk. Anat. 87, 101-117.

Nørrevang, A., 1968. Electron microscopic morphology of oogenesis. Int. Rev. Cytol. 23, 114-187.

O'DOR, R. K. \& Wells, M. J., 1973. Yolk protein synthesis in the ovary of Octopus vulgaris and the control by the optic gland gonadotropin. J. exp. Biol. 59, 665-674.

Pasteel.s, J. \& de Harven, E., 1962. Etude au microscope electronique de cortex de l'oeuf de Barnea candida (Mullusque bivalve) et son evolution au moment de la fecondation, de la maturation et de la segmentation. Archs Biol., Liège 73, 465-490.

Plate, L., 1901. Die Anatomie und Phylogenie der Chitonen. Zool. Jb. (Suppl.) 5, 281-592.

Popham, J. D., 1975. The fine structure of the oocyte of Bankia australis (Teredinidae, Bivalvia) before and after fertilization. Cell Tiss. Res. 157, 521-534.

RebHun, L. I., 1956a. Electron microscopy of basophilic structures of some invertebrate oocytes. I. Periodic lamellae and nuclear envelope. J. biophys. biochem. Cytol. 2, 93-104.

- 1956b. Electron microscopy of basophilic structures of some invertebrate oocytes. II. Fine structure of the yolk nuclei. J. biophys. biochem. Cytol. 2, 159-170.

- 1961. Some electron microscopic observations on membraneous basophilic elements of invertebrate eggs. J. Ultrastruct. Res. 5, 208-225.

- 1962. Electron microscopic studies on the vitelline membrane of the surf clam Spisula solidissima. J. Ultrastruct. Res. 6, 107-122.

ReCourt, A., 1961. Elektronenmikroskopisch onderzoek naar de oogenese bij Limnaea stagnalis $\mathrm{L}$. Thesis, Utrecht.

REVERBERI, G., 1966. Electron microscopy of some cytoplasmic structures of the oocyte of Mytilus. Exp. Cell Res. 42, 392-394.

- 1967. Some observations on the ultrastructure of the ovarian Mytilus eggs. Acta Embryol. Morphol. exp. 10, 1-14.

Richter, H.-P. \& GötTing, K.-J., 1974. Oogenese und Sexualität der Käferschnecke Lepidochitona cinereus L. (Mollusca, Polyplacophora). Helgoländer wiss. Meeresunters. 26, 42-62.

KomEIs, B., 1968. Mikroskopische Technik. Oldenbourg, München, 757 pp.

Sabatini, D. D., Bensch, K. \& Barrnett, R. J., 1963. Cytochemistry and electron microscopy: The preservation of cellular ultrastructure and enzymatic activity by aldehyd fixation. $J$. Cell Biol. 17, 19-58.

Schmekel, L. \& Froroni, P., 1974. The ultrastructure of the yolk nucleus during early cleavage of Nassarius reticulatus L. Cell Tiss. Res. 153, 79-88.

Schweikart, A., 1904. Beiträge zur Morphologie und Genese der Eihüllen der Cephalopoden und Chitonen. Zool. Jb. (Suppl.) 6, 353-406.

SELwOOD, L., 1968. Interrelationships between developing oocytes and ovarian tissues in the chiton Sypharocbiton septentriones AshiY (Mollusca, Polyplacophora). J. Morph. 125, 71-103.

- 1970. The role of the follicle cells during oogenesis in the chiton Sypharochiton septentriones Ashry (Polyplacophora, Mollusca). Z. Zellforsch. mikrosk. Anat. 104, 178-192.

SJöstrand, F. S., 1963. A new ultrastructural element of the membrane in mitochondria and of some cytoplasmic membranes. J. Ultrastruct. Res. 9, 340-361. 
Stegner, H. E., 1967. Die elektronenmikroskopische Struktur der Eizelle. Ergebn. Anat. EntwGesch. 39 (6), 1-1.13.

STEPHENS, R. E., 1975. The basal apparatus, mass isolation from molluscan ciliated gill epithelium and a preliminary characterization of striated rootlets. J. Cell Biol. 64, 408-420.

SwIFT, H., 1956. The fine structure of annulate lamellae. J. biophys. biochem. Cytol. 2, 415-418.

TakAhashi, N. \& Yамамото, K., 1972. Crystalline structure in the maturing yolk granules of surf clam oocytes. Annot. zool. jap. 45, 201-207.

TAYlor, G. T. \& Anderson, E., 1969. Cytochemical and fine structural analysis of oogenesis in the gastropod, Ilyanassa obsoleta. J. Morph. 129, 211-248.

Terakado, K., 1974. Origin of yolk granules and their development in the snail, Pbysa acuta. J. Electr. Microsc. 23, 99-106.

Venable, J. H. \& Coggeshall, R., 1965. A simplified lead citrate stain for use in electron microscopy. J. Cell Biol. 25, 407-408.

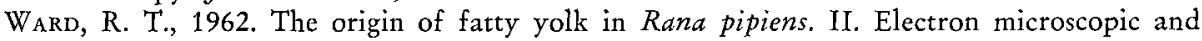
chemical observations of young and mature oocytes. J. Cell Biol. 14, 309-341.

Wartenberg, H., 1973. Die Eizellen. In: Grundlagen der Cytologie. Hrsg. von G. C. Hirsch, H. Ruska, P. SiTte. Fischer, Stuttgart, 790 pp.

- \& STEGNER, H.-E., 1960. Uber die elektronenmikroskopische Feinstruktur des menschlichen Ovarialeies. Z. Zellforsch. mikrosk. Anat. 52, 450-474.

Wohlfarth-BotTermann, K. E., 1957. Die Kontrastierung tierischer Zellen und Gewebe im Rahmen ihrer elektronenmikroskopischen Untersuchung an ultradünnen Schnitten. Naturwissenschaften 44, 287-288.

WORLEY, L. G. \& Moriber, L. G., 1961. The origin of protein yolk from the Golgi apparatus in gastropods. Trans. N.Y. Acad. Sci. 23, 352-356.

Anschrift des Autors: Dr. H.-P. Richter

Max-Planck-Institut für Biophysik

Heinrich-Hoffmann-Str. 7

D-6000 Frankfurt/M.

Bundesrepublik Deutschland 